\title{
Electrophoretic Characterization of Carbon Nanotubes: Elucidation of Surface Functionalization and Interaction
}

Tyler A. Davis

Follow this and additional works at: https://researchrepository.wvu.edu/etd

\section{Recommended Citation}

Davis, Tyler A., "Electrophoretic Characterization of Carbon Nanotubes: Elucidation of Surface Functionalization and Interaction" (2018). Graduate Theses, Dissertations, and Problem Reports. 5450. https://researchrepository.wvu.edu/etd/5450

This Dissertation is protected by copyright and/or related rights. It has been brought to you by the The Research Repository @ WVU with permission from the rights-holder(s). You are free to use this Dissertation in any way that is permitted by the copyright and related rights legislation that applies to your use. For other uses you must obtain permission from the rights-holder(s) directly, unless additional rights are indicated by a Creative Commons license in the record and/ or on the work itself. This Dissertation has been accepted for inclusion in WVU Graduate Theses, Dissertations, and Problem Reports collection by an authorized administrator of The Research Repository @ WVU.

For more information, please contact researchrepository@mail.wvu.edu. 
Electrophoretic Characterization of Carbon Nanotubes: Elucidation of Surface

Functionalization and Interaction

Tyler A. Davis

Dissertation submitted to the Eberly College of Arts and Sciences at West Virginia

University in partial fulfillment of the requirements for the degree of Doctor of Philosophy in Chemistry

Lisa A. Holland, Ph.D., Committee Chair

Jonathan W. Boyd, Ph.D.

Jeremy M. Dawson, Ph.D.

Harry O. Finklea, Ph.D.

Stephen Valentine, Ph.D.

Department of Chemistry

Morgantown, West Virginia

2018

Keywords: Carbon Nanotube, Capillary Electrophoresis, Affinity, Peptide, Carboxylation Copyright 2018 Tyler A. Davis 


\begin{abstract}
Electrophoretic Characterization of Carbon Nanotubes: Elucidation of Surface

Functionalization and Interaction
\end{abstract}

Tyler A. Davis

\begin{abstract}
Carboxylation of multiwall carbon nanotubes is used to enhance physical properties by improving dispersion, increasing compatibility and providing an interface for surface interaction. Accurate characterization of the multiwall carbon nanotubes surface is important as multiple applications depend on controlled functionalization. This dissertation is based on research that led to the adaption, validation and application of a capillary electrophoresis method for characterization of surface modification and interaction of carboxylated multiwall carbon nanotubes. The affinity based method uses electrostatic interaction of a selective peptide probe (WRWWWW) with multiwall carbon nanotubes to determine the degree of carboxylation. A $20 \%$ RSD in method reproducibility and repeatability was determined using within and cross day sample analysis. Method validation performed with two commercially available multiwall carbon nanotubes samples showed a significant difference in carboxylation, which was confirmed with X-ray photoelectron microscopy. In addition, the method was applied to assess the degree of carboxylation of acidified pristine multiwalled carbon nanotubes. A significant decrease in apparent dissociation constant was determined with increased acid treatment time, while no significant difference was determined using zeta potential analysis. Furthermore, capillary electrophoresis was also applied to isolate key factors that govern the interaction between multiwall carbon nanotubes and amino acids, arginine and tryptophan. For this analysis, the peptide probe was substituted with peptides containing either single or multiple amino acid substitutions or deletions. The study showed a two-fold increase in an electrostatic interaction of arginine in comparison to lysine and increased hydrophobic interaction with tryptophan chain length, revealing that both arginine and tryptophan drive peptide-carbon nanotube interactions. This method, for the first-time, allows for quantification of the individual contributions of amino acids and characterization of bulk multiwall carbon nanotubes samples with capillary electrophoresis. This research is significant to the study and development of nanotube-biomolecule applications and provides a cost-effective, rapid and simple alternative to current methods.
\end{abstract}




\section{DEDICATION:}

This document is dedicated to my parents, Marsha and Danny Davis, who told their little girl that "I can do all things through Christ who strengthens me".

Thank you for everything.

I love you! 


\section{ACKNOWLEDGEMENTS:}

I would like to acknowledge my advisor, Dr. Lisa Holland for being a teacher both in and out of the laboratory. I appreciate all the guidance, assistance, time, and support you have put forth to make me the scientist and professional I am today. Thank you for pushing me and believing that I could always be and do more!

I would like to acknowledge and thank my committee members, Drs. Lisa A. Holland, Jonathan Boyd, Jeremy Dawson, Harry O. Finklea and Stephen Valentine for their support as mentors and instructors.

Thank you to my invaluable co-advisor Dr. Linda Sargent for her guidance and support throughout my graduate experience.

A special thank you to Drs. Constinia Charbonnette and Kimberly Quedado for their pep-talks, advice, caring and support!

I would also like to thank the National Science Foundation's Interdisciplinary Graduate Education Research Traineeship and NanoSAFE programs for funding, as well as, leadership and business training.

I would like to acknowledge my lab mates (past and present): Dr. Stephanie Archer-Hartmann, Dr. Ted Langan, Dr. Xingwei Wu, Dr. Brandon Durney, Vincent Nyakubaya, Srikanth Gattu, Cassandra Crihfield, Marriah Ellington, Lloyd Bwanali, and Dr. Grace Lu. Thank you for the laughter and support during the highs and lows, and keeping me sane during those multiple allnighters. Couldn't have done it without you guys. I pray for joy and prosperity for each one of you in the future! 
Electrophoretic Characterization of Carbon Nanotubes: Elucidation of Surface Functionalization and Interaction.

\section{TABLE OF CONTENT:}

List of Figures $\quad$ ix

List of Tables $\quad$ xi

List of Symbols and Abbreviations xiii

\section{CHAPTER 1:}

Characterization of Oxidized Carbon Nanotubes: Surface Functionalization and Interaction

1.0. Introduction 2

$\begin{array}{ll}\text { 1.1. Background } & 3\end{array}$

$\begin{array}{ll}\text { 1.2. Characterization of Carbon Nanotube Functionalization } & 7\end{array}$

$\begin{array}{ll}\text { 1.2.1. Infrared Spectroscopy } & 8\end{array}$

$\begin{array}{ll}\text { 1.2.2. Raman Spectroscopy } & 10\end{array}$

1.2.3. X-ray Photoelectron Spectroscopy 12

$\begin{array}{ll}\text { 1.2.4. Thermogravimetric Analysis } & 14\end{array}$

1.3. Other Characterization Techniques 16

1.3.1. Titration (Boehm pH method) 16

$\begin{array}{ll}\text { 1.3.2. Zeta Potential } & 18\end{array}$

$\begin{array}{ll}\text { 1.3.3. Electron Microscopy } & 20\end{array}$

1.4. Quantification of Carbon Nanotube Interaction 22

$\begin{array}{ll}\text { 1.4.1. Fluorescence } & 23\end{array}$

1.4.2. UV-vis Spectrometry 25

$\begin{array}{ll}\text { 1.4.3. Atomic Force Microscopy } & 27\end{array}$

1.4.4. Dynamic Light Scattering 30

1.5. Emerging Technology - Capillary Electrophoresis 32 


\section{CHAPTER 2:}

Capillary Electrophoresis Analysis of Affinity to Assess Carboxylation of Multi-Walled Carbon Nanotubes

2.0. Introduction

2.1. Materials and Methods

2.1.1. Chemicals and Reagents

2.1.2. Capillary Electrophoresis

2.1.3. Sample Preparation

2.1.4. Acid Treatment

2.1.5. Dynamic Light Scattering

2.1.6. Zeta Potential Measurements

2.1.7. X-ray Photoelectron Spectroscopy

2.1.8. Safety Considerations

2.2.1. Interaction of WRWWWW with Multi-walled Carbon Nanotubes

2.2.2. Affinity Capillary Electrophoresis of Multi-walled Carbon Nanotubes

2.2.3. Translating Electrophoretic Mobility into Affinity

2.2.4. Calculating the $K_{D}$ from Shifts in Electrophoretic Migration Time

2.2.5. Criteria for $K_{D}$ Determinations

2.2.6. Repeatability of Migration Shift Assays of the Same Carbon Nanotube Suspension

2.2.7. Effect of Separation Conditions on $\mathrm{K}_{\mathrm{D}}$

2.2.8. Reproducibility of $K_{D}$ Determination of the Same Carbon Nanotube Powder Stock

2.2.9. Application of Affinity Capillary Electrophoresis to Carbon Nanotubes from Different Sources 
2.2.10. Application of Affinity Binding to a Set of Functionalized Carbon Nanotubes

2.3. Conclusions and Future Directions

2.4. Bibliography

\section{CHAPTER 3:}

Peptide Probe for Multi-walled Carbon Nanotubes: Electrophoretic Assessment of the Binding Interface and Evaluation of Surface Functionalization

3.0. Introduction

3.1. Material and Methods

3.1.1. Chemicals and Reagents

3.1.2. Capillary Electrophoresis

3.2. Results and Discussion

3.2.1. Role of Amino Acid Composition in Physical Adsorption to Carboxylated Carbon Nanotubes

3.2.2. Effect of Arginine on Binding Interaction

3.2.3 Effect of Aromaticity on Peptide-Carboxylated Carbon Nanotube Binding

3.2.4. Tryptophan Composition Contributes to WRWWWW Binding

3.2.5. Evaluation of Weak $\pi-\pi$ Binding with Capillary Electrophoresis

3.2.6. Evaluation of Peptide Fragments from Protein

3.3. Conclusions and Future Directions

3.4. Bibliography

\section{CHAPTER 4:}

Future Direction

4.0. Introduction 
4.2. Other Areas of Interest

4.2.1. Characterization of Other Surface Modifications and Nanomaterials

4.2.2. Other Affinity Based Capillary Electrophoresis Methods

\section{APPENDIX A:}

Equations

$\begin{array}{ll}\text { A.1.0. Equations } & 117\end{array}$

A.1.1. Derivation for the Hill Equation from Chemical Equation 117

A.1.2. Derive Binding Fraction for Affinity Capillary Electrophoresis 118

A.1.3. Calculating $K_{D}$ from the Increase in Migration Time (i.e. Shift) 120

$\begin{array}{lr}\text { A.1.4. Capacity Factor } & 123\end{array}$

$\begin{array}{lr}\text { A.1.5. Bibliography } & 125\end{array}$

\section{APPENDIX B:}

$\begin{array}{lr}\text { Supporting Figures and Tables } & 126\end{array}$

$\begin{array}{ll}\text { B.1.0. Supporting Figures and Tables } & 127\end{array}$

$\begin{array}{ll}\text { B.1.1. Bibliography } & 134\end{array}$

$\begin{array}{ll}\text { CURRICULUM VITAE: } & 135\end{array}$ 


\section{LIST OF FIGURES:}

\section{CHAPTER 1:}

Figure 1-1: Schematic of Carbon Nanotubes 4

Figure 1-2: Schematic of Oxidized Carbon Nanotube 5

Figure 1-3: Schematic of Fourier Transform Infrared Spectroscopy 9

Figure 1-4: Schematic of Raman Spectroscopy Instrumentation 11

Figure 1-5: Schematic of X-ray Photoelectron Spectroscopy Instrumentation 13

Figure 1-6: Schematic of Thermogravimetric Analysis Instrumentation 15

Figure 1-7: Schematic of Boehm Titration Methodology 17

Figure 1-8: Schematic of Zeta Potential Instrumentation 19

Figure 1-9: Schematic of Electron Microscopy Instrumentation 21

Figure 1-10: Schematic of Fluorescence Instrumentation 24

Figure 1-11: Schematic of UV-vis Spectrometry Instrumentation 26

Figure 1-12: Schematic of Atomic Force Microscopy Instrumentation 29

Figure 1-13: Schematic of Dynamic Light Scattering Instrumentation 31

Figure 1-14: Schematic of Capillary Electrophoresis Instrumentation 33

\section{CHAPTER 2:}

Figure 2-1: Schematic of Affinity Capillary Electrophoresis for Carbon Nanotubes

Figure 2-2: Dynamic Light Scattering Measurements of the Carbon

Nanotube-Peptide Complex Size Distribution Plot

Figure 2-3: Electropherograms of Peptide and Precarboxylated Multi-walled Carbon Nanotubes

Figure 2-4: Binding curve for WRWWWW and NanoLab Precarboxylated Multi-walled Carbon Nanotubes

Figure 2-5: Electropherograms and Resulting GraphPad Fitted for Within Single Sample Preparation Analysis

Figure 2-6: Dissociation Constant Curves for Three Powder Stock 
Figure 2-7: Deconvoluted Peak Fitting for Carbon Region for NanoLab

Precarboxylated Carbon Nanotubes in X-ray Photoelectron Spectroscopy

Figure 2-8: Deconvoluted Peak Fitting for Carbon Region for US-Nano

Precarboxylated Carbon Nanotubes in X-ray Photoelectron Spectroscopy

\section{CHAPTER 3:}

Figure 3-1: Conceptual Diagram of Tryptophan and Arginine Interaction with Carboxylated Carbon Nanotubes

Figure 3-2: Schematic of Affinity Capillary Electrophoresis

Figure 3-3: Electropherograms and Resulting GraphPad Fitted for WRWWWW Peptide and NanoLab Precarboxylated Carbon Nanotubes

Figure 3-4: Electrophoregrams of WW and WR peptide interaction with NanoLab Precarboxylated Carbon Nanotubes

Figure 3-5: Electropherograms WMCLAKW peptide and NanoLab Precarboxylated Carbon Nanotubes

\section{APPENDIX B:}

Figure B-1: Plot of Increase in Peptide-Carbon Nanotube Complex Size with Time

Figure B-2: Sedimentation of Peptide-Carbon Nanotube Complex

Figure B-3: Control Runs Demonstrating Complex Formation Due to Interaction

Figure B-4: Deconvoluted Peak Fitting for Carbon Region for Acid Treated Carbon Nanotubes in X-ray Photoelectron Spectroscopy 


\section{LIST OF TABLES:}

\section{CHAPTER 1:}

Table 1-1: Analytical Techniques Used to Characterization Surface Oxidation of Carbon Nanotubes

Table 1-2: Analytical Techniques Used to Characterization Surface Interaction of Carbon Nanotubes

\section{CHAPTER 2:}

Table 2-1: Dynamic Light Scattering Measurements of the Carbon Nanotube-Peptide Complex 56

Table 2-2: Effect of Peptide Concentration on Dissociation Constant 62

Table 2-3: Effect of Temperature and Buffer Composition on Dissociation Constant 67

Table 2-4: Dissociation Constant values for Three Powder Stock 69

Table 2-5: Characterization of Precarboxylated Carbon Nanotubes 71

Table 2-6: Characterization of Oxidized Carbon Nanotube Library 76

\section{CHAPTER 3:}

Table 3-1: K K' Values of Peptides $\quad 95$

Table 3-2: Solubility Measurement of WR(W)n peptide series 98

Table 3-3: Capacity Factor Values 100

Table 3-4: Reduction of Polytryptophan Peak Area from Carbon Nanotube $\begin{array}{ll}\text { Interaction } & 100\end{array}$

Table 3-5: Peptide Regions Selected from Lysozyme Protein Primary Structure 101

\section{APPENDIX A:}

Table A-1: Sample Calculation of Fractional Binding of each point in a single curve

\section{Appendix B:}

Table B-1: Effects of Acid Treatment Temperature on Dissociation Constant

Table B-2: Dissociation Constant Obtained within a Single Preparation of 
Carbon Nanotubes ( $n=3$ curves)

Table B-3: Dissociation Constant and $\mathrm{n}$ values 


\section{LIST OF SYMBOLS /NOMENCLATURE:}

1. CNT - carbon nanotube

2. SWCNT - single walled carbon nanotube

3. MWCNT - multiwalled carbon nanotube

4. CE - capillary electrophoresis

5. FTIR/IR - Fourier Tranform Infrared spectroscopy/ Infrared spectroscopy

6. RS - Raman spectroscopy

7. XPS - X-ray photoelectron spectroscopy

8. TGA - thermogravimetric analysis

9. EM - electron microscopy

10. SEM - scanning energy microscopy

11. TEM - transmission energy microscopy

12. KE - kinetic energy

13. $\mathrm{BE}$ - binding energy

14. eV - binding energy

15. hv - energy

16. w - work function

17. $\mathrm{NaHCO}_{3}$ - Sodium Bicarbonate

18. $\mathrm{Na}_{2} \mathrm{CO}_{3}$ - Sodium Carbonate or

19. $\mathrm{NaOH}$ - Sodium Hydroxide

20. $\mathrm{HCl}-$ hydrochloric acid

21. UV-vis - ultra-violet- visible absorbance

22. AFM - atomic force microscopy

23. DLS - dynamic light scattering

24. I - intensity

25. $\mathrm{K}_{\mathrm{sv}}$ - Stern Volmer Constant

26. $\mathrm{k}_{\mathrm{q}}$ - quenching rate coefficient

27. $\mathrm{T}_{0}$ - fluorescence lifetime

28. $\mathrm{q}_{\mathrm{e}}$ - adsorption capacity at equilibrium

29. $\mathrm{C}_{e}$ - concentration of substrate at equilibrium

30. $\mathrm{K}_{\mathrm{L}}$ - affinity parameter

31. $\mathrm{K}_{\mathrm{F}}$ - sorption coefficient

32. EOF - electroosmotic flow

33. $\mathrm{K}_{\mathrm{D}}-$ dissociation constant

34. $n-$ cooperativity coefficient

35. MOPS - 3-N-morpholinopropane-1-sulfonic acid

36. M.O. - mesityl oxide

37. $\pi-\pi-$ pi-pi interaction or stacking

38. $\quad \mathrm{C}-\mathrm{C} / \mathrm{C}-\mathrm{H}-$ single carbon bond

39. $\mathrm{C}=\mathrm{O}-$ double carbon bond

40. O-C-O - carbonyl

41. $\mathrm{COOH}-$ carboxylic acid

42. WRWWWWW - tryptophylarginyltryptophyltryptophyltryptophyltryptophan

43. o.d. - outer diameter

44. i.d.- inner diameter

45. $\mu$ - electrophoretic mobility

46. $\mu_{\text {free }}$ - electrophoretic mobility of unbound peptide

47. $\mu_{\text {mid }}$ - electrophoretic mobility of bound peptide

48. $\mu_{\max }$ - electrophoretic mobility of complexed peptide 
49. $\mathrm{cm}^{2} / \mathrm{V}$-s - centimeter squared per volt second

50. $\theta-$ fraction bound

51. $\mathrm{mV}-$ millivolts

52. kV - killivolts

53. $\mathrm{E} / \mathrm{cm}$ - volts per centimeter

54. $\mu \mathrm{A}-$ milliampere

55. $\mathrm{kJ} / \mathrm{mol}$ - killijoule per mole

56. k' - capacity factor 


\section{CHAPTER 1:}

Characterization of Oxidized Carbon Nanotubes: Surface Functionalization and Interaction 


\subsection{INTRODUCTION}

Surface oxidation of carbon nanotubes is critical for integration into biomedical and industrial applications. Multiple applications require the addition of oxygen containing functional groups, such as carboxylic acids, on the carbon nanotube surface to provide increased solubility or to provide a method of secondary functionalization via covalent and noncovalent interactions. As nano-based applications and research continues into grow in a billion-dollar industry, careful and accurate characterization of the post modified carbon nanotubes surface and surface interactions is critical to future development. This goal results in a strong need for analytical methods that can provide researchers with information about surface functionalization as well as fundamental understanding of surface interactions.

This dissertation summarizes the methodology and optimization of a capillary electrophoresis based method to characterize carboxylated multiwalled carbon nanotubes. The publications reproduced in this dissertation are listed below:

\section{Chapter 2:}

T.A. Davis, S. Patberg, A. Stefaniak, L. Sargent, L.A. Holland, Capillary Electrophoresis Analysis of Affinity to Assess Carboxylation of Multi-Walled, Anal. Chim. Acta (2018) accepted

\section{Chapter 3:}

T.A. Davis, L.A. Holland, Peptide probe for multiwalled carbon nanotubes: electrophoretic assessment of the binding interface and evaluation of surface functionalization., ACS Appl Mater Interfaces, 10 (2018) 11311-11318. 
Chapter 1 focuses on a review of current analytical techniques used to characterize surface oxidation on carbon nanotubes as well as techniques used to quantify interactions. The aim of this review chapter is to provide readers with information about the instrumentation, applications and limitations of commonly used analytical techniques. Chapter 2 describes the development and application of affinity capillary electrophoresis for the differentiation of the degree of carboxylation on multiwalled carbon nanotubes utilizing a peptide binding probe. Chapter 3 expands upon the use of affinity capillary electrophoresis and applies it to characterize the interaction of multiple peptides with carbon nanotubes to isolate individual amino acid binding contribution. Future applications of affinity capillary electrophoresis are briefly discussed in the Chapter 4.

\subsection{BACKGROUND}

Since limija's 1991 publication, carbon nanotubes have rapidly grown in popularity and production due to unique physical properties which can be harnessed in multitube of different applications [1]. These graphene tubes form a single, double, or multiwalled structure as shown in Figure 1 that is light weight while still possessing high tensile strength. Based on the chirality, certain species of carbon nanotubes contain excellent electrical or thermal conductive properties $[2,3]$. These unique properties are used in applications ranging from reduction of overpotential and improved sensitivity in electrochemical biosensors to providing structural reinforcements in composites without significantly increasing mass [3-6]. Despite the potential usefulness, issues surrounding carbon nanotube solubility and toxicity prevent further integration into more applications. Unmodified carbon nanotubes are extremely hydrophobic causing entanglement and self-aggregation $[7,8]$ and the light weight structure allows for easy aerosolization and inhalation with potential asbestos-like toxic outcomes [9-12]. To increase solubility and biocompatibility, carbon nanotubes are functionalized via covalent methods that 
add small molecules on the carbon nanotube surface or through noncovalent interactions with surfactants, proteins, and DNA [13-15]. The surface functionalization reduces hydrophobic entanglement and improves solubility allowing better integration. Accurate characterization of the carbon nanotube surface becomes increasingly important as development nano-based applications depends on the degree of functionalization.

\section{Figure 1-1: Schematic of Carbon Nanotubes}

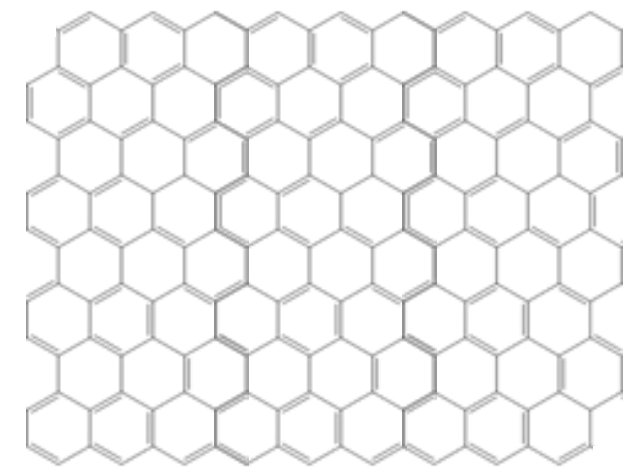

Graphene Sheet

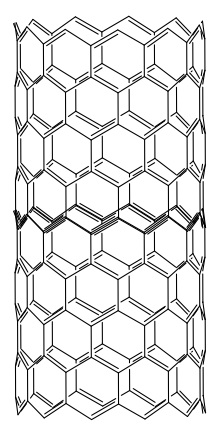

Single Walled

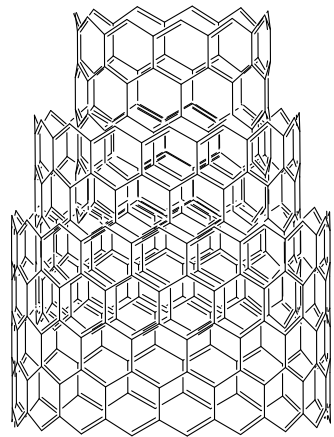

Multi-Walled

Figure 1-1: Graphene sheets are rolled into tubes consisting of single and multiple walled structures. Carbon nanotubes range in length from $0.2-5 \mu \mathrm{m}$ and range in diameter from $0.4-$ $2 \mathrm{~nm}$ for single walled carbon nanotubes and $2-100 \mathrm{~nm}$ for multiwalled carbon nanotubes. [16] 


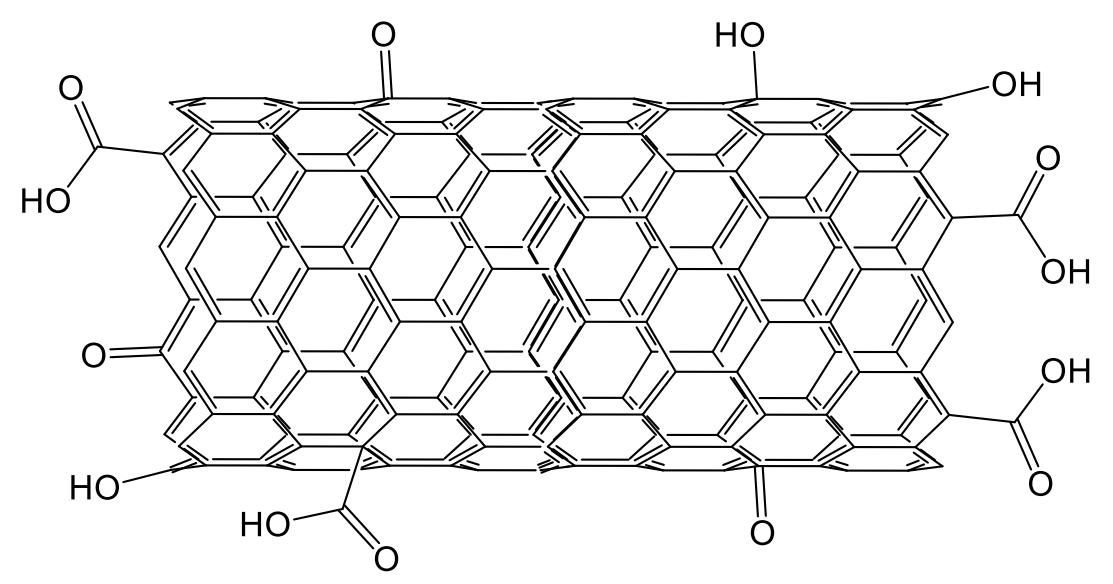

Figure 1-2: Various oxidants are used to add oxygen-containing (carbonyl, carboxylic acid, hydroxides) functional groups on the surface on carbon nanotubes at nanodefect side.

The most prevalent form of carbon nanotube functionalization is through covalent modification with surface oxidation. Traditionally, oxidization forms as a byproduct of carbon nanotube metal purification [15]. During chemical vapor deposition production, metal catalysts are imbedded in the carbon nanotube side walls. To remove metal impurities acidification is performed. This metal purification process results in the addition of oxygen containing functional groups like carboxyl, hydroxyl, or carbonyl at nanodefect sites along the side walls or open-end caps on the carbon nanotubes (see Figure 2). Throughout the years several oxidation methodologies have been reported. The most common utilize sonication, thermal reflux, microwave and plasma oxidation [17-20] with various chemical oxidants, like sulfuric acid, nitric acid and hydrogen peroxide. Variations in the degree of oxidation have been reported with changes in method, time, temperature, or oxidant [19-24]. Research has indicated that increasing the oxidation time or temperature results in increased concentration of oxygen containing functional groups yet reduces the length of the carbon nanotubes [25-27]. Variations in the chemical oxidant 
selected aids in controlling the type and/or concentration of oxygen containing function groups added to the carbon nanotube surface [24]. Additionally, the concentration of the acid used during oxidation is also used to control the percent oxidation. Research by Smith et. al. demonstrated a linear trend between the concentration of the nitric acid oxidant and carboxylation on multiwalled carbon nanotubes [28].

While surface oxidation does increase solubility and potentially reduces the carbon nanotube toxicity by increase surface hydrophilicity $[13,29]$, the oxidation has also proven useful in aiding surface interaction. Oxidization provides a means to add other functional groups on the carbon nanotube surface by covalent or non-covalent interaction. This binding platform is often the initial step for multiple other functionalization pathways, including acylation, amidation, metalation, and hydroxylation [30] and is used to graft other molecules like polymer, peptides and enzymes on to the carbon nanotube surface [29,31-34]. Oxidation is also used to control non-covalent adsorption of substrates onto the carbon nanotube surface [34,35]. Zhao recently studied the impact of the degree of oxidation on the enzymatic activity of $\alpha$-chymotrypsin and demonstrated the importance of concentration of surface functionalization played on biosensors function [36]. Additionally, adsorption of metal contaminants is improved through the electrostatic interaction with carboxylation on the carbon nanotubes surface improving nanobased filtration systems [37]. Given that concentration of functional groups impacts the interaction of carbon nanotubes with environment and biomolecules, accurate characterization of the carbon nanotube surface is crucial [36,38-40].

This chapter focuses on a review of seven relevant analytical methods for the characterization of carbon nanotube surface oxidation. Several other well written reviews [13,41-44] for characterization of carbon nanotubes have been published over the years; however, this review focuses particular attention on analytical instrumentation, applications and limitations as they 
pertain to oxidation. In addition, analytical techniques, like fluorescence, UV-vis, Atomic Force Microscopy and Dynamic Light Scattering, which are used to quantify surface interactions between carbon nanotubes and substrates are also discussed. Lastly, this review discusses the emerging application of capillary electrophoresis, which to our knowledge is the only analytical technique that can provide both characterization of functionalization and quantification of interactions.

\subsection{CHARACTERIZATION OF CARBON NANOTUBE FUNCTIONALIZATION}

\begin{tabular}{|c|c|c|c|}
\hline Method & $\underline{\text { Technique }}$ & $\underline{\text { Analytical Measurement }}$ & Limitation \\
\hline FTIR & Spectroscopic & Identification of Functional Groups & Poor quantification \\
\hline Raman & Spectroscopic & Quantification of Functional Groups & Poor selectivity \\
\hline XPS & Spectroscopic & Quantification of Elemental $\mathrm{C}$ and $\mathrm{O}$ & Poor selectivity \\
\hline TGA & Thermal Analysis & Quantification of Functional Groups & Poor selectivity \\
\hline $\mathrm{pH}$ Titration & Potentiometric & Quantification of Functional Groups & $\begin{array}{l}\text { Sample size } \\
\text { Laborious }\end{array}$ \\
\hline Zeta Potential & Electrophoretic & Surface Charge & $\begin{array}{l}\text { Poor selectivity } \\
\text { Poor quantification }\end{array}$ \\
\hline SEM/TEM & Microscopy & Dimension, Length and Width & $\begin{array}{l}\text { Poor selectivity } \\
\text { Sample preparation }\end{array}$ \\
\hline
\end{tabular}

Multiple analytical techniques can be applied to study carbon nanotube oxidation. Table 1-1 reviews the seven techniques that will be discussed and briefly describes the application and limitation of each. Often times multiple characterization techniques are used to identify, quantify and locate the position of carbon-oxygen functional groups on the carbon nanotube 
surface $[21,23,25,38,45-47]$. Combinations of these methods are used to fully characterize changes in the carbon nanotubes surface with oxidation. Xue et. al combined multiple techniques to characterize and compare pristine carbon nanotubes to carboxyl, hydroxyl, and amine functionalized samples [40]. First, the identification of functional groups was performed with infrared spectroscopy. The amount of functionalization was then assessed with thermal degradation analysis with TGA, and the dispersion and length of each sample was determined with transmission electron microscopy. Integration of each carbon nanotube samples into a polypiperazine-amide nanofiltration membrane were investigated with several other techniques. Bond formation was investigated with $\mathrm{x}$-ray photoelectron spectroscopy, surface topography/roughness was analyzed with atomic force microscopy and visualized with scanning electron microscopy. These techniques work together to understand both surface functionalization and interaction and each technique can be leveraged to produce complementary results based on the need of the researcher. Therefore, a fundamental understanding of how each technique works and what information is provided is key to successful characterization.

\subsubsection{Infrared Spectroscopy}

Infrared Spectroscopy (IR) is one of the most commonly used methodologies for identifying functional groups on the oxidized carbon nanotube surface. Samples are irradiated with photon energy from the IR light source causing the bonds of the functional group to vibrate. When the frequency of the bond vibration matches the frequency of the infrared source, light is absorbed. Each functional group will absorb at different frequencies (reported as wavenumber $\mathrm{cm}^{-1}=(1 / \lambda$ or $\mathrm{v} / \mathrm{c})$ ) and, by analysis of the IR spectra, functional groups are identified. Common detectors only quantify the total loss of intensity with absorbance; therefore, to differentiate the absorbed frequencies, a Michelson interferometer is used to create an interference IR pattern. (See 
Figure 1-3 for details about Michelson interferometer). As light is absorbed by the carbon nanotube sample, the interference pattern changes and is decoded using the Fourier Transform [48].

Figure 1-3: Schematic of Fourier Transform Infrared Spectroscopy

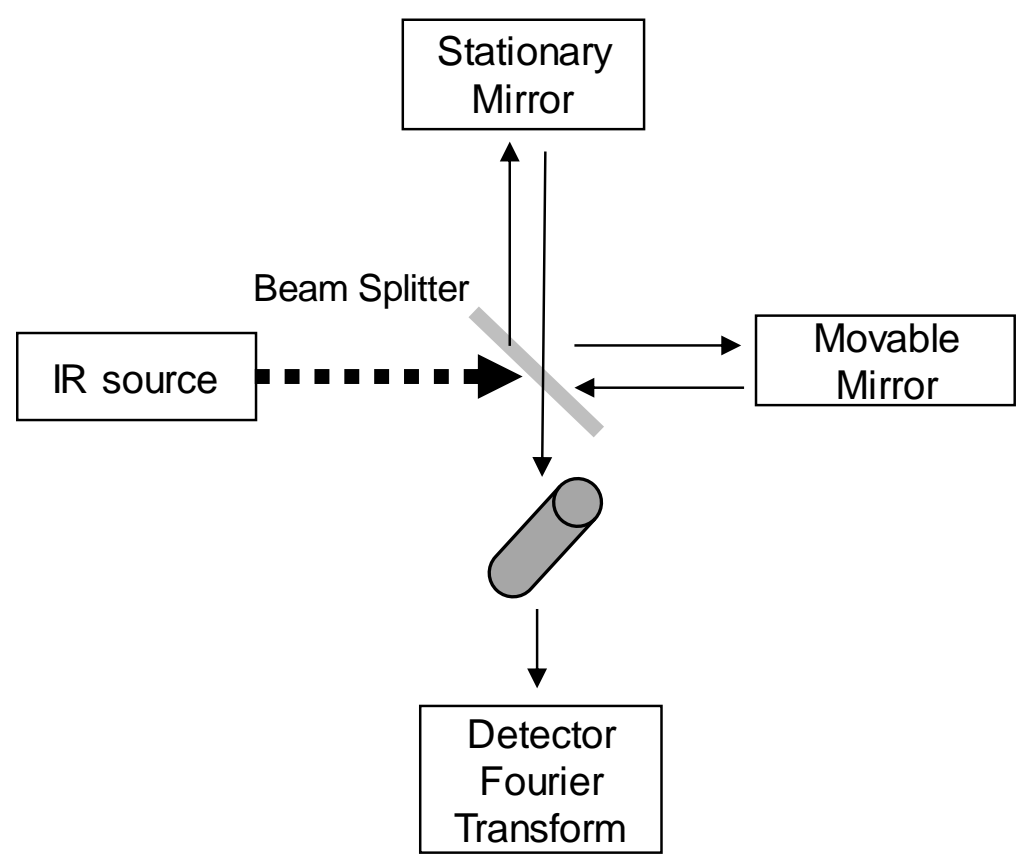

Figure 1-3: Infrared Spectroscopy: A) Block schematic of Fourier Transform Infrared Spectroscopy. The Michelson interferometer splits the IR source light into two beams of equal power at a beam splitter. Each of the split beams goes two either a stationary or moving mirror. The beam is reflected to the beam splitter and through the sample. As the moving mirror shifts back and forth in space, it causes fluctuations in beam as it passes through the sample and creating an interference light pattern that can be decode by Fourier Transform.

Distinct IR absorbance bands are used to differentiate and identify functional groups. For example, the $\mathrm{OH}$ functional group vibrates at $3427 \mathrm{~cm}^{-1}$, while the $\mathrm{C}-\mathrm{O}$ in the carboxylic acid functional group is identified by absorbance at $1384 \mathrm{~cm}^{-1}$. Traditionally, IR is often employed as 
a means of characterization of carbon nanotubes prior to applications in polymer composites, toxicity studies, and biomedical devices [38]. Beyond this use IR has been applied to monitor change in functionalization with secondary interactions [31]. Changes in absorbance bands have been used to confirm the reaction mechanism and addition of small molecules for creation of multifunctional carbon nanotubes for biosensors [23,49]. Recently, IR analysis was applied to confirm the addition of gold nanoparticles onto the surface of oxidized carbon nanotubes by monitoring the reduction of $-\mathrm{OH}$ with gold functionalization [50]. IR has been employed to monitor the increase in oxidation utilizing shifts in band absorbance [22]. However, poor limits of detection and poor band resolution diminishes the ability of IR to quantify the concentration of functional groups on the carbon nanotubes [42,51]. Some reports state that the poor limits of detection has even hindered the detection of low concentration functional groups [24]. Yet, the ease of use and commercial availability of IR systems continue to make it one of the most prevalent methods.

\subsubsection{Raman Spectroscopy}

Raman Spectroscopy is often used in conjunction with IR measurements to determine purity of carbon nanotube samples. Like IR, Raman measurements are based on the vibration of the bonds; however, inelastic light scattering caused by vibration is measured rather than absorbance. Inelastic scattering or Raman scattering is a shift in frequency of a monochromatic light source caused by interaction of functional groups on the carbon nanotubes. The frequency shift results from interaction of the light with vibration bonds that change in polarizability when excited. Figure 1-4 shows a simplistic schematic of the Raman Spectroscopy. A monochromatic light source or laser is used to irradiate the sample. The Raman scattered light is detected at a fixed angle after filtration. The majority of light scattered from the sample is from elastic scattered light or Raleigh scattering, which is scattered light that does not change 
frequency with interaction. Therefore, this wavelength of light needs to be filtered to improve the signal to noise ratio. Only 1 in $10^{11}$ photons produced are from Raman scattering [52]; however, the amount of light scattering is directly proportional to the amount of sample present and provides quantification [48].

Figure 1-4: Schematic of Raman Spectroscopy Instrumentation.

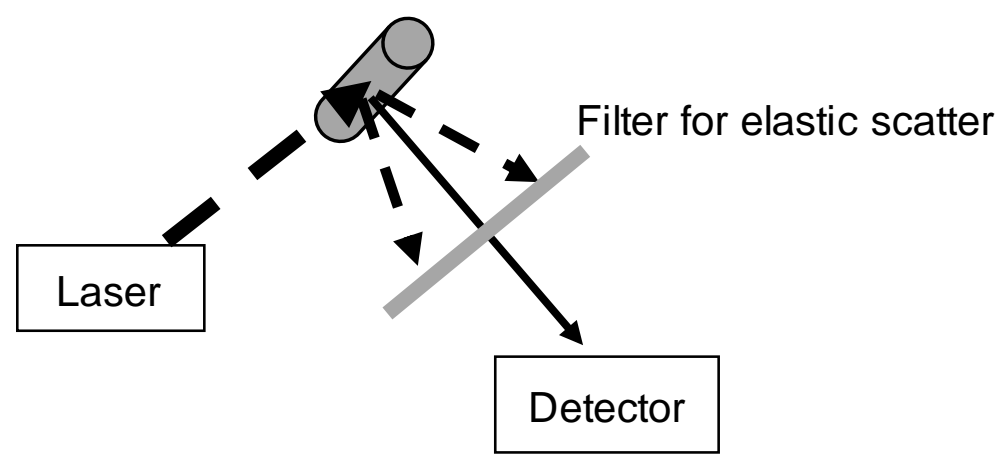

Figure 1-4: Block diagram for Raman Spectroscopy. The laser light source irradiates the carbon nanotube inducing light scatter. The elastic light scatter is filtered out allowing detection of only the inelastic scattered light.

In the case of oxidized carbon nanotube, two distinct Raman bands are used for characterization of sample purity. The first band is generated from the sp2 bonds (double bonded carbon) of the carbon nanotubes graphitic structure. This bond is detected at $\sim 1600 \mathrm{~cm}$ 1 in the Raman spectra and termed the G-band. The second, termed the D-band, arises from the "disordered" or sp3 bonds (single bonded carbon) and is detected at $\sim 1350 \mathrm{~cm}^{-1}$ [53]. Other bands are detected in the Raman spectra for carbon nanotubes. The $\mathrm{G}^{\prime}$ band $\left(\sim 2700 \mathrm{~cm}^{-}\right.$ ${ }^{1}$ ) is produced from the second scattering process while bands between $100-400 \mathrm{~cm}^{-1}$ are used to identify chirality in single walled carbon nanotubes [54]. When the $D$ band and $G$ band are compared, the ratio of disordered to ordered carbon $\left(\mathrm{I}_{\mathrm{D}} / \mathrm{I}_{\mathrm{G}}\right)$ can be used to quantitatively assess the amount of disorder. Often time this ratio is used to show the purity of the carbon nanotube 
samples, with samples containing a lower ratio indicating less disorder and higher graphitic

purity. Measurements of change in oxidation with time and temperature have been

comparatively assessed by the $I_{D} / I_{G}$ ratio $[21,24,25]$. Shifts in the ratio have are monitored to estimate covalent or noncovalent modification. However, the signal intensity of Raman

measurements results in a lower sensitivity that makes differentiation between functional groups

difficult. As a consequence, the D-band quantifies the total amount of disorder including carbon nanotube defect sites and amorphous carbon impurities [54]. Yet Raman Spectroscopy proves a simple way to rapidly quantify sample purity.

\subsubsection{X-ray Photoelectron Spectroscopy}

X-ray Photoelectron Spectroscopy (XPS) provides elemental analysis of the carbon nanotube post oxidation. The amounts of oxygen deposited on the carbon nanotube as well as the total carbon and potential metal contaminates are measured when the carbon nanotube is irradiated with a monochromatic $x$-ray. The energy from the $\mathrm{x}$-ray source excites electrons in the core shell of each atom causing the electrons to be emitted. The energy of the electrons is measured and converted to binding energy:

$\mathrm{BE}=\mathrm{KE}-\mathrm{hv}-\mathrm{w}$

where binding energy, $\mathrm{BE}$, is the sum of the kinetic energy, $\mathrm{KE}$, of the electron after it is released from the atom minus the energy of the x-ray source, hv, and the work function of the instrument, $w$ [48]. The kinetic energy of the electron is quantified with an electron energy analyzer, which separates the electrons by energy for identification and quantification with the multichannel detector (Figure 1-5) [52]. The analysis must be kept under vacuum [55] which can lead to expensive instrumental cost. 
Figure 1-5: Schematic of X-ray Photoelectron Spectroscopy Instrumentation

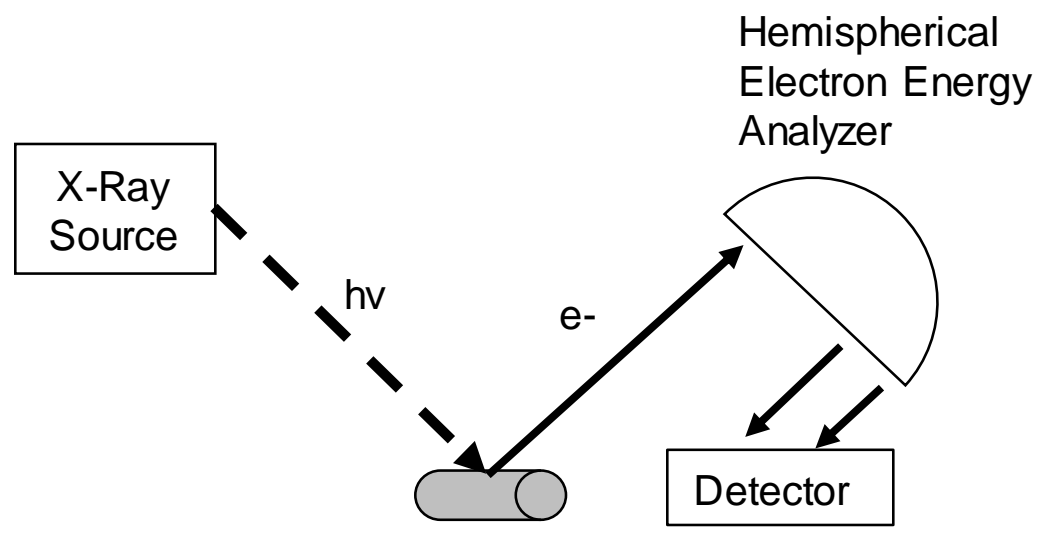

Figure 1-5: Block diagram of X-ray Photoelectron Spectroscopy. The carbon nanotube surface is irradiated with an X-ray source causing release of core shell electrons. Electrons are separated based on energy in hemispherical field spectrometer and analyzed with a multichannel detector.

XPS is superior at analyzing and quantifying changes in oxygen and carbon elemental composition with carbon nanotube surface oxidation [19,54]. Datsyuk and others used XPS to determine how the total amount of oxygen changes with oxidants selection, time and temperature $[21,24,40]$. Additionally, quantification of individual functional groups is assessed by analyzing shifts in the binding energy. Shifts in binding energy occur when the electron density of the core electron is pulled by neighboring elements bonded together [40]. However, this can be problematic because binding energies of oxidized carbon nanotube functional groups overlap. To differentiate the carbon or oxygen atoms involved in carbonyl, carboxyl acid, or hydroxyl bonds, peak deconvolution is needed. In deconvolution, the maximum binding energy for each bond is selected based on reference materials and utilized to determine the atom $\%$ of each group. Selectivity of maximum binding energy has differed significantly in published literature resulting in differences in functional group quantification. Wepasnick shows 
that slight change in the binding energy selection from 289.1 to $288.9 \mathrm{eV}$ increases the estimated percentage of carboxylic acid roughly 2-fold [42]. In order to eliminate this limitation, chemical derivation of functional groups is used to isolate peaks and easily quantify functional groups [24]. Despite this advancement, XPS with deconvolution still remains a prevalent method for the characterization of functionalize groups on carbon nanotubes.

\subsubsection{Thermogravimetric Analysis}

Changes in the thermal properties of oxidized carbon nanotubes are also used to characterize surface functionalization. Thermogravimetric analysis (TGA) elucidates the physical purity of the carbon nanotubes as a function of increased temperature and decrease in mass. As the inside of a furnace, which containing a carbon nanotube sample, is heated, the sample loses mass. Mass loss at specific temperature is used to elucidate physical structures or molecules present on the carbon nanotube surface. A schematic of the TGA instrumentation (see Figure 1-6) shows the thermobalance used to measure change in mass at high temperatures. The carbon nanotube sample is placed on the balance arm which is thermally isolated within the furnace and the environment surrounding the sample is maintained with an atmospheric gas. As the weight on the sample decreases, the balance arm shifts and the changes to the balance arm are detected [48]. 
Figure 1-6: Schematic of Thermogravimetric Analysis Instrumentation

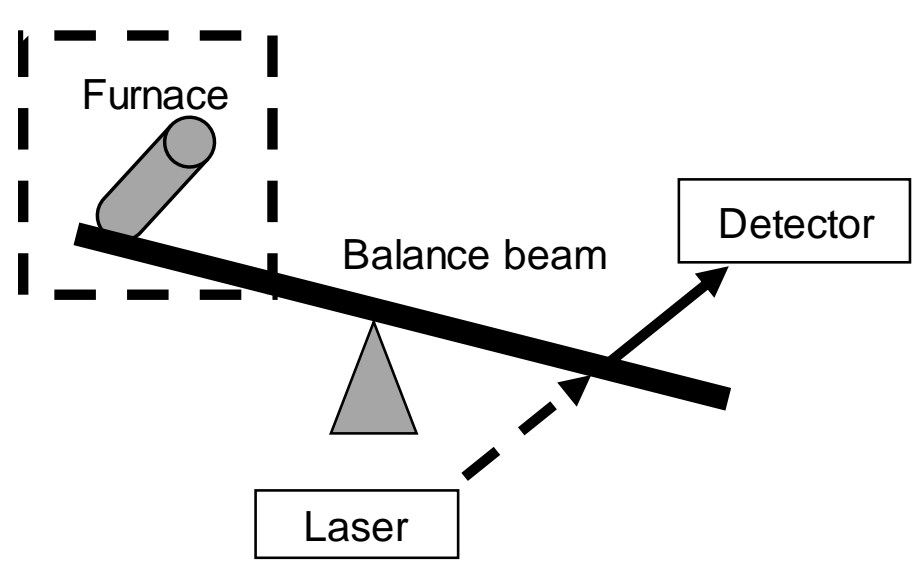

Figure 1-6: Block diagram of Thermogravimetric Analysis Thermobalance. The carbon nanotube sample, in a furnace under controlled atmospheric gas, is attached to the balance component via the balance beam. Mass loss is monitored by movement on the balance beam and is detected by a laser and photodiode.

TGA is often used to compare the change in thermal degradation of pristine and oxidized carbon nanotubes $[47,56-58]$. By comparing the percentage of mass lost with thermal degradation, the total concentration of functional groups is easily obtained. Some researchers have used the thermal degradation of carbon nanotubes to determine functional groups by analyzing mass reduction at specific temperatures [40,56]. Initial mass drops around 100-150 ${ }^{\circ} \mathrm{C}$ are from the removal of water absorbed on the carbon nanotube surface. A drop between $150-300 \stackrel{\circ}{ } \mathrm{C}$ has been associated with carboxylic acid, 350-500 ${ }^{\circ} \mathrm{C}$ indicate the hydroxyl group while $500-600 \stackrel{\circ}{\mathrm{C}}$ is attributed to disordered amorphous carbon [56]. However, the method requires a large sample size, up to $100 \mathrm{mg}[47,48]$. Minute changes in mass are difficult to detect especially when the concentration of the functionalization group is much lower than that of the total amount of carbon. To improve detection of functional groups, TGA has recently been coupled with mass spectroscopy (MS) $[59,60]$. Chernyak utilized TGA coupled to a quadrupole mass spectrometer to analyze the mechanism of thermal degradation of carbon 
nanotubes at various thermal rates [60]. As the carbon nanotube sample is heated the environmental gas is removed, ionized and analyzed in the mass spectrometer. The study then determined that as carbon nanotube samples thermal degraded, water, carbon monoxide, carbon dioxide, and nitric oxide are released, providing the sequence of surface transformation.

\subsection{OTHER CHARACTERIZATION TECHNIQUES}

\subsubsection{Titration (Boehm pH method)}

Another method for the analysis of carbon nanotube oxidation is by using multiple titrations following the Boehm method. The method uses $\mathrm{pH}$ titration to quantify the acid functional groups; carboxylic acid, lactone, and phenol, on the carbon nanotube surface. The carbon nanotube sample is stirred up to $24-72$ hours $[49,61-63]$ to ensure maximum neutralization by buffer solutions of either Sodium Bicarbonate $\left(\mathrm{NaHCO}_{3}\right)$, Sodium Carbonate $\left(\mathrm{Na}_{2} \mathrm{CO}_{3}\right)$, or Sodium Hydroxide $(\mathrm{NaOH})$. It is assumed the $\mathrm{NaOH}$ neutralizes carboxylic acid, lactone, and phenol groups; $\mathrm{Na}_{2} \mathrm{CO}_{3}$ neutralizes carboxylic acid and lactone groups; while $\mathrm{NaHCO}_{3}$ neutralizes carboxylic groups. The concentration of base required for carbon nanotube neutralization is proportional to the concentrations of the functional groups. Therefore, after incubation the neutralized carbon nanotubes are removed via filtration and the concentration of the remaining base is determined by titration with hydrochloric acid $(\mathrm{HCl})$ (see Figure 1-7) $[61,64]$. The amount of each functional group is then elucidated by subtraction of the concentration of functional groups determine in the $\mathrm{NaHCO}_{3}$ or $\mathrm{Na}_{2} \mathrm{CO}_{3}$ titrations from the $\mathrm{NaOH}$ titration. 


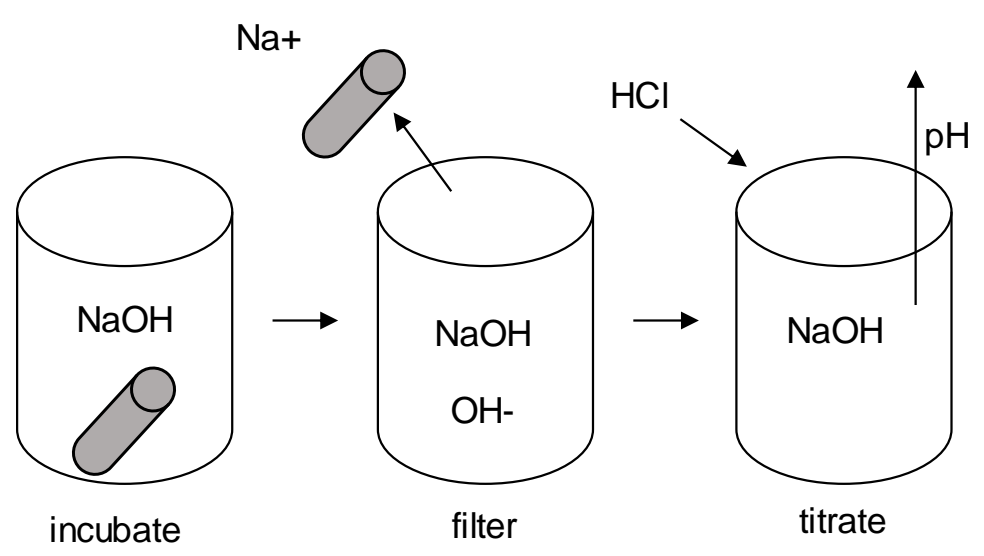

Figure 1-7: Schematic of the Boehm pH Titration Methodology: A) Schematic depicting the stepwise process of carbon nanotube $\mathrm{pH}$ titration with Sodium Hydroxide $(\mathrm{NaOH})$. The carbon nanotubes are incubated with excess $\mathrm{NaOH}$ base. Post incubation the carbon nanotubes are removed via filtration. The filtrate is then titrated with hydrochloric acid $(\mathrm{HCl})$.

The Boehm pH titration is often applied to determine the concentration of functional groups and is often used with other techniques to confirm oxidation $[46,57,61]$. Changes in modification with oxidant, method and time have all been confirmed with $\mathrm{pH}$ titration [63]. Yet, several limitations prevent the increased use of titration for characterization [61]. First, the Boehm method requires three laborious and time-consuming titrations with incubation required for up to 3 days prior to filtration $[49,62,63]$. Each titration requires a significant amount of carbon nanotubes samples (up to $200 \mathrm{mg}$ ) to differentiate minute $\mathrm{pH}$ changes caused by the typically low concentration functional groups [64]. Lastly, these samples must be devoid of dissolved carbon dioxide to prevent false positives [65]. To eliminate some of these shortcomings a one pot titration method has recently been introduced [66]. The method directly titrates carbon nanotubes with $\mathrm{NaOH}$. Utilizing the known pKa of each functional group and the titration curve, individual concentrations of each group are determined with the Henderson-Hasselbach equation. The one-pot titration method was compared and shown to have similar results to the 
multiple titration method, therefore, reducing the need for multiple titration steps without loss of information.

\subsubsection{Zeta Potential}

Quantifying the change in surface charge is another rapid way to differentiate pristine and oxidized carbon nanotubes. Surface charge is often quantified as the zeta potential or the potential difference between the electric double layer surrounding the carbon nanotubes and the buffer [67]. The electric double layer forms around carbon nanotubes dispersed in buffer and consist of two layers; the Stern layer, a fixed layer of oppositely charged ions on the carbon nanotube surface, and the diffuse layer, a less tightly packed layer consisting of both positive and negative ions surrounding the Stern layer. The potential difference between the diffuse layer and the buffer is directly proportional to the carbon nanotubes charge [67]. The zeta potential is determined by analyzing the carbon nanotubes electrophoretic mobility and calculated using Henry's equation. To determine the electrophoretic mobility, the velocity of carbon nanotube is monitored in a cell or capillary under an applied or alternating electric field; see Figure 1-8 for a schematic [67]. 


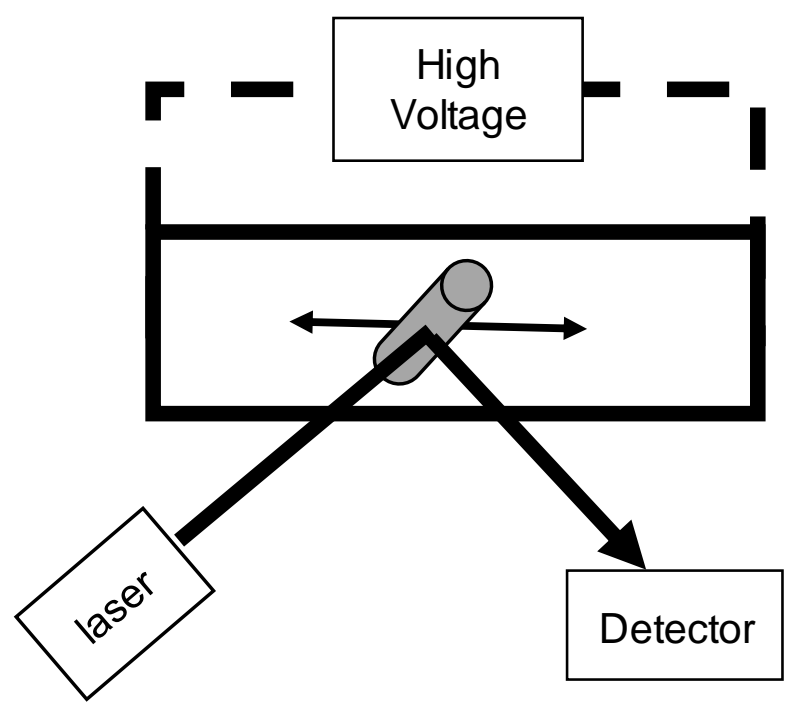

Figure 1-8: Block diagram of Zeta Potential Instrumentation. The carbon nanotube is suspended in aqueous solution, an alternating electric field is applied and the carbon nanotube moves back and forward. Migration of the carbon nanotubes in the electric field monitored and detected via light scattering.

Zeta Potential is frequently employed to determine differences in surface charge post functionalization or interaction $[45,62,68,69]$. Significant differences between pristine and oxidized carbon nanotubes are often reported because the oxidation process increases the net negative charge. This increase in negative surface charge results in increased electrostatic repulsion, therefore zeta potential is used as a metric to describe carbon nanotubes suspension $[51,57,69]$. Differences in zeta potential with $\mathrm{pH}$ or buffer conditions have been used to determine carbon nanotube stability as a function of aqueous environment [69]. In addition, zeta potential measurements have been used to characterize the absorption of proteins, polymers, and surfactants onto the carbon nanotube surface [65]. This change in surface charge indicates interaction of the protein and carbon nanotubes and a higher absolute zeta 
potential value with protein interaction indicates increased stability with coverage. While zeta potential measurements are useful for quick and simple analysis of surface charge, identification and quantification of charge functional groups cannot be determined. Additionally, significant differences in oxidation time or temperature are not readily determined at each $\mathrm{pH}$ [58].

\subsubsection{Electron Microscopy}

Electron microscopy (EM) techniques like scanning and transmission Electron Microscopy (SEM and TEM, respectively) visualize the change in carbon nanotube length, distribution and side defects as a function of oxidation. These techniques do not provide identification or quantification of surface oxidation but are so frequently used with all other methods previously discussed that it is included in this review $[17,21,45,56]$. Both SEM and TEM utilize an electron beam to increase magnification and image the nanometer size carbon nanotubes. Figure 1.-9 shows a schematic of EM instrumentation. The electron beam is either scattered off of the carbon nanotube surface or transmitted through the carbon nanotube surface [48]. SEM detects the scattering of secondary electrons (weakly bound conductive electrons at the sample surface) as the electron beam moves across the sample. The scattered electrons are converted to photons in a scintillator before detection with a photomultiplier. SEM cannot be performed without the addition of conductive gold sputtering, this aids in the reduction of charging which can prevents the production of additional secondary electrons. TEM measures the phase shift diffraction of electrons traveling through the sample. The entire sample surface is analyzed at once and a magnified image is formed with a charge couple device. To obtain high resolution of images in TEM, samples must be thin enough for electrons to pass through. 
Figure 1-9: Schematic of Electron Microscopy Instrumentation

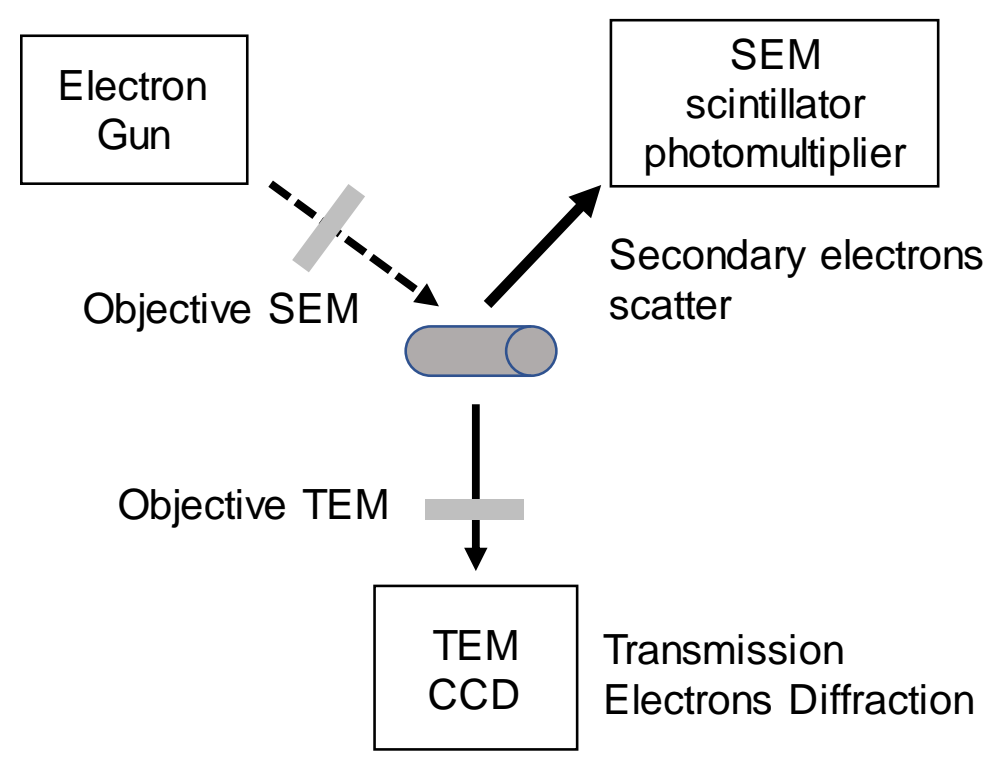

Figure 1-9: Schematic of Electron Microscopy Instrumentation depicting the difference between Transmission Electron Microscopy (TEM) and Scanning Electron Microscopy (SEM). The electron beam generates scattered electron that are detected in photomultipler in SEM while the electron beams at pass through the carbon nanotube sample are detected with charge couple device in TEM.

EMs are used to observes structural changes of the carbon nanotube post oxidation. Changes in carbon nanotube diameter, length and self-aggregation as a function of oxidation can be determined by visualizing the carbon nanotube samples with TEM or SEM $[21,22,70]$. The EM methods have been used to visualized increased surface roughness, amorphous carbon and side defects with oxidation, leading to the hypothesis that oxidation of carbon nanotubes is caused by induced damage of the carbon nanotube surface [37]. Additionally, TEM and SEM have been used to monitor morphology to determine which oxidative method causes the most damaging defects $[24,25,38,40,45,71,72]$. TEM and SEM have also been applied to visualize change in morphology when gold electrostatically bonded to the carbon nanotube surface to form a nanocomposite $[50,65]$ and most importantly to visualize dispersion of carbon nanotubes 
throughout composites [73]. However, these methods solely visualize qualitative change in carbon nanotube structure and do not provide information about the functional groups. Nevertheless, EMs methods are powerful tools for carbon nanotube characterization.

\subsection{QUANTIFICATION OF CARBON NANOTUBE INTERACTION}

Oxidization is often used as the initial step for other covalent and noncovalent modification pathways. The carboxylic acid molecules are covalently modified to add other small molecules like amide, chloride and other small molecules $[23,31,70]$. These small molecule attachments are important for biosensors and drug delivery as they provide a mechanism for targeted immobilization of proteins and enzymes [32,34,74-80]. While covalent modification is of significance importance for further functionalization, it can lead to denaturation of proteins and reduction in enzymatic activity $[74,81,82]$. Non-covalent interaction allows biomolecules to maintain tertiary structure [36]. Biomolecules can form bonds with oxidized carbon nanotubes' surface through electrostatic, pi-pi, and hydrophilic interaction [49] and several studies have reported utilized the oxidation of carbon nanotubes to control surface adsorption of metals and organic material, and to improve dispersion in nanocomposites $[29,62,68,71,83,84]$. These surface interactions play key roles in biosensors and biomedical devices as well as environmental and human toxicity and therefore it is critical to understanding how oxidation impacts surface interaction.

The following section details analytical techniques used to characterize and quantify surface interactions. Some of the techniques already discussed in detail are capable of detecting changes in carbon nanotube surface composition caused by interaction with proteins and in nanocomposites. The analytical techniques in this section quantitatively assess the amount of substrate adsorbed to the carbon nanotubes, the kinetic/aggregation rates or the affinity of 
substrate binding on the carbon nanotube surface. Table 1-2 details the four analytical techniques that will be discussed. Each technique has advantages and disadvantages and should be selected based on the researchers' need. Like the previous discussion, this section reviews the instrumentation, applications and limitations of each technique in addition to the mathematical models used to quantify interaction.

Table 1-2: Analytical Techniques Applied to Characterization Surface Oxidation of Carbon Nanotubes

\begin{tabular}{|c|c|c|c|c|}
\hline Method & Technique & $\frac{\text { Analytical }}{\text { Measurement }}$ & $\begin{array}{l}\text { Mathematical } \\
\text { Model }\end{array}$ & Limitation \\
\hline Fluorescence & Spectroscopy & Fluorescence & $\begin{array}{l}\text { Stern Volmer } \\
\text { Double-Logarithmic }\end{array}$ & $\begin{array}{l}\text { Fluorescent } \\
\text { Substrate }\end{array}$ \\
\hline UV-vis & Spectroscopy & $\begin{array}{l}\text { Molecular } \\
\text { Absorption }\end{array}$ & $\begin{array}{l}\text { Langmuir } \\
\text { Freundlich }\end{array}$ & $\begin{array}{l}\text { Pre-separation } \\
\text { Free/Bound, } \\
\text { Multiple Analysis }\end{array}$ \\
\hline AFM & Microscopy & Adhesion Force & $\begin{array}{l}\text { Force-Distance } \\
\text { Curve }\end{array}$ & $\begin{array}{l}\text { Covalent } \\
\text { Modification of Tip }\end{array}$ \\
\hline DLS & $\begin{array}{l}\text { Hydrodynamic } \\
\text { Radius }\end{array}$ & Aggregation Size & $\begin{array}{l}\text { Aggregation Rate } \\
\text { Kinetics }\end{array}$ & $\begin{array}{l}\text { Only sizes } \\
\text { Spherical Particles }\end{array}$ \\
\hline
\end{tabular}

\subsubsection{Fluorescence}

Fluorescence Spectroscopy is often used to quantify the interaction of carbon nanotubes with a substrate by monitoring change in the emission signal. Fluorescence detection occurs in two steps. First, an electron in the molecule of interest is excited using energy of a specific wavelength. Then a photon is released as the excited electron relaxes back to its ground state. The amount of signal produce during relaxation is directly proportional to the concentration of sample present. The emitted photons typically have a lower frequency than the excitation 
source. To detect the emitted photons without interference from the incident laser light, the detector is set at a $90^{\circ}$ angle as shown in the simplified schematic in Figure 1-10 [48]. To quantify binding however, a reduction in the emission signal must occur. This reduction in signal or fluorescence quenching occurs when energy from the excited stated is redirected to the carbon nanotube [85-88]. Because the excitation and emission are unique to the substrate, the reduction in signal with binding is directly related to surface interaction. Therefore, fluorescence quenching analysis can occur without the need for separation of the free and bound state, making fluorescence quenching a powerful metric to quantify binding interactions.

\section{Figure 1-10: Schematic of Fluorescence Instrumentation.}

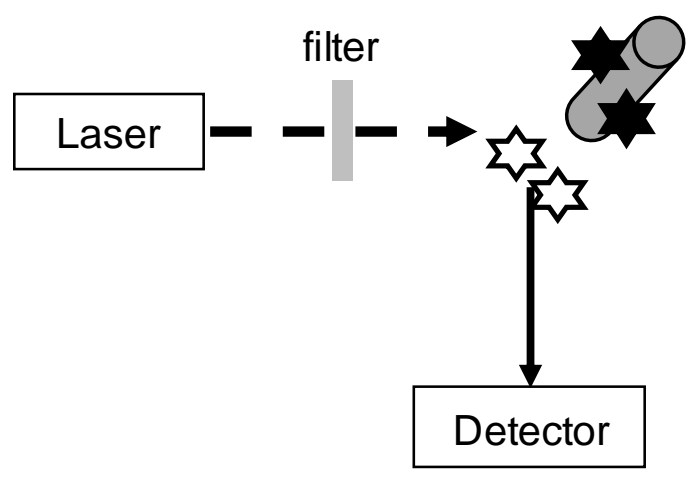

Figure 1-10: Schematic of Fluorescence Instrumentation. The laser light source illuminates the sample containing free analyte and analyte bound to the carbon nanotube surface. The bound analyte will not fluoresce while the free analyte fluoresces at a difference wavelength than the source light.

The interaction of carbon nanotube and substrate using fluorescence quenching is quantified using the Stern-Volmer equation:

$\mathrm{I}_{\mathrm{o}} / \mathrm{I}=1+\mathrm{K}_{\mathrm{Sv}}[\mathrm{CNT}]$ 
where $I_{0}$ is the initial intensity of the substrate without carbon nanotubes present, $I$ is the intensity at a given carbon nanotube concentration, [CNT], and $\mathrm{K}_{\mathrm{sv}}$ is the Stern-Volmer quenching constant. The Stern-Volmer quenching constant is the product of the $\mathrm{k}_{\mathrm{q}}$ or quenching rate coefficient and $\mathrm{T}_{0}$, which is the fluorescence lifetime of the substrate in the absence of a quencher $\left(\mathrm{K}_{\mathrm{sv}}=\mathrm{k}_{\mathrm{q}} \mathrm{T}_{0}\right)$ [89]. After taking multiple fluorescence measurements with increasing concentrations of carbon nanotube, the Stern-Volmer constant is determined from the slope of the $I_{0} / l$ versus the carbon nanotube concentration [86]. As the concentration of the carbon nanotube continues to increase, the fluorescence signal decreases. Recently, the fluorescence quenching has been applied to analyze adsorption of proteins onto carboxylated carbon nanotubes $[36,71,90,91]$. Zhao et. al. used fluorescence quenching analysis of alphachymotrypsin to determine protein adsorption onto carbon nanotubes functionalized with varying degrees of oxidation [36]. As the degree of oxidation increased, the protein adsorption increased while enzymatic activity decreased. These results indicate that surface oxidation plays a key role in protein adsorption. The study showed the need for methods that can rapidly probe carbon nanotube surface interaction to determine how changes in oxidation effect biosensor performance. Fluorescence quenching analysis, however, is limited to fluorescent substrates or requires the substrates be labeled with fluorophores [85,86,92]. Additionally, the carbon nanotube and substrate must be allowed to incubate so that equilibrium is reached prior to analysis.

\subsubsection{UV-vis Spectrometry}

UV-vis spectrometry is another technique used to elucidate interaction of substrates with carbon nanotubes based on the substrate absorbance. UV-vis spectrometry quantifies the absorbance or transmission of ultraviolet and visible light through a substrate. Utilizing Beer's law changes in substrate concentration or carbon nanotube stability/turbidity can be quantified $[58,69,93]$. 
UV measurements are obtained when light from a UV light source passes through a sample.

The amount of light passing through the sample is detected and used to quantify concentration while the wavelength of light absorbed is indicative of composition [94]. Figure 1-11 shows the instrumental schematic of absorbance at a specific wavelength. In the simplest form, light from a white light source is split into multiple wavelengths using a diffraction grating. A filter or slit is then used to select the single wavelength that passes through the substrate. This instrument often used to measure the unbound concentration of the substrate post interaction with functionalized carbon nanotubes and to determine the adsorption rate and coefficient.

\section{Figure 1-11: Schematic UV-vis Spectrometry Instrumentation}

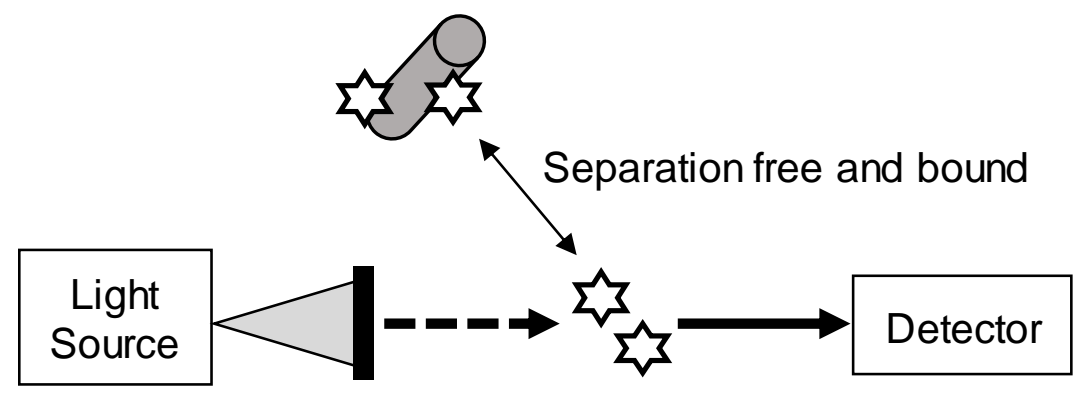

Figure 1-11. Block diagram of UV-vis Spectrometry. Light from the source is selected and filtered through a filter or monochromator. The unbound analyte, that has been separated from the analyte- carbon nanotube complex, is irradiated and the light passing through the sample is quantified.

Quantification of substrate adsorption with UV-vis requires multiple steps and can be analyzed with two different mathematical models. Typically, a known constant concentration of carbon nanotubes is incubated with the substrate over various time periods. Post incubation the complexed carbon nanotubes and substrate are removed via centrifugation. The concentration of the unbound or free substrate is then quantified with UV-vis. By plotting the substrate 
concentration versus incubation time, the aggregation rate kinetics, the adsorption capacity at equilibrium ( $\mathrm{q}_{\mathrm{e}}$, the amount of substrate adsorbed per $\mathrm{g}$ carbon nanotube) and the concentration of substrate at equilibrium, $\mathrm{C}_{\mathrm{e}}$, are determined. From the absorption capacity equilibrium, the $\mathrm{K}_{\mathrm{L}}$ or affinity parameter or $\mathrm{K}_{\mathrm{F}}$, sorption coefficient can be quantified, The Langmuir equation $q_{e}=q_{m a x} K_{L} C_{e} / 1+K_{L} C_{e}$

is used to determine capacity equilibrium, while the affinity parameter in quantified with the Freundlich equation:

$\mathrm{q}_{e}=\mathrm{K}_{\mathrm{f}}+\mathrm{C}_{e^{\mathrm{n}}}$

The Langmuir model is used to analyze monolayer adsorption while Freundlich model is used to model multi-layer adsorption $[84,93,95,96]$ and frequently both models are applied to data to determine adsorption mechanism. Statistical analysis using extra sum of the square $\mathrm{F}$ test, Akaike's criterion test or comparisons of $\mathrm{R}$ squared can been used to rank these models and determine the best fit [96]. Both models have been applied to compare the ability of pristine and oxidized CNT to bind toxicants [84,97,98], study the adsorption of composite materials [96] and protein binding $[36,90,91]$. A study of the adsorption of dissolved organic matter, humic acid, was performed using both models. The study revealed that adsorption of organic humic acid could be controlled based on carbon nanotube oxidation, thus potentially reducing carbon nanotube interference in the environment [93]. While UV-vis spectroscopy provides a means of assessing adsorption, the analysis process is tedious requiring multiple separation and incubation steps for a single analysis. Samples need to be separated before analyses so that no carbon nanotubes remain. This can require additional purification optimization with each carbon nanotube substrate interaction as well as potential loss of unbound substrate.

\subsubsection{Atomic Force Microscopy}


Atomic force microscopy is a scanning probe microscopy technique used to create $3 \mathrm{D}$ images based on the elastic properties of the surface. Figure 1-12 shows the traditional set up for AFM measurements. A tip connected to a cantilever moves across a sample by either tapping or scanning. As the height of the tip shifts, a laser light directed on the back of the cantilever measures the distance. The laser is reflected off the cantilever and the position of the laser is monitored using a photodiode. These measurements are converted to determine the force of the tip as it comes into contact with the surface using Hooke's law ( $F=k d$, where $k$ is the spring constant of the tip oscillation and $d$ is the deflection of the tip). The deflection of the tip as it moves across the surface on the $x$ and $y$ axis is used to plot the changes in topography of the surface. Like SEM and TEM, AFM is often used to determine the change in topography of carbon nanotubes with surface interaction and has even been used to monitor change in carbon nanotube length with increase oxidation [27,40]. Additionally, AFM can be used to easily image the interaction of carbon nanotubes with biological substrates $[99,100]$. These methods can provide information about the structure of carbon nanotube substrate interactions; however, AFM can additionally be used to determine binding strength. 
Figure 1-12: Schematic of Atomic Force Microscopy Instrumentation

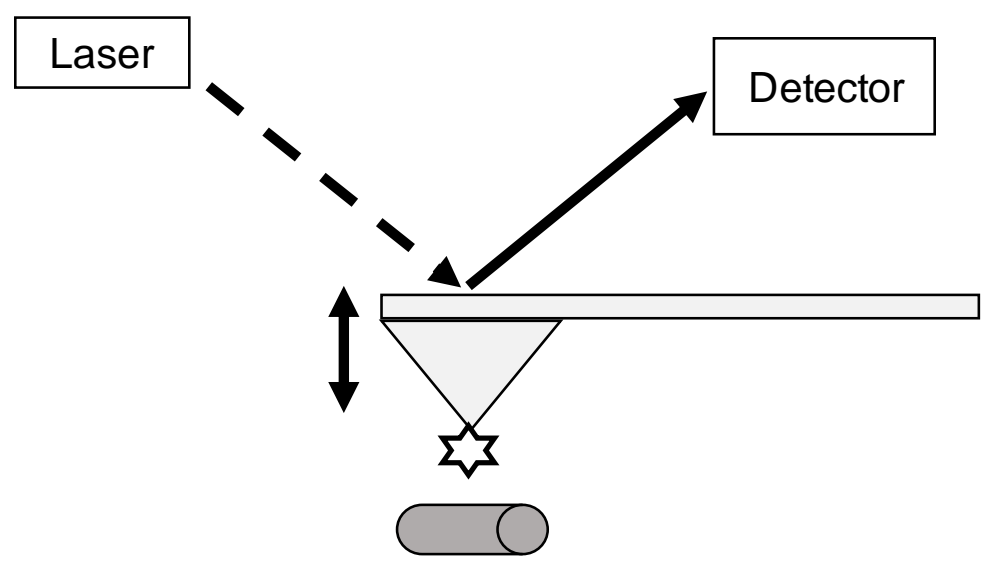

Figure 1-12: Schematic of Atomic Force Microscopy Instrumentation. The modified tip comes into contact with the carbon nanotube surface and binds. The cantilever moves the tip upward and the force required to break the bond is quantified by the shift in laser position.

AFM has the unique ability to measure the changes in force caused by interaction of a modified tip with an analyte surface. AFM tips have been modified to either contain the substrate of interest or an oxidized carbon nanotube $[81,101]$. In both cases the force and distance the tip must migrate up after it comes into contact with the surface is used to analyze carbon nanotube substrate interaction. The force required to move the tip from the surface is directly proportional to the adhesion force of the carbon nanotube and substrate interaction and is quickly analyzed using a force vs distance curve. Studies with AFM tips decorated with polytryptophan or polylysine were used to analyze the intermolecular forces of polypeptide adhesion to carboxylated carbon nanotubes [101]. Variations across $\mathrm{pH}$ and percent oxidation revealed increased electrostatic interaction of polylysine in comparison to $\pi-\pi$ interaction with the polytryptophan. AFM is an excellent way to determine adhesion strength of carbon nanotube and substrate but does require chemical modification of the AFM tips. Controlling the concentration or amount of substrate or carbon nanotube on the tip can be difficult if not 
impossible. Tip modification is also limited to the interaction of carbon nanotube and substrate on a single surface, therefore changes in substrate structure due to wrapping or denaturing cannot be determined.

\subsubsection{Dynamic Light Scattering}

Change in carbon nanotubes aggregate with interaction is measured with dynamic light scattering (DLS). DLS is used to measure the hydrodynamic radius of particles suspended in aqueous solution. Figure 1-13 shows the instrumental set up to measure particle size with DLS. As particles move based on random Brownian motion, laser light induces Rayleigh light scattering [67]. Fluctuation in the light scattering in time is used to determine the exponential decay of particles motion which is converted to the diffusion coefficient. Utilizing the diffusion coefficient and Stokes-Einstein equation, the hydrodynamic radius of a particle is determined. The Stokes-Einstein equation, however, only applies to spherical particles, therefore the accurate size of a carbon nanotube cannot be determined and the hydrodynamic radius is often measured as much less than the actual carbon nanotube length [67]. While size measurements for carbon nanotubes are not obtained with DLS, changes in apparent size can be used to monitor self-aggregation of carbon nanotubes or size change with interaction. Time-resolved DLS measures the change in complex size with time to determine the aggregation rate constant $[28,39]$. By utilizing this rate constant, researchers have been able to determine particle stability, aggregation kinetics and the critical coagulation concentration, which is the minimum concentration of electrolyte needed to induce carbon nanotube aggregation $[28,102]$. 
Figure 1-13: Schematic of Dynamic Light Scattering Instrumentation

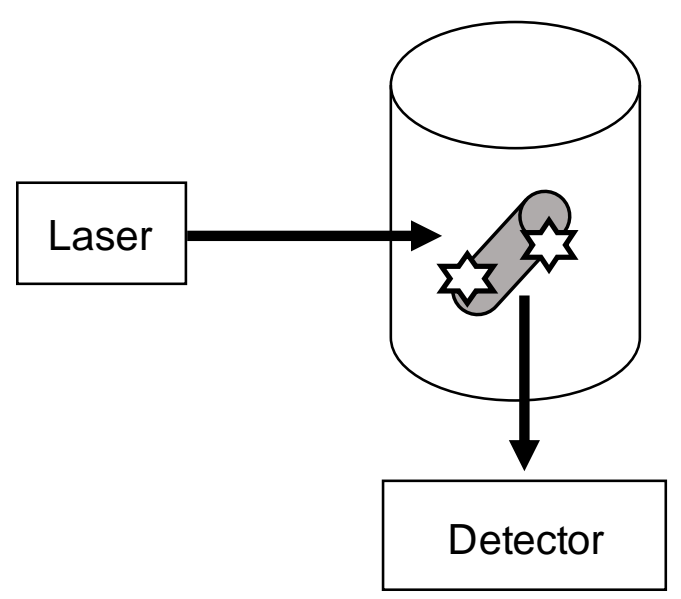

Figure 1-13: Schematic of Dynamic Light Scattering Instrumentation. The analyte-carbon nanotube complex is suspended in an aqueous solution. The random Brownian motion of the complex is monitored by laser induced light scattering and converted to size measurements.

Dynamic light scattering is applied to monitor how environmental conditions affect oxidized carbon nanotubes self-interaction by varying ionic buffers, buffer composition or substrate concentration $[28,39,51,102]$. Recently a study determined the effect of oxidation on carbon nanotubes stability. The hydrodynamic radius of carbon nanotubes with $9.5 \%$ oxygen (as determined by XPS) remain relatively the same as time increases, indicating a direct correlation between increased surface oxidation and increased stability while carbon nanotubes with lower oxidation aggregated with time [39]. Other studies have used DLS to monitor the change in complex size with time as a means to understand surface interactions $[90,103]$. The interaction with globular protein bromelain with oxidized carbon nanotubes have been studied with DLS by monitoring change in size with protein concentration. When combined with other measurement techniques, the authors concluded that increased concentration of protein resulted in complex aggregation and not stability. Despite the usefulness of DLS in monitoring particle stability and rates of aggregation, the method cannot provide information about binding strength nor the 
intermolecular forces governing binding. Additionally, the method requires multiple measurements across various buffer conditions and substrate or carbon nanotube concentrations.

\subsection{EMERGING TECHNIQUE- CAPILLARY ELECTROPHORESIS TO CHARACTERIZE CARBON NANOTUBE SURFACE OXIDATION AND SURFACE INTERACTION}

Capillary electrophoresis has recently demonstrated the capability to perform both surface functionalization and surface interaction characterization of carbon nanotubes. This innovative method employs affinity capillary electrophoresis to characterize carbon nanotube functionalization by monitoring shifts in the mobility of a specific binding probe. Figure 1-14 shows how electrophoretic mobility is obtained in capillary electrophoresis. Analytes migrate to the detection window with the bulk flow (electroosmotic flow, EOF) and separate based on individual electrophoretic mobility, which is determined by analytes charge-to-size ratio [104]. Differences in carbon nanotube electrophoretic mobility have previously been used to analyze carbon nanotube length and distribution [105], the details of which will be discussed in chapter

2. However, for this analysis, the mobility shift of a specific binding probe (WRWWWW) is used to characterize the degree of functionalization. As the peptide migrates and interacts with oxidized carbon nanotubes distributed through the capillary, the peptide's charge-to-size ratio shifts, decreasing migration. By systematically increasing the carbon nanotube concentration in the capillary, the shifts in mobility are used to determine the dissociation constant for the electrostatic interaction of carbon nanotube and peptide using the Hill equation $[106,107]$. The dissociation constant is inversely proportional to the degree of oxidation, and by changing the peptide probe, the surface interaction of oxidative carbon nanotubes can be easily analyzed. 
Figure 1-14: Schematic of Capillary Electrophoresis Instrumentation.

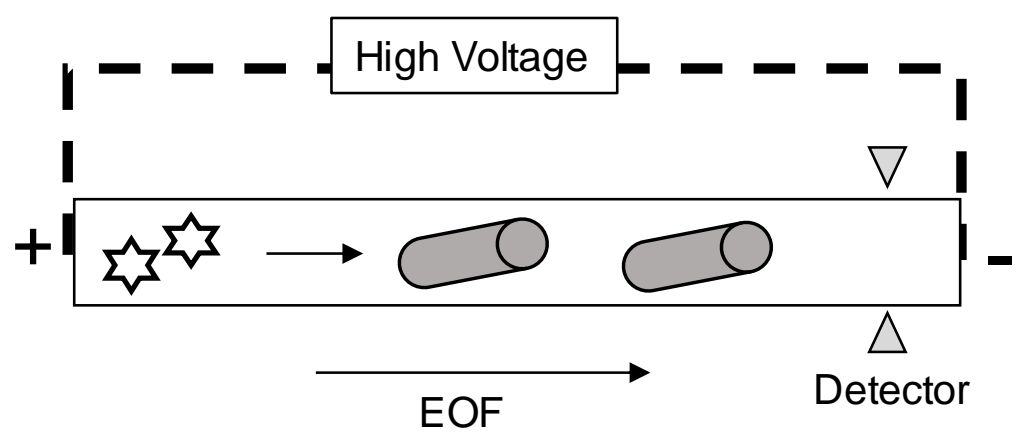

Figure 1-14: Schematic of Capillary Electrophoresis Instrumentation. Substrate is injected into and interacts with carbon nanotube dispersed throughout the capillary. Substrate migration is based on charge-to-size ratio and the electroosmotic flow through the capillary. The substrate migration changes based on carbon nanotube interaction. Shifts in the substrate migration are monitored with UV-vis detection and used to quantify binding.

The affinity capillary electrophoresis method has been applied to analyze variations in carbon nanotube oxidation and interaction using the Hill equation to determine the dissociation constant. The Hill equation, which models the equilibrium binding between peptide and carbon nanotube, is as follows:

$\theta=\frac{[C N T]^{n}}{[C N T]^{n}+K_{D}{ }^{n}}$

where $\theta$ is the fraction of peptide bound over peptide total as determined from the mobility shift, $[C N T]$ is the concentration of the carbon nanotube under investigation, $K_{D}$ is the dissociation constant and $n$ is the cooperativity coefficient. Dissociation constant measurements have been used to characterize differences across carbon nanotube manufacturers and oxidation time [108]. Dissociation constant measurements were also used to elucidate intermolecular forces governing protein-carbon nanotube interaction using subtraction and substitution of amino acid 
from the WRWWWW peptide probe [109]. The study isolated key roles amino acids arginine and tryptophan play in electrostatic and pi-pi interaction with carboxylated carbon nanotubes. By dispersing the carbon nanotubes in the background electrolyte, two fundamental issues with carbon nanotube injections are avoided; peak band broadening due to carbon nanotube heterogeneity and the poor UV-VIS detection of multiwalled carbon nanotubes. Both issues make detecting and monitoring carbon nanotubes migration nearly impossible and instead a peptide was injected and monitored. By overcoming these issues, affinity capillary electrophoresis becomes an enabling tool to analyze surface oxidation and surface interaction and, to our knowledge, is the only technique capable of both. 


\subsection{BIBLIOGRAPHY}

[1] S. lijima, Helical microtubules of graphitic carbon, Nature. 354 (1991) 56-58.

[2] R.H. Baughman, A.A. Zakhidov, W.A. de Heer, Carbon nanotubes--the route toward applications., Science. 297 (2002) 787-792.

[3] E.T. Thostenson, Z. Ren, T.-W. Chou, Advances in the science and technology of carbon nanotubes and their composites: a review, Composites Science and Technology. 61 (2001) 1899-1912.

[4] Q. Zhang, J.-Q. Huang, W.-Z. Qian, Y.-Y. Zhang, F. Wei, The road for nanomaterials industry: a review of carbon nanotube production, post-treatment, and bulk applications for composites and energy storage., Small. 9 (2013) 1237-1265.

[5] C.B. Jacobs, T.L. Vickrey, B.J. Venton, Functional groups modulate the sensitivity and electron transfer kinetics of neurochemicals at carbon nanotube modified microelectrodes., Analyst (Lond). 136 (2011) 3557-3565.

[6] M.F.L. De Volder, S.H. Tawfick, R.H. Baughman, A.J. Hart, Carbon nanotubes: present and future commercial applications., Science. 339 (2013) 535-539.

[7] A. Kis, G. Csányi, J.P. Salvetat, T.-N. Lee, E. Couteau, A.J. Kulik, et al., Reinforcement of single-walled carbon nanotube bundles by intertube bridging., Nat Mater. 3 (2004) 153-157.

[8] M. Zheng, A. Jagota, E.D. Semke, B.A. Diner, R.S. McLean, S.R. Lustig, et al., DNAassisted dispersion and separation of carbon nanotubes., Nat Mater. 2 (2003) 338-342.

[9] Y. Liu, Y. Zhao, B. Sun, C. Chen, Understanding the toxicity of carbon nanotubes., Acc Chem Res. 46 (2013) 702-713.

[10] R.P. Singh, M. Das, V. Thakare, S. Jain, Functionalization density dependent toxicity of oxidized multiwalled carbon nanotubes in a murine macrophage cell line., Chem Res Toxicol. 25 (2012) 2127-2137.

[11] K. Bhattacharya, F.T. Andón, R. El-Sayed, B. Fadeel, Mechanisms of carbon nanotubeinduced toxicity: focus on pulmonary inflammation., Adv Drug Deliv Rev. 65 (2013) 2087-2097.

[12] R. Li, X. Wang, Z. Ji, B. Sun, H. Zhang, C.H. Chang, et al., Surface charge and cellular processing of covalently functionalized multiwall carbon nanotubes determine pulmonary toxicity., ACS Nano. 7 (2013) 2352-2368.

[13] Y. Yan, J. Miao, Z. Yang, F.-X. Xiao, H.B. Yang, B. Liu, et al., Carbon nanotube catalysts: recent advances in synthesis, characterization and applications., Chem Soc Rev. 44 (2015) 3295-3346.

[14] E. Katz, I. Willner, Biomolecule-functionalized carbon nanotubes: applications in nanobioelectronics., Chemphyschem. 5 (2004) 1084-1104. 
[15] C. Herrero-Latorre, J. Barciela-García, S. García-Martín, R.M. Peña-Crecente, Graphene and carbon nanotubes as solid phase extraction sorbents for the speciation of chromium: A review., Anal Chim Acta. 1002 (2018) 1-17.

[16] A. Eatemadi, H. Daraee, H. Karimkhanloo, M. Kouhi, N. Zarghami, A. Akbarzadeh, et al., Carbon nanotubes: properties, synthesis, purification, and medical applications., Nanoscale Res Lett. 9 (2014) 393.

[17] Y. Wang, Z. Iqbal, S. Mitra, Rapidly functionalized, water-dispersed carbon nanotubes at high concentration., J Am Chem Soc. 128 (2006) 95-99.

[18] H. Ago, T. Kugler, F. Cacialli, W.R. Salaneck, M.S.P. Shaffer, A.H. Windle, et al., Work functions and surface functional groups of multiwall carbon nanotubes, J. Phys. Chem. B. 103 (1999) 8116-8121.

[19] M. Li, M. Boggs, T.P. Beebe, C.P. Huang, Oxidation of single-walled carbon nanotubes in dilute aqueous solutions by ozone as affected by ultrasound, Carbon N Y. 46 (2008) 466-475.

[20] Y. Xing, L. Li, C.C. Chusuei, R.V. Hull, Sonochemical oxidation of multiwalled carbon nanotubes., Langmuir. 21 (2005) 4185-4190.

[21] V. Datsyuk, M. Kalyva, K. Papagelis, J. Parthenios, D. Tasis, A. Siokou, et al., Chemical oxidation of multiwalled carbon nanotubes, Carbon N Y. 46 (2008) 833-840.

[22] J. Zhang, H. Zou, Q. Qing, Y. Yang, Q. Li, Z. Liu, et al., Effect of Chemical Oxidation on the Structure of Single-Walled Carbon Nanotubes, J. Phys. Chem. B. 107 (2003) 37123718.

[23] A.K. Jain, V. Dubey, N.K. Mehra, N. Lodhi, M. Nahar, D.K. Mishra, et al., Carbohydrateconjugated multiwalled carbon nanotubes: development and characterization., Nanomedicine. 5 (2009) 432-442.

[24] K.A. Wepasnick, B.A. Smith, K.E. Schrote, H.K. Wilson, S.R. Diegelmann, D.H. Fairbrother, Surface and structural characterization of multi-walled carbon nanotubes following different oxidative treatments, Carbon N Y. 49 (2011) 24-36.

[25] S. Gómez, N.M. Rendtorff, E.F. Aglietti, Y. Sakka, G. Suarez, Intensity of sulfonitric treatment on multiwall carbon nanotubes, Chem Phys Lett. 689 (2017) 135-141.

[26] Z. Wu, S. Mitra, Length reduction of multi-walled carbon nanotubes via high energy ultrasonication and its effect on their dispersibility, J Nanopart Res. 16 (2014) 2563.

[27] M.W. Marshall, S. Popa-Nita, J.G. Shapter, Measurement of functionalised carbon nanotube carboxylic acid groups using a simple chemical process, Carbon N Y. 44 (2006) 1137-1141.

[28] B. Smith, K. Wepasnick, K.E. Schrote, A.R. Bertele, W.P. Ball, C. O'Melia, et al., Colloidal properties of aqueous suspensions of acid-treated, multi-walled carbon nanotubes., Environ Sci Technol. 43 (2009) 819-825.

[29] C.B. Jacobs, M.J. Peairs, B.J. Venton, Review: Carbon nanotube based electrochemical sensors for biomolecules., Anal Chim Acta. 662 (2010) 105-127. 
[30] S. Banerjee, T. Hemraj-Benny, S.S. Wong, Covalent Surface Chemistry of SingleWalled Carbon Nanotubes.pdf, Adv Mater Weinheim. 17 (2005) 17-29.

[31] A. Eitan, K. Jiang, D. Dukes, R. Andrews, L.S. Schadler, Surface modification of multiwalled carbon nanotubes: toward the tailoring of the interface in polymer composites, Chem. Mater. 15 (2003) 3198-3201.

[32] W. Feng, P. Ji, Enzymes immobilized on carbon nanotubes., Biotechnol Adv. 29 (2011) 889-895.

[33] N.G. Sahoo, S. Rana, J.W. Cho, L. Li, S.H. Chan, Polymer nanocomposites based on functionalized carbon nanotubes, Prog Polym Sci. 35 (2010) 837-867.

[34] A. Antonucci, J. Kupis-Rozmysłowicz, A.A. Boghossian, Noncovalent Protein and Peptide Functionalization of Single-Walled Carbon Nanotubes for Biodelivery and Optical Sensing Applications., ACS Appl Mater Interfaces. 9 (2017) 11321-11331.

[35] N. Li, Y. Luo, A highly selective chemical gas sensor based on functionalization of multiwalled carbon nanotubes with poly(ethylene glycol), Sensors and Actuators B. 126 (2007) 361-367.

[36] X. Zhao, F. Hao, D. Lu, W. Liu, Q. Zhou, G. Jiang, Influence of the Surface Functional Group Density on the Carbon-Nanotube-Induced a-Chymotrypsin Structure and Activity Alterations., ACS Appl Mater Interfaces. 7 (2015) 18880-18890.

[37] L. Zhang, G. Wen, H. Liu, N. Wang, D.S. Su, Preparation of palladium catalysts supported on carbon nanotubes by an electrostatic adsorption method, ChemCatChem. 6 (2014) 2600-2606.

[38] N. George, J.C. C.S., A. Mathiazhagan, R. Joseph, High performance natural rubber composites with conductive segregated network of multiwalled carbon nanotubes, Composites Science and Technology. 116 (2015) 33-40.

[39] B. Smith, K. Wepasnick, K.E. Schrote, H.-H. Cho, W.P. Ball, D.H. Fairbrother, Influence of surface oxides on the colloidal stability of multi-walled carbon nanotubes: a structureproperty relationship., Langmuir. 25 (2009) 9767-9776.

[40] S.-M. Xue, Z.-L. Xu, Y.-J. Tang, C.-H. Ji, Polypiperazine-amide Nanofiltration Membrane Modified by Different Functionalized Multiwalled Carbon Nanotubes (MWCNTs)., ACS Appl Mater Interfaces. 8 (2016) 19135-19144.

[41] C. Herrero-Latorre, J. Álvarez-Méndez, J. Barciela-García, S. García-Martín, R.M. PeñaCrecente, Characterization of carbon nanotubes and analytical methods for their determination in environmental and biological samples: a review., Anal Chim Acta. 853 (2015) 77-94.

[42] K.A. Wepasnick, B.A. Smith, J.L. Bitter, D. Howard Fairbrother, Chemical and structural characterization of carbon nanotube surfaces., Anal Bioanal Chem. 396 (2010) 10031014.

[43] T. Belin, F. Epron, Characterization methods of carbon nanotubes: a review, Materials Science and Engineering: B. 119 (2005) 105-118. 
[44] D.R. Baer, D.J. Gaspar, P. Nachimuthu, S.D. Techane, D.G. Castner, Application of surface chemical analysis tools for characterization of nanoparticles., Anal Bioanal Chem. 396 (2010) 983-1002.

[45] S. Gómez, N.M. Rendtorff, E.F. Aglietti, Y. Sakka, G. Suárez, Surface modification of multiwall carbon nanotubes by sulfonitric treatment, Appl Surf Sci. 379 (2016) 264-269.

[46] G. Wen, J. Diao, S. Wu, W. Yang, R. Schlögl, D.S. Su, Acid Properties of Nanocarbons and Their Application in Oxidative Dehydrogenation, ACS Catal. 5 (2015) 3600-3608.

[47] S. Musso, J.-M. Tulliani, G. Ferro, A. Tagliaferro, Influence of carbon nanotubes structure on the mechanical behavior of cement composites, Composites Science and Technology. 69 (2009) 1985-1990.

[48] D.A. Skoog, F.J. Holler, T.A. Nieman, Principles of Instrumental Analysis, 6th ed., Saunders College Pub, Philadelphia, 1998.

[49] C. Hu, S. Hu, Surface design of carbon nanotubes for optimizing the adsorption and electrochemical response of analytes., Langmuir. 24 (2008) 8890-8897.

[50] B. Deiminiat, G.H. Rounaghi, M.H. Arbab-Zavar, I. Razavipanah, A novel electrochemical aptasensor based on f-MWCNTs/AuNPs nanocomposite for label-free detection of bisphenol A, Sensors and Actuators B: Chemical. 242 (2017) 158-166.

[51] A. Schierz, H. Zänker, Aqueous suspensions of carbon nanotubes: surface oxidation, colloidal stability and uranium sorption., Environ Pollut. 157 (2009) 1088-1094.

[52] J.C. Vickerman, I.S. Gilmore, eds., Surface analysis- the principal techniques, John Wiley \& Sons, Ltd, Chichester, UK, 2009.

[53] S. Osswald, M. Havel, Y. Gogotsi, Monitoring oxidation of multiwalled carbon nanotubes by Raman spectroscopy, J. Raman Spectrosc. 38 (2007) 728-736.

[54] R. Malik, C. McConnell, N.T. Alvarez, M. Haase, S. Gbordzoe, V. Shanov, Rapid, in situ plasma functionalization of carbon nanotubes for improved CNT/epoxy composites, RSC Adv. 6 (2016) 108840-108850.

[55] S. Kundu, Y. Wang, W. Xia, M. Muhler, Thermal Stability and Reducibility of OxygenContaining Functional Groups on Multiwalled Carbon Nanotube Surfaces: A Quantitative High-Resolution XPS and TPD/TPR Study, J. Phys. Chem. C. 112 (2008) 16869-16878.

[56] R. Yudianti, Analysis of Functional Group Sited on Multi-Wall Carbon Nanotube Surface, TOMSJ. 5 (2011) 242-247.

[57] Z. Talaei, A.R. Mahjoub, A. morad Rashidi, A. Amrollahi, M. Emami Meibodi, The effect of functionalized group concentration on the stability and thermal conductivity of carbon nanotube fluid as heat transfer media, International Communications in Heat and Mass Transfer. 38 (2011) 513-517.

[58] M. Farbod, A. Ahangarpour, S.G. Etemad, Stability and thermal conductivity of waterbased carbon nanotube nanofluids, Particuology. 22 (2015) 59-65. 
[59] H. Peng, L.B. Alemany, J.L. Margrave, V.N. Khabashesku, Sidewall carboxylic acid functionalization of single-walled carbon nanotubes., J Am Chem Soc. 125 (2003) 15174-15182.

[60] S.A. Chernyak, A.S. Ivanov, N.E. Strokova, K.I. Maslakov, S.V. Savilov, V.V. Lunin, Mechanism of thermal defunctionalization of oxidized carbon nanotubes, J. Phys. Chem. C. 120 (2016) 17465-17474.

[61] B. Scheibe, E. Borowiak-Palen, R.J. Kalenczuk, Oxidation and reduction of multiwalled carbon nanotubes - preparation and characterization, Materials Characterization. 61 (2010) 185-191.

[62] Y.-H. Li, S. Wang, Z. Luan, J. Ding, C. Xu, D. Wu, Adsorption of cadmium(II) from aqueous solution by surface oxidized carbon nanotubes, Carbon N Y. 41 (2003) 10571062.

[63] Z. Wang, M.D. Shirley, S.T. Meikle, R.L.D. Whitby, S.V. Mikhalovsky, The surface acidity of acid oxidised multi-walled carbon nanotubes and the influence of in-situ generated fulvic acids on their stability in aqueous dispersions, Carbon N Y. 47 (2009) 73-79.

[64] A.M. Oickle, S.L. Goertzen, K.R. Hopper, Y.O. Abdalla, H.A. Andreas, Standardization of the Boehm titration: Part II. Method of agitation, effect of filtering and dilute titrant, Carbon N Y. 48 (2010) 3313-3322.

[65] B. Kim, W.M. Sigmund, Functionalized multiwall carbon nanotube/gold nanoparticle composites., Langmuir. 20 (2004) 8239-8242.

[66] Y.S. Kim, C.R. Park, One-pot titration methodology for the characterization of surface acidic groups on functionalized carbon nanotubes, Carbon N Y. 96 (2016) 729-741.

[67] S. Bhattacharjee, DLS and zeta potential - What they are and what they are not?, J Control Release. 235 (2016) 337-351.

[68] Q. Fang, B. Chen, Adsorption of perchlorate onto raw and oxidized carbon nanotubes in aqueous solution, Carbon N Y. 50 (2012) 2209-2219.

[69] X. Peng, J. Jia, X. Gong, Z. Luan, B. Fan, Aqueous stability of oxidized carbon nanotubes and the precipitation by salts., J Hazard Mater. 165 (2009) 1239-1242.

[70] Z. Zhao, Z. Yang, Y. Hu, J. Li, X. Fan, Multiple functionalization of multi-walled carbon nanotubes with carboxyl and amino groups, Appl Surf Sci. 276 (2013) 476-481.

[71] L. Li, R. Lin, H. He, L. Jiang, M. Gao, Interaction of carboxylated single-walled carbon nanotubes with bovine serum albumin., Spectrochim Acta A Mol Biomol Spectrosc. 105 (2013) 45-51.

[72] T. Zhang, M. Tang, L. Kong, H. Li, T. Zhang, S. Zhang, Comparison of cytotoxic and inflammatory responses of pristine and functionalized multi-walled carbon nanotubes in RAW 264.7 mouse macrophages., J Hazard Mater. 219-220 (2012) 203-212. 
[73] D. Benetti, K.T. Dembele, J. Benavides, H. Zhao, S. Cloutier, I. Concina, Functionalized multi-wall carbon nanotubes $/ \mathrm{TiO}_{2}$ composites as efficient photoanodes for dye sensitized solar cells, J. Mater. Chem. C. 4 (2016) 3555-3562.

[74] M. Prato, K. Kostarelos, A. Bianco, Functionalized carbon nanotubes in drug design and discovery., Acc Chem Res. 41 (2008) 60-68.

[75] Z. Liu, S. Tabakman, K. Welsher, H. Dai, Carbon Nanotubes in Biology and Medicine: In vitro and in vivo Detection, Imaging and Drug Delivery., Nano Res. 2 (2009) 85-120.

[76] A. Bianco, K. Kostarelos, M. Prato, Applications of carbon nanotubes in drug delivery., Curr Opin Chem Biol. 9 (2005) 674-679.

[77] H. He, L.A. Pham-Huy, P. Dramou, D. Xiao, P. Zuo, C. Pham-Huy, Carbon nanotubes: applications in pharmacy and medicine., Biomed Res. Int. 2013 (2013) 578290.

[78] S.S. Karajanagi, H. Yang, P. Asuri, E. Sellitto, J.S. Dordick, R.S. Kane, Protein-assisted solubilization of single-walled carbon nanotubes., Langmuir. 22 (2006) 1392-1395.

[79] S.F. Oliveira, G. Bisker, N.A. Bakh, S.L. Gibbs, M.P. Landry, M.S. Strano, Protein functionalized carbon nanomaterials for biomedical applications, Carbon N Y. 95 (2015) 767-779.

[80] K. Min, J. Kim, K. Park, Y.J. Yoo, Enzyme immobilization on carbon nanomaterials: Loading density investigation and zeta potential analysis, Journal of Molecular Catalysis B: Enzymatic. 83 (2012) 87-93.

[81] S.S. Wong, E. Joselevich, A.T. Woolley, C.L. Cheung, C.M. Lieber, Covalently functionalized nanotubes as nanometre-sized probes in chemistry and biology., Nature. 394 (1998) 52-55.

[82] Y.-L. Zhao, J.F. Stoddart, Noncovalent functionalization of single-walled carbon nanotubes., Acc Chem Res. 42 (2009) 1161-1171.

[83] W.-H. Liao, H.-W. Tien, S.-T. Hsiao, S.-M. Li, Y.-S. Wang, Y.-L. Huang, Effects of multiwalled carbon nanotubes functionalization on the morphology and mechanical and thermal properties of carbon fiber/vinyl ester composites., ACS Appl Mater Interfaces. 5 (2013) 3975-3982.

[84] M.I. Kandah, J.-L. Meunier, Removal of nickel ions from water by multi-walled carbon nanotubes., J Hazard Mater. 146 (2007) 283-288.

[85] S. Palencia, S. Vera, A.M. Díez-Pascual, M.P. San Andrés, Quenching of fluorene fluorescence by single-walled carbon nanotube dispersions with surfactants: application for fluorene quantification in wastewater., Anal Bioanal Chem. 407 (2015) 4671-4682.

[86] D.K. Singh, P.K. lyer, P.K. Giri, Role of molecular interactions and structural defects in the efficient fluorescence quenching by carbon nanotubes, Carbon N Y. 50 (2012) 44954505.

[87] J.J. Brege, C. Gallaway, A.R. Barron, Fluorescence Quenching of Single-Walled Carbon Nanotubes with Transition-Metal Ions, J. Phys. Chem. C. 113 (2009) 4270-4276. 
[88] G. Bisker, J. Dong, H.D. Park, N.M. Iverson, J. Ahn, J.T. Nelson, Protein-targeted corona phase molecular recognition., Nat Commun. 7 (2016) 10241.

[89] C.D. Geddes, Optical halide sensing using fluorescence quenching: theory, simulations and applications - a review, Meas. Sci. Technol. 12 (2001) R53-R88.

[90] I. Jha, P. Venkatesu, Deciphering the Interactions of Bromelain with Carbon Nanotubes: Role of Protein as Well as Carboxylated Multiwalled Carbon Nanotubes in a Complexation Mechanism, J. Phys. Chem. C. 120 (2016) 15436-15445.

[91] P. Du, J. Zhao, H. Mashayekhi, B. Xing, Adsorption of bovine serum albumin and lysozyme on functionalized carbon nanotubes, J. Phys. Chem. C. 118 (2014) 2224922257.

[92] C. Li, G. Shi, Carbon nanotube-based fluorescence sensors, Journal of Photochemistry and Photobiology C: Photochemistry Reviews. 19 (2014) 20-34.

[93] F. Wang, J. Yao, H. Chen, Z. Yi, B. Xing, Sorption of humic acid to functionalized multiwalled carbon nanotubes., Environ Pollut. 180 (2013) 1-6.

[94] X. Zhao, R. Liu, Z. Chi, Y. Teng, P. Qin, New insights into the behavior of bovine serum albumin adsorbed onto carbon nanotubes: comprehensive spectroscopic studies., J Phys Chem B. 114 (2010) 5625-5631.

[95] M. Ghaedi, S. Heidarpour, S. Nasiri Kokhdan, R. Sahraie, A. Daneshfar, B. Brazesh, Comparison of silver and palladium nanoparticles loaded on activated carbon for efficient removal of Methylene blue: Kinetic and isotherm study of removal process, Powder Technol. 228 (2012) 18-25.

[96] X. Xie, L. Gao, J. Sun, Thermodynamic study on aniline adsorption on chemical modified multi-walled carbon nanotubes, Colloids and Surfaces A: Physicochemical and Engineering Aspects. 308 (2007) 54-59.

[97] O. Moradi, M. Norouzi, A. Fakhri, K. Naddafi, Interaction of removal Ethidium Bromide with Carbon Nanotube: Equilibrium and Isotherm studies., J Environ Health Sci Eng. 12 (2014) 17.

[98] O. Moradi, A. Fakhri, S. Adami, S. Adami, Isotherm, thermodynamic, kinetics, and adsorption mechanism studies of Ethidium bromide by single-walled carbon nanotube and carboxylate group functionalized single-walled carbon nanotube., J Colloid Interface Sci. 395 (2013) 224-229.

[99] J. Du, C. Ge, Y. Liu, R. Bai, D. Li, Y. Yang, The interaction of serum proteins with carbon nanotubes depend on the physicochemical properties of nanotubes., J Nanosci Nanotechnol. 11 (2011) 10102-10110.

[100] C. Ge, J. Du, L. Zhao, L. Wang, Y. Liu, D. Li, Binding of blood proteins to carbon nanotubes reduces cytotoxicity., Proc Natl Acad Sci U S A. 108 (2011) 16968-16973.

[101] X. Li, W. Chen, Q. Zhan, L. Dai, L. Sowards, M. Pender, Direct measurements of interactions between polypeptides and carbon nanotubes., J Phys Chem B. 110 (2006) 12621-12625. 
[102] P. Yi, K.L. Chen, Influence of surface oxidation on the aggregation and deposition kinetics of multiwalled carbon nanotubes in monovalent and divalent electrolytes., Langmuir. 27 (2011) 3588-3599.

[103] Z. Xiao, M. Gupta, G. Baltas, T. Liu, H.G. Chae, S. Kumar, Probe diffusion of singlewalled carbon nanotubes in semidilute solutions of polyacrylonitrile homo- and copolymers: Effects of topological constraints and polymer/Nanorod interactions, Polymer. 53 (2012) 5069-5077.

[104] D. Heiger, High Performance Capillary Electrophoresis, 3rd ed., Hewlett Packard Company, France, 1997.

[105] S.K. Doorn, R.E. Fields, H. Hu, M.A. Hamon, R.C. Haddon, J.P. Selegue, High resolution capillary electrophoresis of carbon nanotubes., J Am Chem Soc. 124 (2002) 3169-3174.

[106] N. Li, S. Zeng, L. He, W. Zhong, Probing nanoparticle--protein interaction by capillary electrophoresis., Anal Chem. 82 (2010) 7460-7466.

[107] S.P. Boulos, T.A. Davis, J.A. Yang, S.E. Lohse, A.M. Alkilany, L.A. Holland, Murphy Nanoparticle-protein interactions: a thermodynamic and kinetic study of the adsorption of bovine serum albumin to gold nanoparticle surfaces., Langmuir. 29 (2013) 14984-14996.

[108] T. Davis, S. Patberg, A. Stefaniak, L. Sargent, L. Holland, Capillary Electrophoresis Analysis of Affinity to Assess Carboxylation of Multi-Walled, Anal. Chimica Acta (2018) accepted

[109] T.A. Davis, L.A. Holland, Peptide probe for multiwalled carbon nanotubes: electrophoretic assessment of the binding interface and evaluation of surface functionalization., ACS Appl Mater Interfaces, 10 (2018) 11311-11318. 


\section{Chapter 2:}

Capillary Electrophoresis Analysis of Affinity to Assess Carboxylation of Multi-Walled Carbon Nanotubes

\section{Reproduced from [1]}

T.A. Davis, S. Patberg, A. Stefaniak, L. Sargent, L.A. Holland, Capillary Electrophoresis Analysis of Affinity to Assess Carboxylation of Multi-Walled, Anal. Chim. Acta (2018) accepted 


\subsection{INTRODUCTION}

Carbon nanotubes are significant to different manufacturing sectors, including advanced performance materials [2], biosensors [3], and other health applications [4]. Production is estimated at 4,500 tons of carbon nanotubes per year. Increased demand for multi-walled carbon nanotubes is anticipated [2, 5] because of their mechanical properties and bulk cost [2]. Functionalization of carbon nanotubes enhances performance in a variety of applications such as composites [6, 7], electrochemical sensors [8], or for the immobilization of biomolecules [9, 10]. There is even evidence that surface modification can be used to modulate toxicity $[4,11$ 13]. Oxidation of carbon nanotubes, which produces carboxyl functional groups, is the most prevalent method of surface modification, and is accomplished in the laboratory setting with acidification. New technologies are being developed to increase the feasibility of surface modification. Recently, carbon nanotubes were rapidly and economically functionalized in composites with the use of a plasma in an oxygen rich environment [14]. Simple, inexpensive, and accurate methods to characterize carbon nanotube surface functionalization are fundamental to advancing translational research in biosensing and biotechnology and to provide quality control required in manufacturing.

Analytical methods used to characterize the carboxylation of carbon nanotubes have different capabilities and limitations [15]. The surface charge of the carbon nanotubes can be measured with a zeta potential analyzer, which subjects a nanoparticle suspension to an electric field and monitors the resultant particle motion with laser scattering. The method can only detect significant changes in surface charge [12], and has not been used successfully to distinguish subtle differences in changes of the degree of carboxylation. Spectroscopy techniques like Xray photoelectron spectroscopy, infrared spectroscopy and Raman spectroscopy can be used for qualitative characterization of carbon nanotube carboxylation if sample sizes up to $5 \mathrm{mg}$ are 
available [15]. X-ray photoelectron spectroscopy has been used to obtain the percent composition of functional groups ( $\left.\mathrm{C} \pi-\pi^{*}, \mathrm{C}-\mathrm{C} / \mathrm{C}-\mathrm{H}, \mathrm{C}=\mathrm{O}, \mathrm{O}-\mathrm{C}-\mathrm{O}, \mathrm{COOH}\right)$ by deconvolution of the 284.5 to $290.8 \mathrm{eV}$ binding energy region; however, the percent composition of carbonyl group cannot be determined unambiguously. The carboxylic acid composition changed by $5 \%$ for the same data depending on the peak fitting parameters used for the deconvolution [15]. Indirect and direct $\mathrm{pH}$ titration of carbon nanotube analyses require times as long as 72 hours [16] and up to $1.5 \mathrm{~g}$ of sample [17]. These and other concerns about unmet needs for nanoparticle characterization have led to a call for new methods [18].

Classical affinity capillary electrophoresis is an analytical method that can be used to evaluate the carboxylation of carbon nanotubes. The receptor is injected and separated in a capillary containing ligand. The migration time of the receptor depends on the time that the receptor is in the free versus bound state during the separation and the amount of complex formed is dictated by both the ligand concentration and the binding constant. The change in the apparent mobility of receptor is monitored at different ligand concentrations to calculate the dissociation constant. A number of receptor-ligand systems involve a change in the charge-to-size ratio upon binding and the approach has been widely applied to molecular interactions [19-23]. Measurements of mobility shift with affinity capillary electrophoresis have been successfully applied to some nanoparticles [24, 25], but it has not successfully been applied to measurements of carbon nanotube binding interactions. This is significant because previous reports to quantify the dissociation constants of carbon nanotube:biomolecule systems are limited to the analyses of single walled carbon nanotubes and DNA with an isochronal assay [26], multi-walled carbon nanotubes and surfactant with photoluminescent shifting assay [27], and multi-walled carbon nanotubes and wheat agglutinin protein with UV absorbance of the free protein at $280 \mathrm{~nm}$ [28]. 
A classical affinity electrophoresis approach is presented that uses a peptide as a probe to produce a measurable change in the charge-to-size ratio of carboxylated carbon nanotubes upon forming a complex. This peptide, amidated tryptophylarginyltryptophyltryptophyltryptophyltryptophan (WRWWWW), is selected based on prior studies that demonstrated the role of tryptophan and arginine in strong $\pi-\pi[29,30]$ and electrostatic interactions [31], respectively. Moreover, the degree of carboxylation on carbon nanotubes can be differentiated using the peptide probe. Advantages of affinity capillary electrophoresis include the low consumption of the peptide receptor and the ability to perform the measurements with a range of ligands without consideration of issues associated with ligand detection. Affinity capillary electrophoresis measurements of biomolecule-carbon nanotube affinity are feasible if the biomolecule is injected into a background electrolyte containing the carbon nanotube ligand. This also overcomes issues related to the slow mobility of functionalized carbon nanotubes, as well as the cost given that carbon nanotubes are less expensive ( $\$ 0.16$ per $\mathrm{mg}$ ) [32] than the peptide receptor ( $\$ 67$ per $\mathrm{mg}$ ) [33].

This is the first report of the implementation of affinity capillary electrophoresis to evaluate the degree of carbon nanotube functionalization with carboxylic acids. The approach is evaluated and the precision of the method is established using commercially available carboxylated multiwalled carbon nanotubes. The effect of acid treatment is quantified using affinity capillary electrophoresis to relate the dissociation constants with the time of acid exposure. Whereas the affinity capillary electrophoresis method produces statistically different dissociation constants, no significant difference is detected using classical zeta potential measurements or X-ray photoelectron spectroscopy.

\subsection{MATERIALS AND METHODS}




\subsubsection{Chemicals and Reagents}

Carbon nanotubes from NanoLab Inc (Waltham, MA) included precarboxylated multi-walled carbon nanotubes (PD15L1-5-COOH) with an outer diameter of $15 \pm 5 \mathrm{~nm}$ and a length of $1-5$ $\mu \mathrm{m}$, and multi-walled carbon nanotubes (PD15L5-20) with an outer diameter of $15 \pm 5 \mathrm{~nm}$ and a length of $5-20 \mu \mathrm{m}$. Precarboxylated multi-walled carbon nanotubes (US4358) with an outer diameter of $10-20 \mathrm{~nm}$ and a length $0.5-2 \mu \mathrm{m}$ were from US Research Nanomaterial, Inc (USNano, Houston, TX). Methanol, 3-N-morpholinopropane-1-sulfonic acid (MOPS), sodium hydroxide and mesityl oxide were from Sigma-Aldrich Corp. (St. Louis, MO). MOPS (25 mM) was prepared in deionized water obtained from an Elga Purelab ultra water system (Lowell, $\mathrm{MA}$ ), and the $\mathrm{pH}$ adjusted to 7 using sodium hydroxide. Acid treatment was accomplished with 95\% sulfuric acid purchased from J.T. Baker (Center Valley, PA) and 69\% nitric acid purchased from GFS Chemicals (Columbus, OH). The amidated peptide WRWWWW-NH $\mathrm{N}_{2}$ was purchased from BaChem (Torrance, CA).

\subsubsection{Capillary Electrophoresis}

Analyses were completed using a P/ACE MDQ instrument (SCIEX, Redwood City, CA) with a photodiode array. A $25 \mu \mathrm{m}$ inner diameter and $360 \mu \mathrm{m}$ outer diameter bare fused silica capillary (Polymicro Technologies, Phoenix, AZ) with an effective length of $20.0 \mathrm{~cm}$ and a total length of $30.2 \mathrm{~cm}$ was used for all analyses. Before analysis the capillary was flushed daily with $1 \mathrm{M}$ $\mathrm{NaOH}$ for $30 \mathrm{~min}$ at $138 \mathrm{kPa}(20 \mathrm{psi})$, deionized water for $15 \mathrm{~min}$ at $138 \mathrm{kPa}$ (20 psi), methanol for $15 \mathrm{~min}$ at $138 \mathrm{kPa}(20 \mathrm{psi})$, and deionized water for $15 \mathrm{~min}$ at $138 \mathrm{kPa}$ (20 psi). Prior to each electrophoretic separation, the capillary was flushed with $1 \mathrm{M} \mathrm{NaOH}$ for 2 min at $138 \mathrm{kPa}(20$ psi), deionized water for $1 \mathrm{~min}$ at $138 \mathrm{kPa}$ (20 psi), and background electrolyte for 2 min at 172 $\mathrm{kPa}(25 \mathrm{psi})$, which contained carbon nanotubes at different concentrations ranging from 0 to 50 
$\mathrm{mg} / \mathrm{L}$ diluted in $25 \mathrm{mM}$ MOPS with the $\mathrm{pH}$ to adjusted 7.0. The anodic and cathodic reservoirs contained the same background electrolyte used to fill the capillary. The WRWWWW peptide and mesityl oxide were diluted in 25 mM MOPS buffer to a final concentration of $25 \mu \mathrm{M}$ and 220 $\mu \mathrm{M}$, respectively. The peptide and mesityl oxide sample was injected at $10 \mathrm{kV}$ for 5 seconds. All separations were at an applied voltage of $10 \mathrm{kV}\left(E=333 \mathrm{~V} \mathrm{~cm}^{-1}\right)$ using normal polarity. The 32 Karat Software version 5.0 (Beckman Coulter) was used for data collection and analyses. Binding curves were obtained using Graphpad Prism Version 4.0 (Graphpad Software, San Diego, CA) curve-fitting software for nonlinear regression.

\subsubsection{Sample Preparation}

All carbon nanotube stock suspensions were prepared from dried powder that was weighed and suspended in deionized water to a concentration of either $0.5 \mathrm{~g} / \mathrm{L}$ (acid treated in-house) or 1 $\mathrm{g} / \mathrm{L}$ (acid treated by the manufacturer) and sonicated in an ice bath for $5 \mathrm{~min}$ then stored at $4{ }^{\circ} \mathrm{C}$. As a note, maintaining the sonic bath at $0{ }^{\circ} \mathrm{C}$ with a nominal amount of ice during the sonication will improve the quality of the dispersion and decrease perturbations in the baseline during the separation. The carbon nanotubes were supplied in a range of length; therefore, the concentration of the polydisperse mixture was not converted into molarity. The distribution of carbon nanotube length was circumvented in this paper by using concentration units of mass per volume, which is a convention used in papers reporting the results of exposure experiments $[12,13,34-36]$. For capillary electrophoresis analyses, the carbon nanotubes were diluted daily in $25 \mathrm{mM}$ MOPS to make stocks ranging from 20 to $50 \mathrm{mg} / \mathrm{L}$ and sonicated in an ice bath for 5 min. This stock was then diluted in $25 \mathrm{mM}$ MOPS to the concentrations required for experiments. The total mass of carbon nanotube used for each analysis is less than $0.2 \mathrm{mg}$. Each sample was individually sonicated for $1 \mathrm{~min}$ in an ice bath. Although carboxylation of the carbon nanotubes improved the dispersion in deionized water, poorly dispersed carbon 
nanotubes produced random spikes during separation. Samples that produced these spikes were sonicated an additional minute and the separation was repeated.

\subsubsection{Acid Treatment}

Multi-walled carbon nanotubes from NanoLab Inc (PD15L5-20, research grade) were exposed to a mixture of sulfuric and nitric acid at 3:1 (v/v) ratio. The carbon nanotube powder was combined with the acid mixture to a concentration of $1 \mathrm{mg}$ carbon nanotube powder per $5 \mathrm{~mL}$ acid, and sonicated with a Branson (Danbury, CT), model $2800,40 \mathrm{KHz}$ sonicator for the specified time. Ice was added as needed to maintain the temperature of the water in the sonicator bath to a range of 20 to $25^{\circ} \mathrm{C}$. Following sonication, the mixture of the carbon nanotubes and acid was diluted with water and filtered using a $0.2 \mu \mathrm{m}$ polycarbonate filter (Whatman TrackEtch membrane filter part \# 111106, GE Healthcare Bio-Sciences, Pittsburgh, PA). The carbon nanotubes were rinsed, covered, and allowed to dry on the filter under vacuum. The resulting pellet was rinsed from the filter into a secondary container with methanol in a fume hood. The carbon nanotubes were covered and allowed to dry in a fume hood before being weighed for analysis.

\subsubsection{Dynamic Light Scattering}

Measurements were done with a Zetasizer Nano ZS90 and analyzed using Zetasizer software version 7.11 (Malvern Instrument, Worcesterhire, UK). Dynamic light scattering quantifies the hydrodynamic radius of spherical particles in solution based on Brownian motion of the particles. Cells (part\# 9014, Perfector Scientific, Atacadero, CA) were prepared by rinsing with 3 $\mathrm{mL}$ methanol, $3 \mathrm{~mL}$ water and $3 \mathrm{~mL} 25 \mathrm{mM}$ MOPS buffer. Each measurement generated a single value calculated from 3 replicate measurements, which were in turn repeated 3 times for 
a total of 9 readings on a single sample loaded into the cell. Data are reported as the mean and standard deviation of these 9 readings. The method was applied to control solutions of MOPS buffer as well as a control of peptide in MOPS buffer. Preparations of carbon nanotubes were analyzed both in the absence and presence of peptide to establish the effect of the peptide on size. In both cases the carbon nanotube concentration successively increased by returning the 1.5-mL solution in the cell to a centrifuge tube, spiking the solution with carbon nanotube from a $1 \mathrm{~g} / \mathrm{L}$ master stock, mixing the preparation with a vortex mixer, and sonicating it for 1-min before returning it to the cell and continuing the measurements. Carbon nanotubes were spiked using an appropriate volume (i.e. $2.3,5.3,24.7 \mu \mathrm{L}$ ) from a standard $1 \mathrm{~g} / \mathrm{L}$ solution prepared by dilution of powder carbon nanotubes into water. The final carbon nanotube concentrations were 1.5 , 5.0 and $20 \mathrm{mg} / \mathrm{L}$. In the case of carbon nanotube measurements made in the absence of peptide, the cell was filled with MOPS buffer, measured, spiked with carbon nanotube, mixed, sonicated, and measured. This process was repeated until the highest concentration of carbon nanotube had been achieved. For the experiments monitoring the effect of the peptide on nanotube size, a solution of $25 \mu \mathrm{M}$ peptide in MOPS was monitored and then successively spiked, mixed, sonicated and measured, adding more carbon nanotubes into the cell until the highest carbon nanotube concentration had been achieved.

\subsubsection{Zeta Potential Measurements}

Measurements were done with a Zetasizer Nano ZS90 and analyzed using Zetasizer software version 7.11 (Malvern Instruments, Worcestershire, UK). Determination of zeta potential is based on first principles so the instrument cannot be calibrated; however, correct operation of this instrument is verified using NIST Standard Reference Material 1980 prior to use. The cells (DTS1070, Malvern Instruments) were prepared by rinsing with $1 \mathrm{~mL}$ of methanol, $2 \mathrm{~mL}$ of deionized water and $2 \mathrm{~mL}$ of $25 \mathrm{mM}$ MOPS. The carbon nanotube samples were prepared by 
diluting stocks to a final concentration of $5 \mathrm{mg} / \mathrm{L}$ in $25 \mathrm{mM}$ MOPS and sonicated in an ice bath for $1 \mathrm{~min}$. The cells were filled with carbon nanotube samples. A single value was obtained from 10 replicate measurements, which were in turn repeated 10 times for a total of 100 readings on a single sample loaded into the cell. Repeatability was $2 \%$ RSD both within three aliquots of a single preparation of precarboxylated carbon nanotube and across three independent preparations of pre-carboxylated carbon nanotube. All other samples were measured with a single aliquot for a single analysis.

\subsubsection{X-ray Photoelectron Spectroscopy}

Measurements were completed through Rocky Mountain Laboratories (Golden, CO). Samples were prepared by diluting the carbon nanotube samples in HPLC grade methanol and placing sample onto a piece of Mica used for sample mounting. A full X-ray photoelectron spectroscopy survey spectrum and X-ray photoelectron spectroscopy high resolution spectrum of the carbon 1s region were provided and analyzed for the mica substrate, two pre-carboxylated carbon nanotubes samples (PD15L1-5- $\mathrm{COOH}$ and US4358) and five carbon nanotube samples subject to acid oxidation. Deconvolution of the carbon 1s region was performed by CasaXPS software version 2.3.16 software.

\subsubsection{Safety Considerations}

Due to the potential toxicity of respirable carbon nanotubes safe handling was required when working with dried powder [37]. Appropriate personal protective equipment included gloves, a lab coat, and a respirator mask certified to handle a particulate size of $100 \mathrm{~nm}$ (NIOSH P100). The dry carbon nanotubes were only handled in a fume hood. The weight of an empty sample vial and cap was obtained outside of the hood, transported to the hood, filled with dry carbon 
nanotube, closed, the exterior surfaces cleaned, and weighed outside of the hood. Once a mass of approximately $2 \mathrm{mg}$ was weighed, the sample vial was then placed back in the fume hood, opened, and diluted in water. The fume hood and any items inside of it were wiped with a damp cloth after use. Once the dry powder was suspended in water it could be safely handled outside of the hood. The error for this weighing technique was $\pm 0.2 \mathrm{mg}$ determined by weighing, taring and reweighing a vial three times.

\subsection{RESULTS AND DISCUSSION}

\subsubsection{Interaction of WRWWWW with Multi-walled Carbon Nanotubes}

The peptide interacts with the carboxylated carbon nanotubes based on the affinity of tryptophan for the carbon nanotube through $\pi-\pi$ stacking, as well as the electrostatic interaction between the terminal amine and arginine side chain with the carboxylic acid functional groups. Affinity capillary electrophoresis was easily implemented because the peptide and carbon nanotube form a complex that was detected at 214 or $254 \mathrm{~nm}$ and resulted in a measurable change in the charge-to-size ratio. The peptide-carbon nanotube complex, which appeared when peptide and nanotubes were combined, produced a sharp peak, which allowed for detection of the complex so that the migration time could be measured at various concentrations (Figure 2-1). 
Figure 2-1: Schematic of Affinity Capillary Electrophoresis for Carbon Nanotubes

(A)

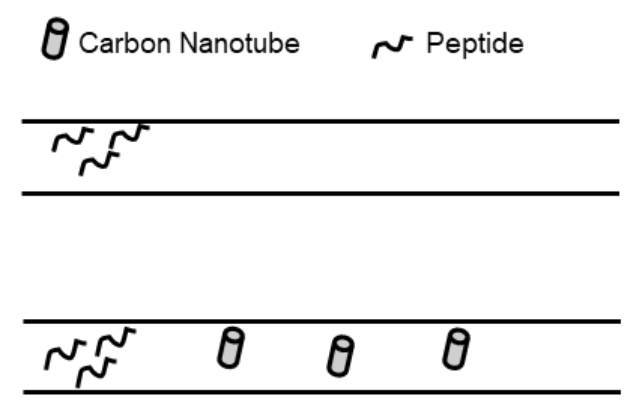

\begin{tabular}{|c|c|}
\hline & $\theta \theta A \cap \theta$ \\
\hline
\end{tabular}

(B)

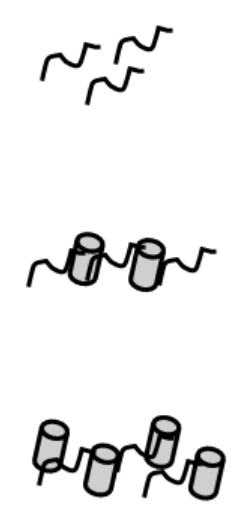

(C)

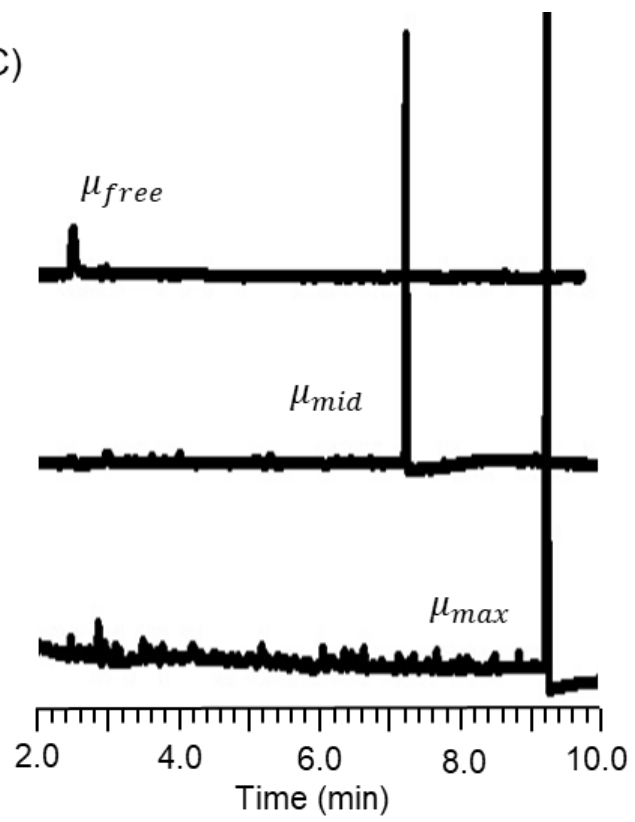

Figure 2-1: Schematic of Affinity Capillary Electrophoresis with carbon nanotubes (A) Migration of WRWWWW model peptide in increasing concentrations of carbon nanotubes in the running buffer. (B) Formation of complex with WRWWWW peptide with multiple multi-walled carbon nanotubes. (C) Detection of WRWWWW peptide and peptide carbon nanotube complex at 0 $\mathrm{mg} / \mathrm{L}\left(\mu_{\mathrm{free}}\right), 5 \mathrm{mg} / \mathrm{L}\left(\mu_{\mathrm{mid}}\right)$ and $20 \mathrm{mg} / \mathrm{L}\left(\mu_{\max }\right)$ carbon nanotubes. Figure reproduced from [1]

Others have observed sharp carbon nanotube peaks in capillary electrophoresis separations and different mechanisms have been postulated including alignment [38] and stacking [39]. A plausible explanation for the sharp peaks obtained by injecting peptide into a background electrolyte composed of multi-walled carbon nanotubes is that the peptide-carbon nanotube complex increases in size, scattering the incident UV light provided by the absorbance detection. Dynamic light scattering was used to evaluate the size of the carbon nanotube preparation in the absence and presence of peptide. Dynamic light scattering measurements of carbon nanotubes are considered qualitative because the aspherical shape of these nanomaterials cannot be modeled using the Stokes-Einstein relationship, and sizes of 
approximately $200 \mathrm{~nm}$ are observed [40-43] in spite of the fact that these nanomaterials generally have an outer diameter of $15 \mathrm{~nm}$ and a length up to $5 \mu \mathrm{m}$.

Dynamic light scattering was used to shed light on how the ratio of peptide and carbon nanotube impacts the complex. Three different ratios of peptide:carbon nanotube (i.e. 28:1.5, $28: 5$, and $28: 20 \mathrm{mg} / \mathrm{L}$ ) were studied to estimate the effects of excess or limiting peptide. The data obtained using NanoLabs precarboxylated multi-walled carbon nanotubes ( $15 \pm 5 \mathrm{~nm}$ o.d., 1-5 $\mu \mathrm{m}$ length), shown in Figure 2-2 and Table 2-1, revealed that the observed size of the multiwalled carbon nanotube increased in the presence of peptide. In the absence of peptide the observed size is $200 \pm 90 \mathrm{~nm}$. When the peptide:carbon nanotube ratio is adjusted to $28: 1.5$ $\mathrm{mg} / \mathrm{L}$, the observed size is $1000 \pm 200 \mathrm{~nm}$, which can be attributed to the formation of a larger agglomerate (see Figure 2-2 A). Upon increasing the peptide:carbon nanotube ratio to $28: 5$ $\mathrm{mg} / \mathrm{L}$, two distinct size populations were observed. The larger size associated with the complex was $800 \pm 300 \mathrm{~nm}$ at time 0 , but increased to $1600 \pm 400 \mathrm{~nm}$ after $30 \mathrm{~min}$ (see Figures 2-2 B and Figure B-1 in Appendix B). A second peak of $190 \pm 40 \mathrm{~nm}$ was simultaneously observed. The smaller peak was attributed to non-complexed carbon nanotube based on measurements in the absence of peptide. This peak is attributed to depletion of the peptide due to sedimentation of complex. This effect is exacerbated at even higher concentrations of carbon nanotubes, and is visually observed over longer periods of time (see Figure B-2 in the Appendix B). The observed size is $200 \pm 100 \mathrm{~nm}$ when the peptide:carbon nanotube ratio is adjusted to $28: 20$ $\mathrm{mg} / \mathrm{L}$ (see Figure 2-2 C). 
Figure 2-2: Dynamic Light Scattering Measurements of the Carbon Nanotube-Peptide Complex

(A)

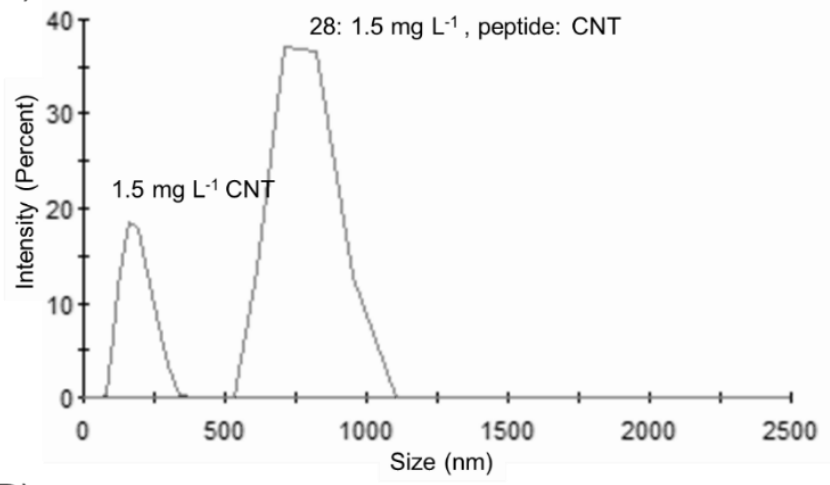

(B)

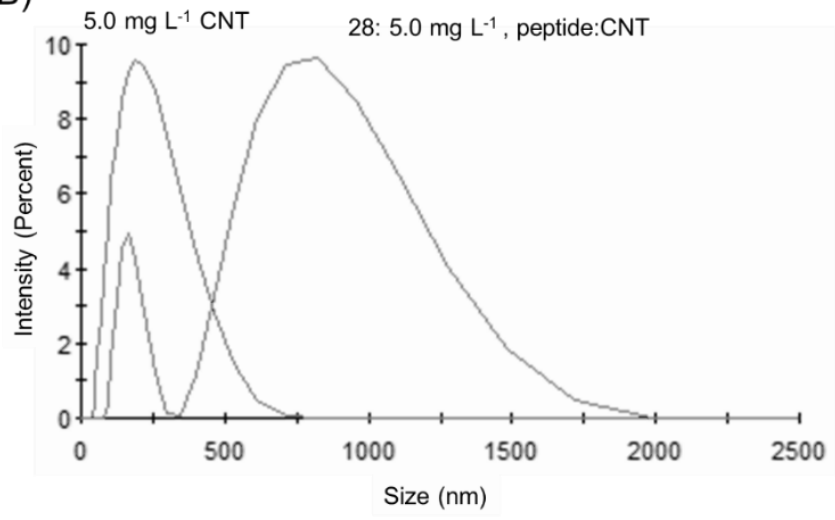

(C)

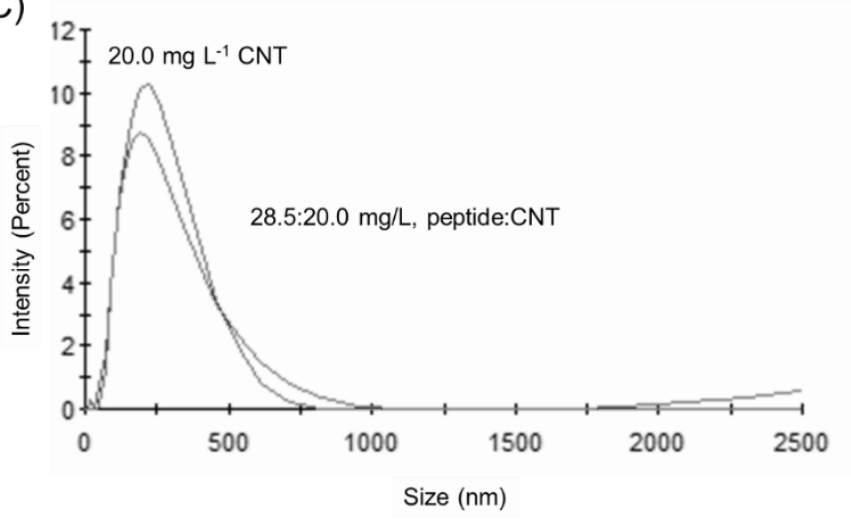

Figure 2-2: Plots of the relative intensity for peptide-carbon nanotubes size measured with dynamic light scattering. Measurements done with NanoLab precarboxylated carbon nanotubes (15 $\pm 5 \mathrm{~nm}$ OD, $1-5 \mu \mathrm{m}$ length) and $25 \mu \mathrm{M}$ WRWWWW peptide at peptide: carbon nanotubes ratios of $(A) 28: 1.5 \mathrm{mg} / \mathrm{L}$, (B) $28: 5 \mathrm{mg} / \mathrm{L}$ and $(\mathrm{C}) 28: 20 \mathrm{mg} / \mathrm{L}$. The other traces are control runs containing carbon nanotube only. Data is plotted from a single DLS measurement. Figure reproduced from [1]. 
Table 2-1: Dynamic Light Scattering Measurements of the Carbon Nanotube-Peptide Complex

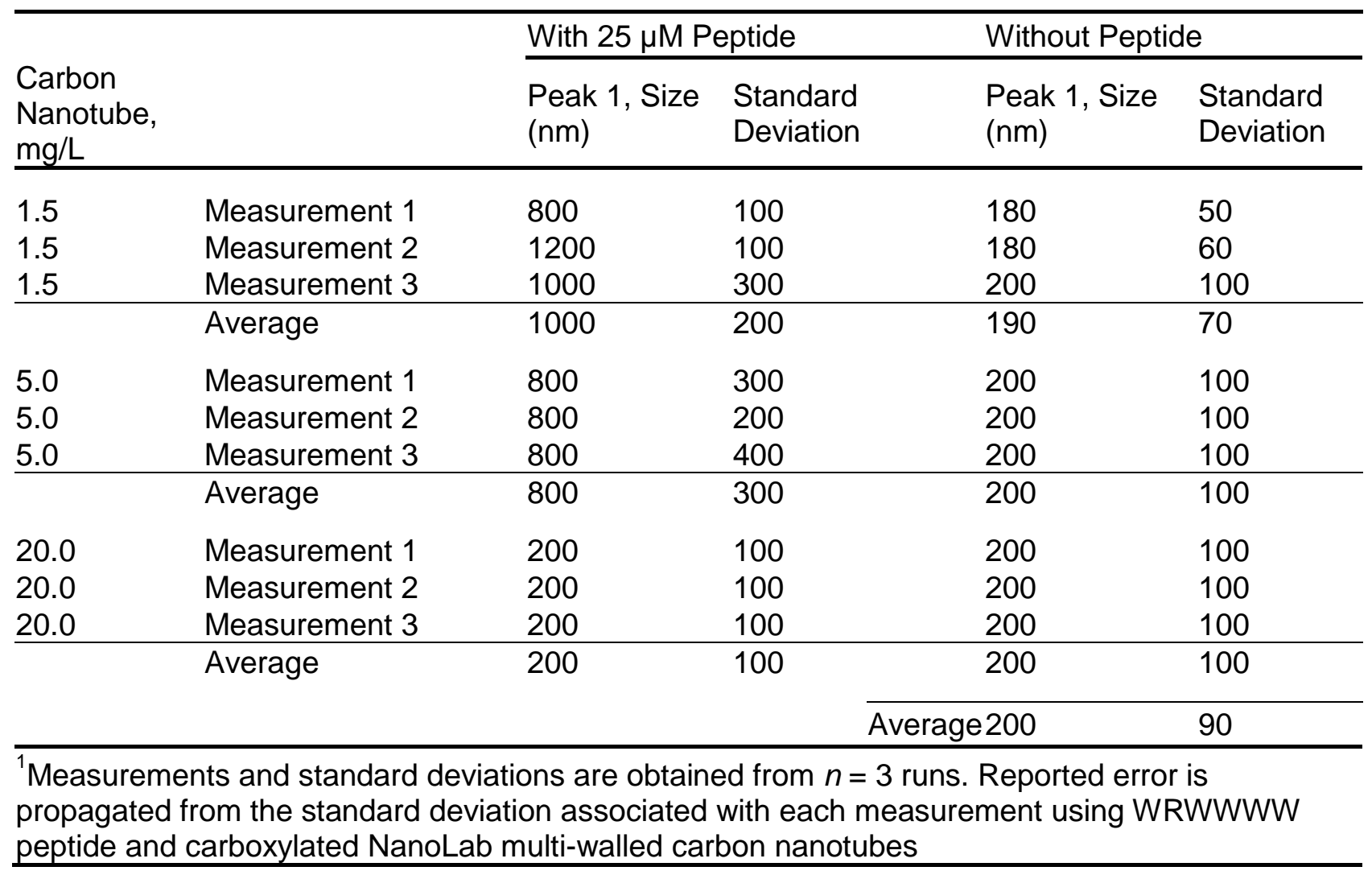

Table reproduced from [1].

\subsubsection{Affinity Capillary Electrophoresis of Multi-walled Carbon Nanotubes}

Classical affinity capillary electrophoresis was used to rapidly quantify the binding of receptor to ligand in-capillary. The peptide receptor was bound to the carbon nanotubes in background electrolyte and the migration of the peptide-carbon nanotube receptor-ligand complex was measured. This method of affinity capillary electrophoresis required accurate measurements of migration time but not peak area. As the concentration of carbon nanotubes was increased, the complex size and migration time increased until migration shift reached the maximum binding because the peptide was saturated with nanotubes. The measurement of migration was repeated using different carbon nanotube concentrations. Changes in the receptor migration 
were directly correlated to the concentration of the ligand dissolved in the capillary electrophoresis background electrolyte. Figure 2-1 depicts a schematic of affinity capillary electrophoresis used to assess peptide-carbon nanotube binding. For analysis, the peptide was injected at a fixed concentration $(25 \mu \mathrm{M})$ and migrated in background electrolyte containing carbon nanotubes (Figure 2-1A). The WRWWWW peptide interacted with the carbon nanotube suspension as it migrated through the capillary (Figure 2-1B).

\subsubsection{Translating Electrophoretic Mobility into Affinity}

The migration shift of the bound peptide reflected the fractional time the peptide was in the free or bound form. The observed mobility of the peptide, $\mu_{\text {mid }}$, which is a function of the dynamic interaction of the peptide with the carbon nanotube in the background electrolyte, was measured with affinity capillary electrophoresis at a particular carbon nanotube concentration as described by equation $1,[19,24,25,44]$

$\mu_{\text {mid }}=f_{1} \cdot \mu_{\text {max }}+f_{2} \cdot \mu_{\text {free }}$

where $f_{1}$ is the fraction of bound peptide and $\mu_{\max }$ is the mobility of the peptide at binding saturation (Figure 2-3, $20 \mathrm{mg} / \mathrm{L}$ trace). The fraction of the peptide that is free or unbound is $\mathrm{f}_{2}$ and $\mu_{\text {free }}$ is the mobility of the peptide in the absence of carbon nanotube (Figure $2-3,0 \mathrm{mg} / \mathrm{L}$ ). The sum of these two fractions equals one $\left(1=f_{1}+f_{2}\right)$, allowing the equation to be rearranged and simplified to:

$f_{1}=\theta=\left(\mu_{\text {mid }}-\mu_{\text {free }}\right) /\left(\mu_{\text {max }}-\mu_{\text {free }}\right)$ 
The fastest migration of the cationic peptide, achieved at a mobility of $\mu_{\text {free, }}$, was obtained in the absence of carbon nanotubes in the background electrolyte (Figure 2-3, $0 \mathrm{mg} / \mathrm{L}$ trace) and the fraction bound was zero. The slowest migration time of the cationic peptide was observed at $\mu_{\max }$, because the injected peptide was fully complexed and the fraction bound was 1 . At all other carbon nanotube concentrations, the fraction of time the peptide existed in the bound state was in between 0 and 1 . For those concentrations, the migration time increased as the carbon nanotube concentration increased in the background electrolyte. A stepwise calculation of fractional binding from migration time and the subsequent error propagation is described and summarized in Table A-1 in the Appendix A. 
Figure 2-3: Electropherograms of Peptide and Precarboxylated Multi-walled Carbon Nanotubes

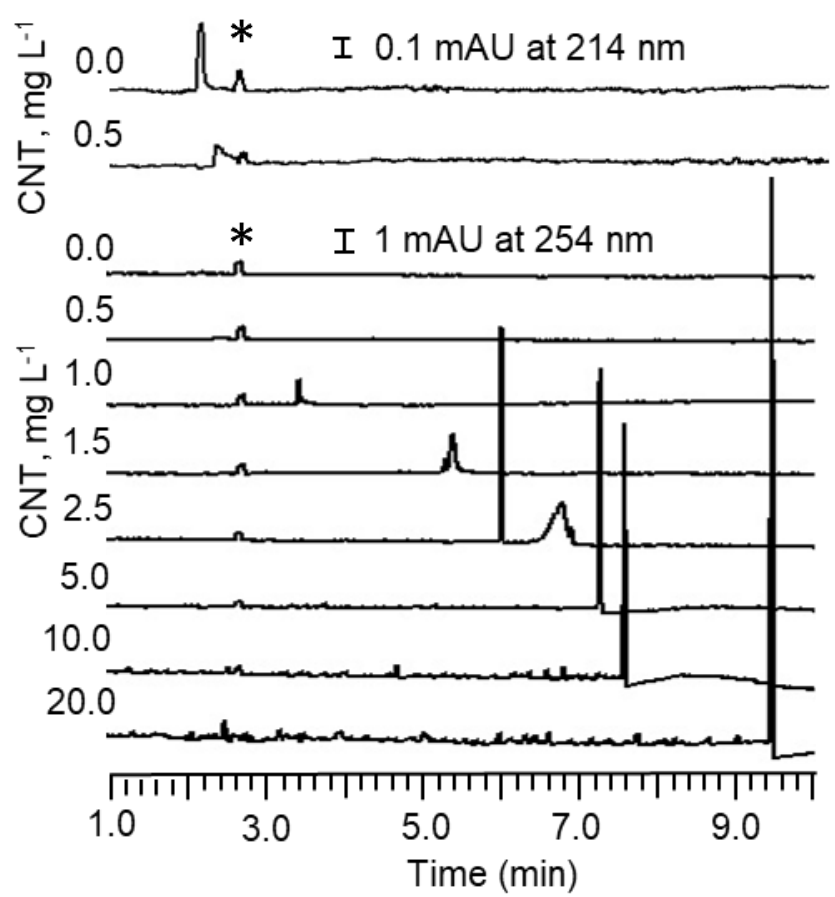

Figure 2-3: Electropherograms of $25 \mu \mathrm{M}$ WRWWWW and NanoLab precarboxylated multiwalled carbon nanotubes used for affinity analyses. Detection of WRWWWW in $0 \mathrm{mg} / \mathrm{L}$ and 0.5 $\mathrm{mg} / \mathrm{L}$ at $214 \mathrm{~nm}$ and detection of $220 \mu \mathrm{M}$ mesityl oxide electroosmotic flow marker and WRWWWW in 0.5, 1.0, 1.5, 2.5, 5.0, 10, $20 \mathrm{mg} / \mathrm{L}$ [CNT] at $254 \mathrm{~nm}$. All runs performed with $\mathrm{E}=$ $333 \mathrm{~V} \mathrm{~cm}^{-1}$ in $25 \mathrm{mM}$ MOPS. Figure reproduced from [1].

\subsubsection{Calculating the $K_{D}$ from Shifts in Electrophoretic Migration Time}

The dissociation constant, $\mathrm{K}_{\mathrm{D}}$, of the peptide-nanotube complex was calculated using the Hill equation, assuming that the binding interaction between ligand and receptor is homogeneous and that complex formation occurs without an intermediate state or with a short-lived intermediate. With the Hill equation, the $\mathrm{K}_{\mathrm{D}}$, as determined by evaluating the fraction, $\theta$, of peptide that is bound to carbon nanotubes, is measured at a specified amount of carbon nanotube, 
$\theta=\frac{[C N T]^{n}}{K_{D}{ }^{n}+[C N T]^{n}}$

where $\mathrm{n}$ is the cooperativity of the binding interaction. In some systems, the value of $\mathrm{n}$ is an indicator of cooperativity where the binding of other ligands is enhanced $(n>1)$, decreased $(n<$ $1)$, or unaffected $(n=1)$ by the presence of other ligands. For the peptide-carbon nanotube studies, the results of nonlinear regression revealed enhanced cooperativity, although conclusions were not made based on these values [45]. The concentration of carbon nanotubes, [CNT], must be defined in units of mass of carbon nanotubes per volume rather than molarity. This is because the density of carboxylic acid functionalization drives the peptidecarbon nanotube interaction. The units used to describe the amount of carbon nanotube effect the units generated for the $K_{D}$ calculation. The value reported for the carbon nanotube analyses is the apparent $K_{D}$ in units of mass of carbon nanotubes per volume $(\mathrm{mg} / \mathrm{L})$. The fractional binding is plotted as shown in Figure 2-4 with the concentration of carbon nanotubes as the $\mathrm{x}$ axis and the fraction bound on the $y$-axis. The data were then evaluated using commercial software to find the best fit to the Hill equation (i.e., equation 3) using nonlinear regression to solve for $K_{D}$ and $n$. 
Figure 2-4: Binding curve for Peptide and Precarboxylated Multi-walled Carbon Nanotubes

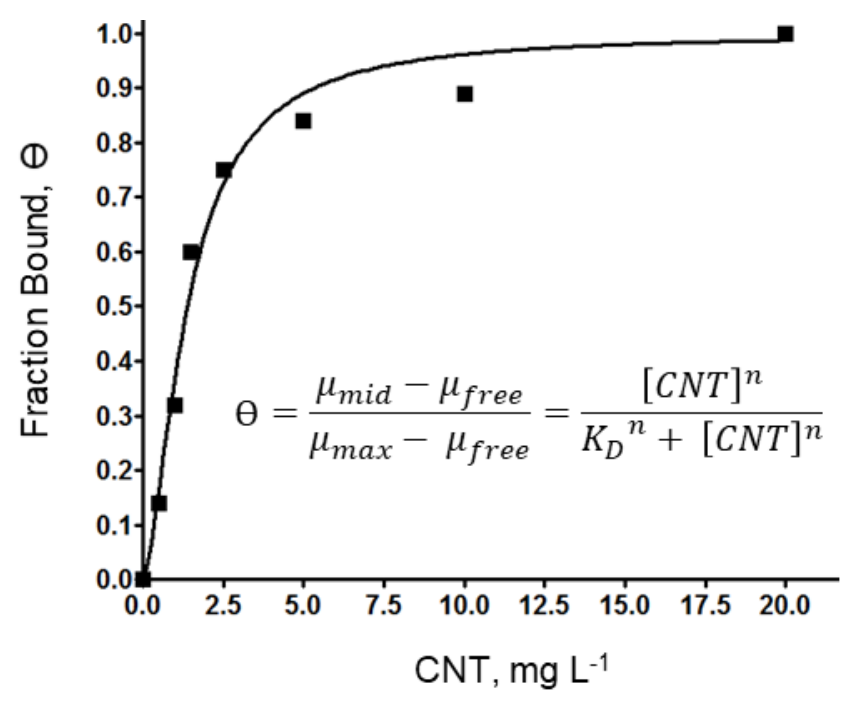

Figure 2-4: Binding curve for WRWWWW and NanoLab precarboxylated multi-walled carbon nanotubes. The dissociation constant is derived from the nonlinear fit of an individual curve using $25 \mu \mathrm{M}$ WRWWWW and increasing concentration of carbon nanotubes. Figure reproduced from [1].

\subsubsection{Criteria for $K_{D}$ Determinations}

The affinity measurements were derived with guidelines regarding ligand depletion and nonlinear curve fitting to ensure that the error in the mobility shift analyses was reasonable and that the nonlinear fit was appropriate. Ligand depletion is an important consideration for $\mathrm{K}_{\mathrm{D}}$ measurements. The assumption that the injected receptor concentration is significantly lower than the ligand concentration in the capillary must be validated otherwise the measured value of $K_{D}$ will be too high as a consequence of ligand depletion [46]. This was verified by measuring $\mathrm{K}_{\mathrm{D}}$ with a wide range of peptide receptor (see Table 2-2). A peptide concentration of $25 \mu \mathrm{M}$ or less was deemed sufficient to avoid depletion of the carbon nanotube concentration used in the 
background electrolyte. Variations in either the composition and purity of different lots of commercially sourced peptide may generate bias in the $K_{D}$ measurements.

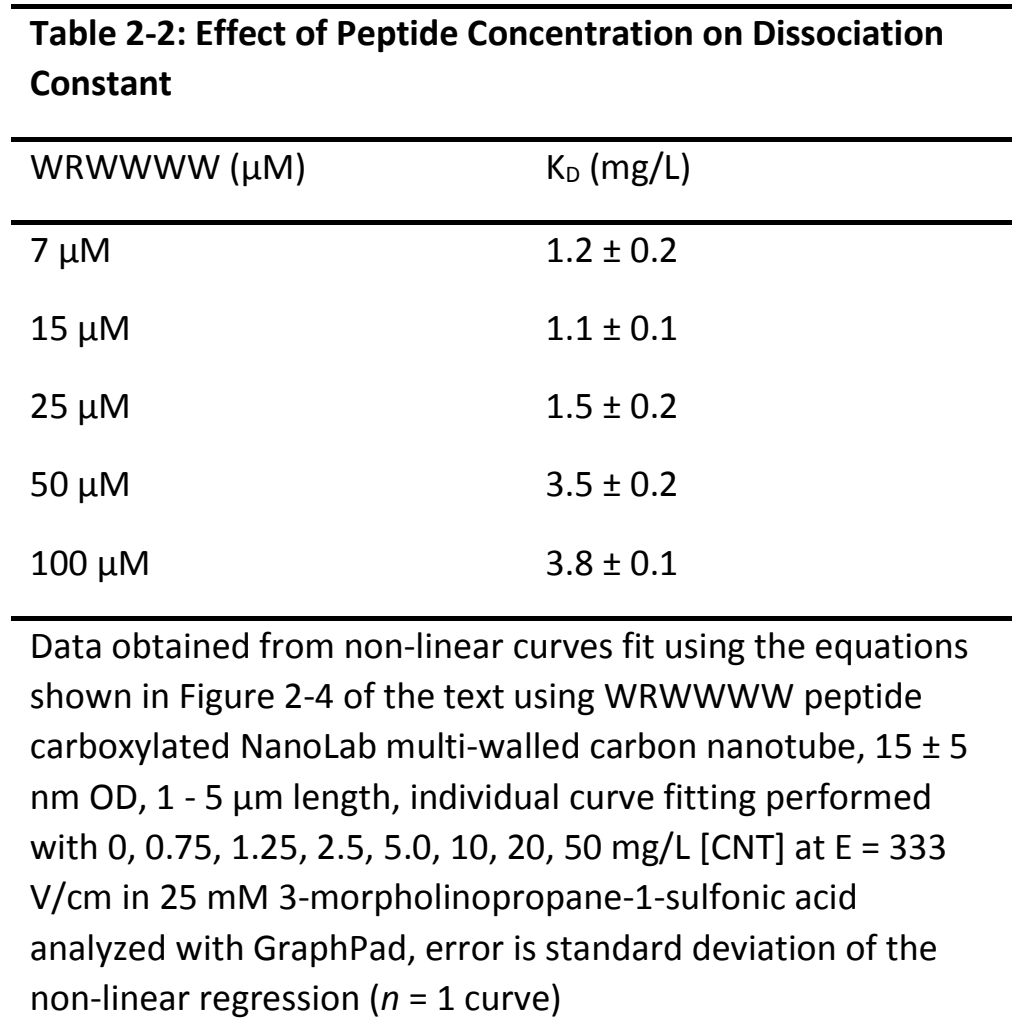

\section{Table reproduced from [1]}

Parameters for curve-fitting centered on the range of measurements, the precision in calculation of fractional binding, and the correlation of the non-linear fit. The distribution of the fractional binding was selected to evenly span the full range of the binding curve. Each curve had a minimum of six carbon nanotube concentrations with two points required to establish binding saturation, a single point before and after the curve inflection, a single point at or around the center of the linear region of the curve, and a single point at the lower end of the curve. The single point at the lower end of the curve was rejected if the relative standard deviation of the fraction bound was greater than $30 \%$, as calculated from the systematic error in the 
measurement. This occurred if the migration shift was too small to maintain 2 significant figures when deriving $\mu_{\text {mid }}-\mu_{\text {free. }}$. An example of an acceptable peak shift is found in Figure $2-3$ in the $0.5 \mathrm{mg} / \mathrm{L}$ carbon nanotube trace obtained at $214 \mathrm{~nm}$. A stepwise calculation for these data can be found in the Appendix A. Fitted curves with a correlation coefficient below 0.96 were also rejected.

\subsubsection{Repeatability of Migration Shift Assays of the Same Carbon Nanotube Suspension}

In order to obtain accurate $K_{D}$ values the migration shift analyses must be reproducible within a sample preparation. To establish reproducibility of the affinity capillary electrophoresis binding method with the curve fitting criteria, replicate measurements of a commercial carbon nanotube sample were performed. Carbon nanotubes had the potential to settle out of solution. If this occurred, then the true concentration of serial dilutions would be unknown. To ensure that this had not occurred, reproducibility was tested using a single set of carbon nanotube concentrations made by dilution from a common $20 \mathrm{mg} / \mathrm{L}$ master stock into $25 \mathrm{mM}$ MOPS buffer. For each $K_{D}$ determination, all dilutions were made from the master stock at the same time and the peptide migration was analyzed sequentially from the lowest to highest carbon nanotube preparations. This analysis of the diluted carbon nanotube samples was repeated twice for a total of 3 analyses to generate three binding curves and three dissociation constants: $\mathrm{K}_{\mathrm{D} 1}=1.4 \pm 0.3 \mathrm{mg} / \mathrm{L}, \mathrm{K}_{\mathrm{D} 2}=1.2 \pm 0.2 \mathrm{mg} / \mathrm{L}$, and $\mathrm{K}_{\mathrm{D} 3}=1.1 \pm 0.2 \mathrm{mg} / \mathrm{L}$ (see Figure 2-5). The average of the three dissociation constants is $1.2 \pm 0.2 \mathrm{mg} / \mathrm{L}(20 \% \mathrm{RSD})$, which was acceptable due to the carbon nanotube heterogeneity, for which a $33 \%$ RSD in outer diameter $(15 \pm 5 \mathrm{~nm})$ is reported by the manufacturer. As stated previously, the apparent $K_{D}$ measurements are reported in units of mass of carbon nanotubes per volume $(\mathrm{mg} / \mathrm{L})$; however, an approximation for concentration $(\mu \mathrm{M})$ of carboxylic acid functional groups can be made using the concentration of functional groups reported by the manufacturer (i.e. 2 to $7 \% \mathrm{w} / \mathrm{w}$ ). Estimating the 
functionalization at $0.05 \mathrm{mg}$ carboxylic acid functionalization per $1 \mathrm{mg}$ of multi-walled carbon nanotube and using a molecular weight of $44 \mathrm{~g}$ per mole carboxylic acid functionalization, the $\mathrm{K}_{\mathrm{D}}$ is approximately $1.4 \pm 0.3 \mu \mathrm{M}$ carboxylic acid functionalization. These results indicated that the single samples were stable for a minimum of three binding curve analyses and the $K_{D}$ values were reproducible within a single set of carbon nanotube concentrations. Affinity capillary electrophoresis is a suitable method to quantify weak affinity interactions (i.e. $\mu \mathrm{M}$ to $\mathrm{mM}$ ) such as that observed for multi-walled carbon nanotubes and peptide. 
Figure 2-5: Electropherograms and Resulting GraphPad Fitted for Within Single Sample Preparation Analysis
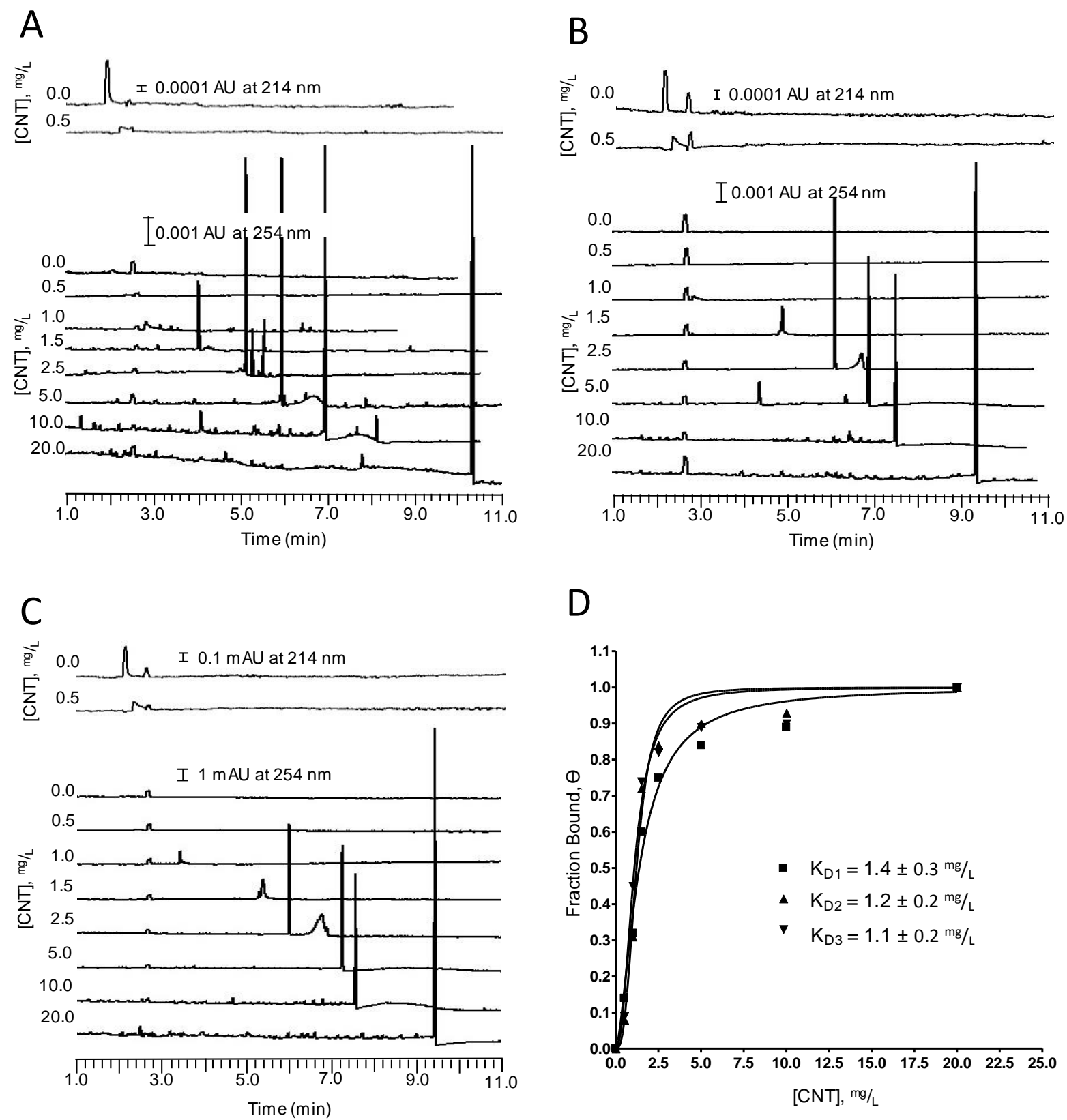

Figure 2-5: Electropherograms (A to $C$ ) and resulting GraphPad fitted curves (D) obtained using 3 replicates of a carbon nanotube preparation made from a single powder stock. Each curve is performed with 7 different concentrations of carbon nanotubes for a total of 8 independent experiments to estimate the solution stability. Figure reproduced from [1]. 


\subsubsection{Effect of Separation Conditions on $K_{D}$}

The separation temperature and buffer composition were additional factors that were considered for the affinity measurements. Temperature, which is dependent upon the thermal regulation of the instrument, can influence $K_{D}$ measurements. While a major portion of the separation capillary is housed in a liquid bath that is thermally regulated, the detection window as well as approximately $4.5 \mathrm{~cm}$ of each end of the capillary are exposed to the ambient temperature and are not thermally controlled. Previous reports have demonstrated that these non-cooled regions can have an actual temperature as much as $15^{\circ} \mathrm{C}$ higher than that of the thermostated region [47]. These differences in temperature were also shown to result in systematic errors in affinity measurements [48]. The separations were performed using an effective capillary length of $20 \mathrm{~cm}$ with the separation capillary thermostated at $25^{\circ} \mathrm{C}$. Affinity

electrophoresis was performed using separations thermostated as $20 \stackrel{\circ}{ } \mathrm{C}, 25 \stackrel{\circ}{\circ}$, and $30 \stackrel{\circ}{ }$ and $K_{D}$ values were determined at each temperature (see Table 2-3). The $K_{D}$ value obtained at each temperature was not significantly different from the average $K_{D}$ value obtained from repeatability studies of the same carbon nanotube suspension (i.e. $1.2 \pm 0.2 \mathrm{mg} / \mathrm{L}$ ) as determined using a one-way ANOVA followed by a Tukey test post analysis with Graphpad software. The thermal regulation provided by the instrument were deemed sufficient for these studies. 
Table 2-3: Effect of Temperature and Buffer Composition on Dissociation Constant

\begin{tabular}{|c|c|c|c|}
\hline \multirow[b]{2}{*}{25 mM Buffer } & \multicolumn{3}{|c|}{ Dissociation Constant (mg/L) } \\
\hline & $20 \stackrel{\circ}{ } \mathrm{C}$ & $25 \stackrel{\circ}{ } \mathrm{C}$ & $30 \stackrel{\circ}{\circ}$ \\
\hline MOPS $^{a}$ & $1.1 \pm 0.2$ & $1.3 \pm 0.2$ & $1.4 \pm 0.2$ \\
\hline sodium phosphate $^{b}$ & - & $1.0 \pm 0.3$ & - \\
\hline
\end{tabular}

${ }^{a}$ Data obtained from non-linear curves fit using the equations shown in Figure 2-4 of the text using $25 \mu \mathrm{M}$ WRWWWW peptide carboxylated NanoLab multi-walled carbon nanotube, $15 \pm 5 \mathrm{~nm}$ OD, $1-5 \mu \mathrm{m}$ length, individual curve fitting performed with $0,1.0,1.5$, $2.5,5.0,10,20,50 \mathrm{mg} / \mathrm{L}$ [CNT] at $\mathrm{E}=333 \mathrm{~V} / \mathrm{cm}$ in $\mathrm{pH} 7$ buffer ${ }^{a}$ Data analyzed with GraphPad, error is propagated from the standard deviation of the non-linear regression ( $n$ $=3$ curves). Data is compared with one-way ANOVA and is not significantly different, $p>$ 0.05. Current in $25 \mathrm{mM}$ MOPS (3-morpholinopropane-1-sulfonic acid) was $0.8 \mu \mathrm{A}$ b Data analyzed with GraphPad, error is the standard deviation of the non-linear regression ( $n=1$ curve). Current in $25 \mathrm{mM}$ sodium phosphate (monobasic) was $4.1 \mu \mathrm{A}$

Table reproduced from [1].

The $\mathrm{K}_{\mathrm{D}}$ measurements were performed using $25 \mathrm{mM}$ MOPS buffered to $\mathrm{pH} 7$ as the background electrolyte because it generated a low separation current (i.e. $0.8 \mu \mathrm{A}$ with an applied voltage of $10 \mathrm{kV}$ ), which in turn minimized the potential for Joule heating. Low ionic strength background electrolytes are also advantageous as carboxylated multi-walled carbon nanotubes aggregate in higher ionic strength solutions [40]. Other background electrolytes may be utilized. For example, a background electrolyte composed of $25 \mathrm{mM}$ sodium phosphate buffered to $\mathrm{pH}$ of 7 generated a higher current (i.e. $4.6 \mu \mathrm{A}$ with an applied voltage of $10 \mathrm{kV}$ ) and a $\mathrm{K}_{\mathrm{D}}$, that was $30 \%$ lower than that obtained with $25 \mathrm{mM}$ MOPS at the same temperature (see Table 2-3). The role of buffer composition may be delineated with extended studies in the future; however, all measurements of KD were conducted using $25 \mu \mathrm{M}$ WRWWWW peptide at $25{ }^{\circ} \mathrm{C}$ in order that relative differences in the $\mathrm{KD}$ values of different multi-walled carbon nanotube preparations could be compared.

\subsubsection{Reproducibility of $K_{D}$ Determination of the Same Carbon Nanotube Powder Stock}


To determine the reproducibility of preparing the carbon nanotubes from dry powder stock, the sample preparations were weighed, suspended, diluted and the peptide migration analyzed sequentially from the lowest to highest carbon nanotube concentration. The analyses of the diluted carbon nanotube samples were repeated twice to generate three binding curves and three dissociation constants for each sample made fresh from dry powder. Determinations were repeated for two additional dry powder stocks. A total of three carbon nanotube powders were analyzed in triplicate for a total of $9 K_{D}$ determinations. For each carbon nanotube stock three dissociation constants were determined from three independent binding curves and averaged into a single dissociation constant. A comparison of these dissociation constants, which was done using a one-way ANOVA followed by a Tukey test post analysis with Graphpad software, showed no significant difference from stock to stock. The $K_{D}$ from each stock was averaged to yield an across sample $K_{D}$ of $1.1 \pm 0.2(20 \%$ RSD). The data were summarized in Table 2-4 and Figure 2-6 in the Supporting Information. The sample preparations of carbon nanotubes were consistent across powder and the affinity capillary electrophoresis method showed a high level of reproducibility for measuring dissociation constants. 
Table 2-4: Dissociation Constant values for Three Powder Stock. Preparations ( $h=3$ powder stocks, $n=9$ curves)

\begin{tabular}{lll}
\hline $\begin{array}{l}\text { Dried Powder } \\
\text { Stock }\end{array}$ & $\begin{array}{l}\mathrm{K}_{\mathrm{D}} \\
(\mathrm{mg} / \mathrm{L})^{2}\end{array}$ & $\begin{array}{l}\text { Zeta Potential } \\
(\mathrm{mV})^{3}\end{array}$ \\
\hline 1 & $1.2 \pm 0.2$ & $-42 \pm 1$ \\
2 & $0.9 \pm 0.2$ & $-43 \pm 1$ \\
3 & $1.1 \pm 0.2$ & $-43 \pm 1$ \\
Average $^{2}$ & $1.1 \pm 0.2(20 \%)$ & $-43 \pm 1$ \\
\hline
\end{tabular}

${ }^{1} n=3$ individual curves, which were fit using the equations shown in Figure 2-4 of the text, performed with 0, 0.5, 1.0, $1.5,2.5,5.0,10,20 \mathrm{mg} / \mathrm{L}$ [CNT] at $\mathrm{E}=333 \mathrm{~V} / \mathrm{cm}$ in $25 \mathrm{mM}$ MOPS with a single preparation

${ }^{2}$ Data are the average and error is propagated from curve fitting of three dried powder stocks ( $n=9$ curve fittings) using $25 \mu \mathrm{M}$ WRWWWW peptide NanoLab carbon nanotubes, $(2-$ 7 wt \% COOH, $15 \pm 5$ nm o.d., $1-5 \mu$ m long).

${ }^{3}$ Data collected from single $5 \mathrm{mg} / \mathrm{L}$ carbon nanotube sample

Table reproduced from [1]. 
Figure 2-6: Dissociation Constant Curves for Three Powder Stock

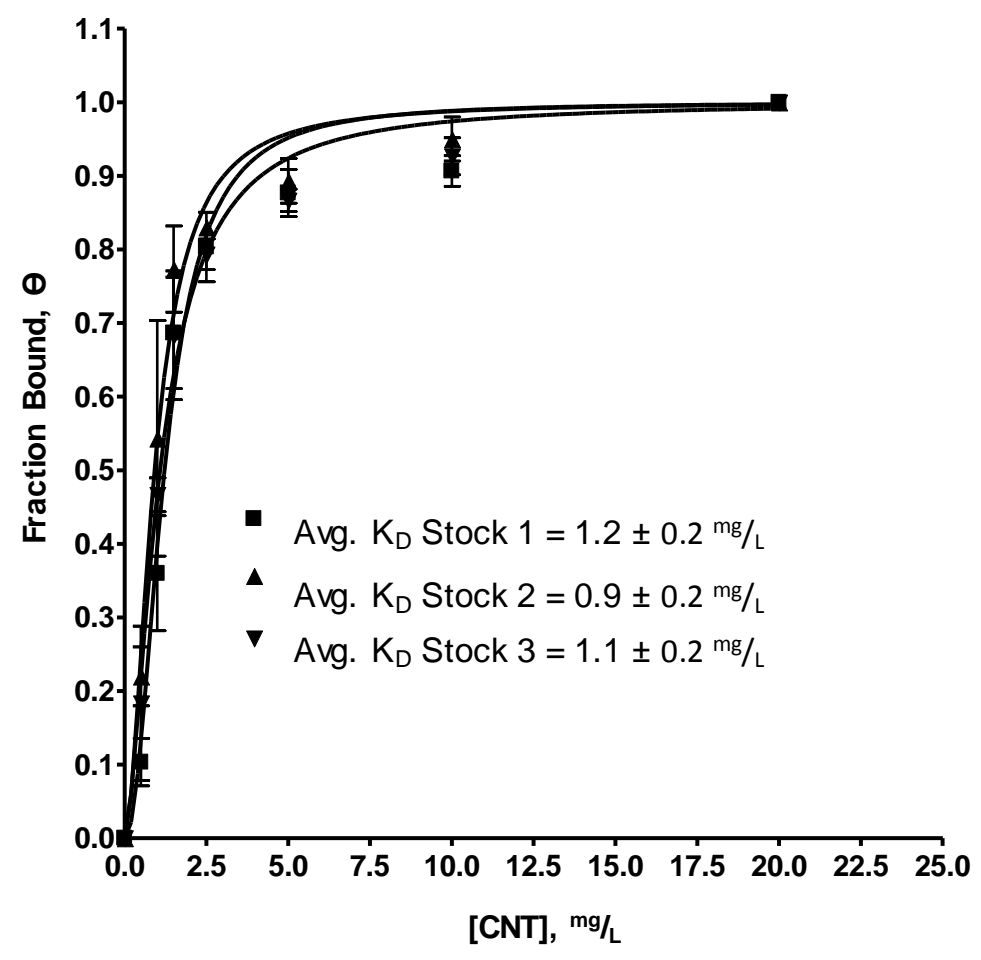

Figure 2-6: Contains binding curves from replicate analysis from three independent dried powder stocks of NanoLab carbon nanotubes, (NanoLab precarboxylated multi-walled carbon nanotubes, $2-7 \mathrm{wt} \% \mathrm{COOH}, 15 \pm 5 \mathrm{~nm}$ o.d., $1-5 \mu \mathrm{m}$ long). All data points are an average of triplicate analyses of the diluted stocks with error bars representing the standard deviation of the average. Figure reproduced from [1].

\subsubsection{Application of Affinity Capillary Electrophoresis to Carbon Nanotubes from Different}

\section{Sources}

The affinity capillary electrophoresis method was applied to compare carboxylated carbon nanotube preparations across manufacturers. Information about manufactured carboxylated carbon nanotubes was limited to the average length and diameter of the carbon nanotubes and either a value for the percent carboxylation or a range of percent carboxylation. Affinity capillary electrophoresis was used to evaluate the amount of carboxylation of carbon nanotubes of similar length and diameter from two different manufacturers (see Table 2-5). The affinity capillary 
electrophoresis measurements were compared to standard zeta potential and X-ray photoelectron spectroscopy analyses. The X-ray photoelectron spectroscopy results obtained by deconvolution (see Figures 2-7 and 2-8 in the Supporting Information) were in agreement with the specifications reported by the vendor. Like the X-ray photoelectron spectroscopy data, the $\mathrm{K}_{\mathrm{D}}$ values obtained using affinity capillary electrophoresis for the NanoLab $\left(\mathrm{K}_{\mathrm{D}}=1.2 \pm 0.2 \mathrm{mg} / \mathrm{L}\right)$ and US-Nano $\left(\mathrm{K}_{\mathrm{D}}=3.9 \pm 0.9 \mathrm{mg} / \mathrm{L}\right)$ multi-walled carbon nanotubes revealed that the degree of functionalization of these two materials was not the same. Zeta potential measurements showed no significant difference as a function of surface charge. These results demonstrated that the affinity capillary electrophoresis method provided more conclusive results compared to X-ray photoelectron spectroscopy, but with simpler equipment and at a lower cost. The benefits of using affinity capillary electrophoresis were investigated further with a wider range of carboxylated carbon nanotube materials.

Table 2-5: Characterization of Precarboxylated Carbon Nanotubes

\begin{tabular}{|c|c|c|c|c|}
\hline MWCNT & $\mathrm{K}_{\mathrm{D}}{ }^{\mathrm{a}}$ & $\mathrm{XPS}^{\mathrm{b}}$ & $X S^{c}$ & Zeta Potential $^{d}$ \\
\hline Manufacturer & $(\mathrm{mg} / \mathrm{L})$ & (\% Oxygen) & $(\% \mathrm{COOH})$ & $(\mathrm{mV})$ \\
\hline NanoLab ${ }^{e}$ & $1.2 \pm 0.2$ & $12 \pm 2$ & 4.8 & $-39 \pm 2$ \\
\hline US-Nano ${ }^{f}$ & $3.9 \pm 0.9$ & $7 \pm 1$ & 1.5 & $-38 \pm 1$ \\
\hline
\end{tabular}

dissociation constant $\left(K_{D}\right)$ error based on propagation from three curve fittings using $25 \mu \mathrm{M}$ WRWWWW peptide

${ }^{b} \mathrm{X}$-ray photoelectron spectroscopy (XPS) error estimated as $15 \%$ from manufactures specification 'error from deconvolution cannot be estimated

d error based on propagation from 10 measurements with a single $5 \mathrm{mg} / \mathrm{L}$ carbon nanotube sample e precarboxylated carbon nanotubes from NanoLab, $15 \pm 5 \mathrm{~nm}$ OD, $1-5 \mu \mathrm{m}$ length precarboxylated carbon nanotubes from US Research Nanomaterial carbon nanotube $10-20 \mathrm{~nm}$ OD, 0.5 - $2 \mu \mathrm{m}$ length

Table reproduced from [1]. 
Figure 2-7: Deconvoluted Peak Fitting for Carbon Region for NanoLab Precarboxylated Carbon Nanotubes in X-ray Photoelectron Spectroscopy

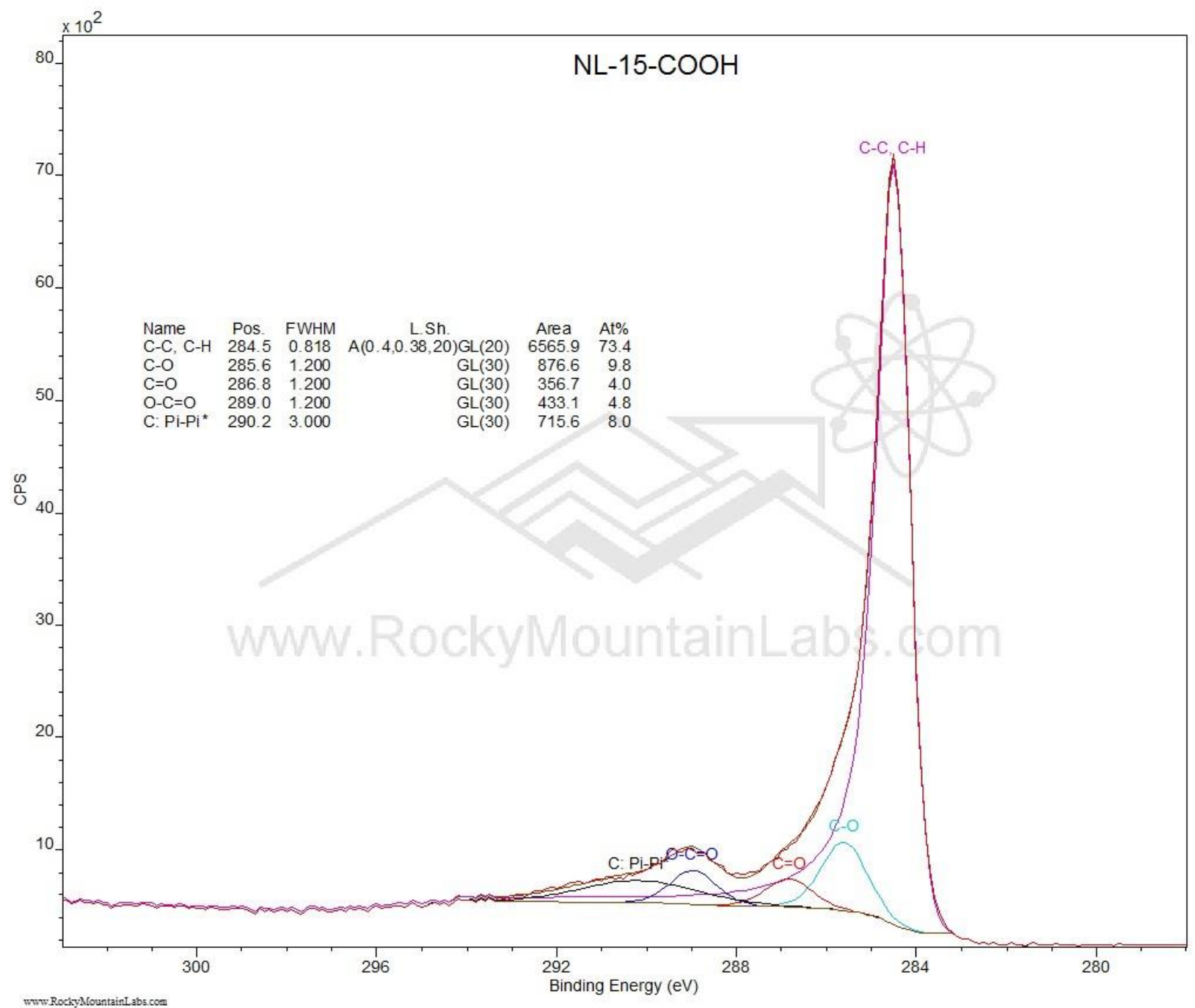

Figure 2-7: Deconvolution and peak fitting of the carbon 1s region for NanoLab precarboxylated multi-walled carbon nanotubes in X-ray photoelectron spectroscopy. Figure reproduced from [1]. 
Figure 2-8: Deconvoluted Peak Fitting for Carbon Region for US-Nano Precarboxylated Carbon Nanotubes in X-ray Photoelectron Spectroscopy

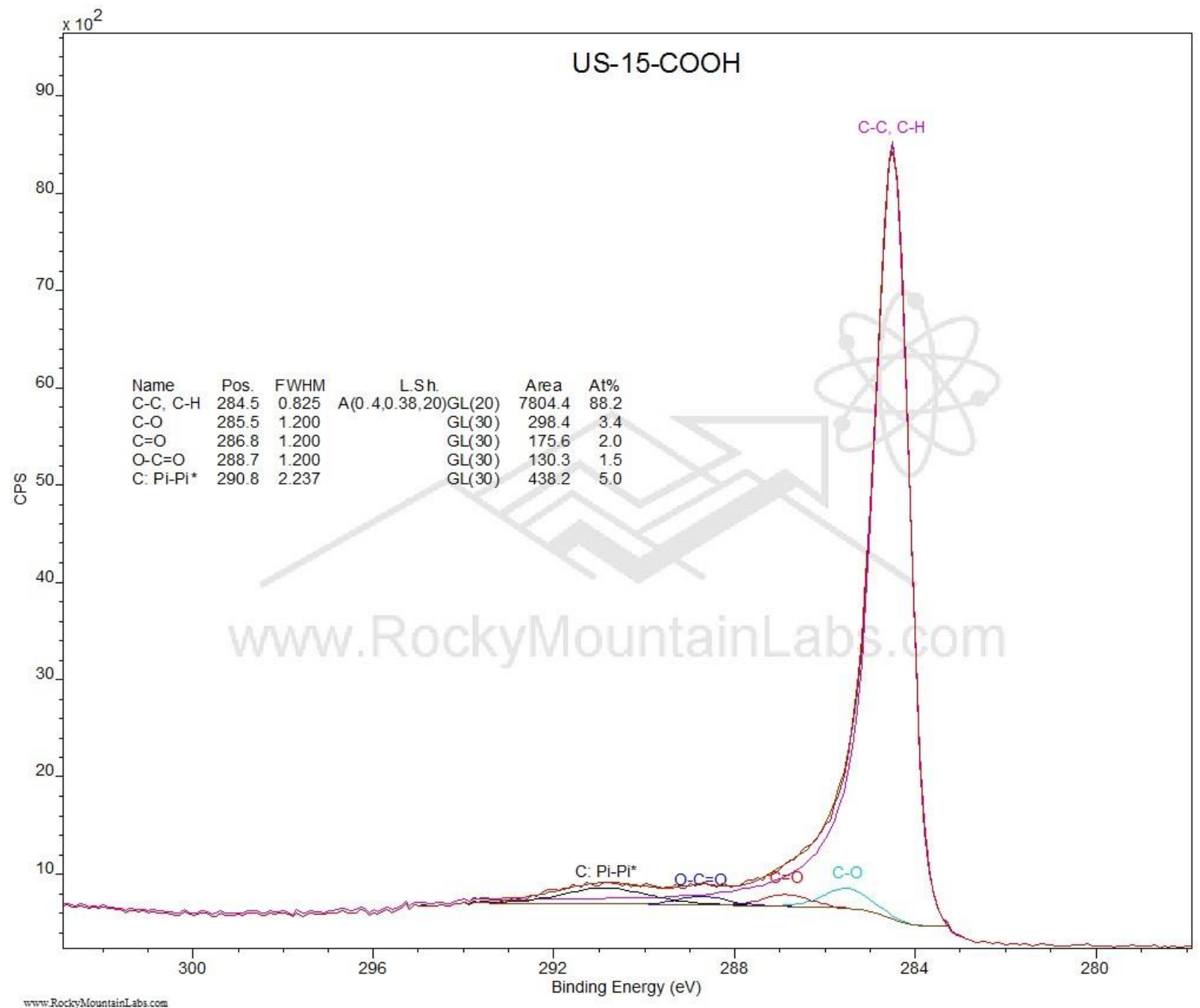

Figure 2-8: Deconvolution and peak fitting for the carbon 1s region of US-Nano precarboxylated multi-walled carbon nanotubes in X-ray photoelectron spectroscopy. Figure reproduced from [1]. 


\subsubsection{Application of Affinity Binding to a Set of Functionalized Carbon Nanotubes}

A library of oxidized carbon nanotubes was created using acid treatment to carboxylate surface defects and end caps on the carbon nanotubes. A standard protocol for oxidation was developed (see section 2.1.4) considering different protocols reported in the literature [36, 4952] with varying acid treatments, oxidation duration, sonication, and temperature. The library was based on the time of acid exposure under constant sonication for specified times. Temperature was established as an important factor to the rate of oxidation (see Table A-2 in the Appendix A) and was maintained between 20 and $25^{\circ} \mathrm{C}$. The reproducibility of the oxidation treatment was demonstrated with replicate measurements of three independent acid treatments of carbon nanotubes at 2 hours, generating an RSD in $K_{D}$ of less than $13 \%$.

The carbon nanotubes were evaluated using zeta potential, X-ray photoelectron spectroscopy and affinity capillary electrophoresis. The zeta potential measurements for all acid-treated samples, which ranged from -35 to $-39 \mathrm{mV}$ were not significantly different. The X-ray photoelectron spectroscopy data obtained by deconvolution for the acid washed samples were also inconclusive (see Figures A-4: A-F in the Appendix A). No predictable trend in the percent carboxylation or total oxygen composition was detected by this method. It is noted that the elemental analyses indicated that the carbon nanotube sample subject to acidification for 45 minutes $(\mathrm{NL}-15-0.75 \mathrm{H})$ had trace levels of elemental nitrogen and sulfur, which may be attributed to residual sulfuric and nitric acid from the acid treatment. Additionally, the carbon nanotube sample subject to acidification for 60 minutes $(\mathrm{NL}-15-1 \mathrm{H})$ had elemental sulfur, but not nitrogen, which may also be attributed to residual sulfuric acid from the acid treatment. These inconsistencies in the results may reflect limitations of X-ray photoelectron spectroscopy for materials with a degree of heterogeneity or may indicate that X-ray photoelectron spectroscopy is better suited for samples that are subject to more rigorous cleaning. 
As an alternative approach, affinity capillary electrophoresis was used to quantify the effects of acid treatment on pristine carbon nanotubes. Verification of carboxylated carbon nanotube product was an important aspect to evaluate the quality of the starting material. Dissociation constant data, summarized in Table 2-6, were collected for acid treated carbon nanotubes at various time points. As the acid treatment time increased the dissociation constant decreased, indicating higher binding affinity with the WRWWWW model peptide. Previous studies revealed that longer acid treatment times led to a higher weight percent of carboxylation on the carbon nanotube surface $[36,53,54]$. Therefore, the increase in binding of the WRWWWW model peptide was attributed to the increase in the carboxylic acids on the carbon nanotube. The zeta potential measurements for all acid-treated samples were not significantly different and ranged from -35 to $-39 \mathrm{mV}$. Both capillary electrophoresis separations and zeta potential were a measure of the migration of analytes in an electric field as a function of the analyte charge and size. However, with affinity capillary electrophoresis the measurement was enhanced through the additional aromatic and electrostatic binding of the peptide to differentiate the degree of carboxylation of treated carbon nanotubes. Small changes in the surface composition were exploited by the binding of the peptide. This provided a new and simple method to compare materials. 


\begin{tabular}{lllll}
\hline \multicolumn{5}{l}{ Table 2-6: } \\
\hline $\begin{array}{l}\text { Acid Treatment } \\
\text { (hours) }\end{array}$ & $\begin{array}{l}\mathrm{K}_{\mathrm{D}}{ }^{\mathrm{a}} \\
(\mathrm{mg} / \mathrm{L})\end{array}$ & $\begin{array}{l}\mathrm{XPS}^{\mathrm{b}} \\
(\% \text { Oxygen })\end{array}$ & $\begin{array}{l}\mathrm{XPS}^{\mathrm{c}} \\
(\% \mathrm{COOH})\end{array}$ & $\begin{array}{l}\text { Zeta Potential }^{\mathrm{d}} \\
(\mathrm{mV})\end{array}$ \\
\hline 3 & $1.3 \pm 0.1$ & $4.9 \pm 0.7$ & 2.3 & $-42 \pm 2$ \\
2 & $2.6 \pm 0.3$ & $3.8 \pm 0.6$ & 2.1 & $-45 \pm 1$ \\
1 & $3.8 \pm 0.1$ & $8.0 \pm 1.0^{\mathrm{e}}$ & 1.0 & $-44 \pm 1$ \\
0.75 & $4.7 \pm 0.8$ & $5.3 \pm 0.8^{\mathrm{e}}$ & 1.4 & $-42 \pm 2$ \\
0.5 & $8.3 \pm 0.5$ & $3.6 \pm 0.5$ & 1.6 & $-43 \pm 1$ \\
\hline
\end{tabular}

\footnotetext{
${ }^{a}$ dissociation constant $\left(K_{D}\right)$ error based on propagation from three curve fittings using $25 \mu \mathrm{M}$ WRWWWW peptide

${ }^{\mathrm{b}} \mathrm{X}$-ray photoelectron spectroscopy (XPS) error estimated as 15\% from manufacture specification cerror from deconvolution cannot estimated

d error based on propagation from 10 measurements with a single $5 \mathrm{mg} / \mathrm{L}$ carbon nanotube sample

${ }^{e}$ increased $\%$ relative oxygen from potential sulfuric and nitric acid contamination
}

Table reproduced from [1].

\subsection{CONCLUSIONS AND FUTURE DIRECTIONS.}

Capillary electrophoresis was adapted to rapidly characterize the degree of carboxylation of multi-walled carbon nanotubes. A polytryptophan peptide that contained a single arginine residue bound to carbon nanotubes through aromatic as well as electrostatic interactions. The dissociation constant was derived from the shift in electrophoretic mobility. The migration shift increased as the concentration of carbon nanotube in the background electrolyte increased until a maximum shift was observed. Six concentrations of carbon nanotubes were used to span the full range of fractional binding. The method was reproducible when applied to stable dispersions made from dry powders and was capable of distinguishing preparations of functionalized carbon nanotubes that were subject to different acid treatment times. As implemented in this application, capillary electrophoresis can differentiate carboxylation substantially better than zeta potential or X-ray photoelectron spectroscopy. 
For routine characterization of nanomaterials, an automated capillary electrophoresis instrument is easy to operate and can be considered a more accessible instrument than electron microscopy methods that provide elemental information. While this report focusses on multiwalled carbon nanotubes, future efforts will expand the application of the method to single walled carbon nanotubes, screening of other peptide sequences through competitive binding experiments, and evaluation of other functional groups. 


\subsection{BIBLIOGRAPHY}

[1] T.A. Davis, S. Patberg, A. Stefaniak, L. Sargent, L.A. Holland, Capillary Electrophoresis Analysis of Affinity to Assess Carboxylation of Multi-Walled, Anal. Chim. Acta (2018) accepted

[2] M.F.L. De Volder, S.H. Tawfick, R.H. Baughman, A.J. Hart, Carbon nanotubes: Present and future commercial applications, Science, 339 (2013) 535-539.

[3] C.B. Jacobs, M.J. Peairs, B.J. Venton, Review: Carbon nanotube based electrochemical sensors for biomolecules, Anal. Chim. Acta, 662 (2010) 105-127.

[4] Z. Liu, S. Tabakman, K. Welsher, H. Dai, Carbon nanotubes in biology and medicine: In vitro and in vivo detection, imaging and drug delivery, Nano Research, 2 (2009) 85-120.

[5] Q. Zhang, J.-Q. Huang, W.-Z. Qian, Y.-Y. Zhang, F. Wei, The road for nanomaterials industry: A review of carbon nanotube production, post-treatment, and bulk applications for composites and energy storage, Small, 9 (2013) 1237-1265.

[6] Z. Chen, X.J. Dai, K. Magniez, P.R. Lamb, D. Rubin de Celis Leal, B.L. Fox, X. Wang, Improving the mechanical properties of epoxy using multiwalled carbon nanotubes functionalized by a novel plasma treatment, Composites, Part A, 45 (2013) 145-152.

[7] Q. Cheng, B. Wang, C. Zhang, Z. Liang, Functionalized carbon-nanotube sheet/bismaleimide nanocomposites: Mechanical and electrical performance beyond carbon-fiber composites, Small, 6 (2010) 763-767.

[8] C.B. Jacobs, T.L. Vickrey, B.J. Venton, Functional groups modulate the sensitivity and electron transfer kinetics of neurochemicals at carbon nanotube modified microelectrodes, Analyst, 136 (2011) 3557-3565.

[9] E. Katz, I. Willner, Biomolecule-functionalized carbon nanotubes: Applications in nanobioelectronics, ChemPhysChem, 5 (2004) 1084-1104.

[10] W. Feng, P. Ji, Enzymes immobilized on carbon nanotubes, Biotechnol. Adv., 29 (2011) 889-895.

[11] L. Zhou, H.J. Forman, Y. Ge, J. Lunec, Multi-walled carbon nanotubes: A cytotoxicity study in relation to functionalization, dose and dispersion, Toxicol. in Vitro, 42 (2017) 292-298.

[12] R. Li, X. Wang, Z. Ji, B. Sun, H. Zhang, C.H. Chang, S. Lin, H. Meng, Y.-P. Liao, M. Wang, Z. Li, A.A. Hwang, T.-B. Song, R. Xu, Y. Yang, J.I. Zink, A.E. Nel, T. Xia, The surface charge and cellular processing of covalently functionalized multiwall carbon nanotubes determine pulmonary toxicity, ACS Nano, 7 (2013) 2352-2368.

[13] G. Visalli, M.P. Bertuccio, D. lannazzo, A. Piperno, A. Pistone, A. Di Pietro, Toxicological assessment of multi-walled carbon nanotubes on a549 human lung epithelial cells, Toxicol. in Vitro, 29 (2015) 352-362. 
[14] R. Malik, C. McConnell, N.T. Alvarez, M. Haase, S. Gbordzoe, V. Shanov, Rapid, in situ plasma functionalization of carbon nanotubes for improved cnt/epoxy composites, RSC Adv., 6 (2016) 108840-108850.

[15] K.A. Wepasnick, B.A. Smith, J.L. Bitter, D. Howard Fairbrother, Chemical and structural characterization of carbon nanotube surfaces, Anal. Bioanal. Chem., 396 (2010) 10031014.

[16] B. Scheibe, E. Borowiak-Palen, R.J. Kalenczuk, Oxidation and reduction of multiwalled carbon nanotubes - preparation and characterization, Mater. Charact., 61 (2010) 185191

[17] A.M. Oickle, S.L. Goertzen, K.R. Hopper, Y.O. Abdalla, H.A. Andreas, Standardization of the boehm titration: Part ii. Method of agitation, effect of filtering and dilute titrant, Carbon, 48 (2010) 3313-3322.

[18] V.H. Grassian, A.J. Haes, I.A. Mudunkotuwa, P. Demokritou, A.B. Kane, C.J. Murphy, J.E. Hutchison, J.A. Isaacs, Y.-S. Jun, B. Karn, S.I. Khondaker, S.C. Larsen, B.L.T. Lau, J.M. Pettibone, O.A. Sadik, N.B. Saleh, C. Teague, Nanoehs - defining fundamental science needs: No easy feat when the simple itself is complex, Environ. Sci.: Nano, 3 (2016) 15-27.

[19] K. Shimura, K.-i. Kasai, Affinity capillary electrophoresis: A sensitive tool for the study of molecular interactions and its use in microscale analyses, Anal. Biochem., 251 (1997) 116.

[20] I.J. Colton, J.D. Carbeck, J. Rao, G.M. Whitesides, Affinity capillary electrophoresis: A physical-organic tool for studying interactions in biomolecular recognition, Electrophoresis, 19 (1998) 367-382.

[21] N.H.H. Heegaard, R.T. Kennedy, Identification, quantitation, and characterization of biomolecules by capillary electrophoretic analysis of binding interactions, Electrophoresis, 20 (1999) 3122-3133.

[22] Y. Tanaka, S. Terabe, Estimation of binding constants by capillary electrophoresis, J. Chromatogr. B, 768 (2002) 81-92.

[23] M. Gayton-Ely, T.J. Pappas, L.A. Holland, Probing affinity via capillary electrophoresis: Advances in 2003-2004, Anal. Bioanal. Chem., 382 (2005) 570-580.

[24] N. Li, S. Zeng, L. He, W. Zhong, Probing nanoparticle-protein interaction by capillary electrophoresis, Anal. Chem., 82 (2010) 7460-7466.

[25] S. Boulos, T.A. Davis, J.A. Yang, S. Lohse, A. Alkilany, L.A. Holland, C.J. Murphy, Nanoparticle-protein interaction: Thermodynamic and kinetic study of adsorption of bovine serum albumin to gold nanoparticle surface, Langmuir, 29 (2013) 14984-14996.

[26] F. Albertorio, M.E. Hughes, J.A. Golovchenko, D. Branton, Base dependent DNAcarbon nanotube interactions: Activation enthalpies and assembly-disassembly control, Nanotechnology, 20 (2009) 395101. 
[27] H. Oh, J. Sim, S.Y. Ju, Binding affinities and thermodynamics of noncovalent functionalization of carbon nanotubes with surfactants, Langmuir, 29 (2013) 1115411162.

[28] X. Chen, J. Fang, Y. Cheng, J. Zheng, J. Zhang, T. Chen, B.H. Ruan, Biomolecular interaction analysis for carbon nanotubes and for biocompatibility prediction, Anal. Biochem., 505 (2016) 1-7.

[29] S. Wang, E.S. Humphreys, S.-Y. Chung, D.F. Delduco, S.R. Lustig, H. Wang, K.N. Parker, N.W. Rizzo, S. Subramoney, Y.-M. Chiang, A. Jagota, Peptides with selective affinity for carbon nanotubes, Nat. Mater., 2 (2003) 196-200.

[30] S.M. Tomásio, T.R. Walsh, Modeling the binding affinity of peptides for graphitic surfaces. Influences of aromatic content and interfacial shape, J. Phys. Chem. C, 113 (2009) 8778-8785.

[31] A.T.E. Vilian, S.-M. Chen, Direct electrochemistry and electrocatalysis of glucose oxidase based poly(I-arginine)-multi-walled carbon nanotubes, RSC Adv., 4 (2014) 50771-50781.

[32] http://www.nano-lab.com/cooh-functionalized-nanotubes. html, Nanolab incorporated. Product pd15l1-5-cooh website updated may 17, 2017, accessed october 22, 2017.

[33] http://shop.bachem.com/h-7596.html, Wrw4 trifluoroacetate salt product number h7596.0001, accessed october 22, 2017.

[34] K. Aschberger, H.J. Johnston, V. Stone, R.J. Aitken, S.M. Hankin, S.A. Peters, C.L. Tran, F.M. Christensen, Review of carbon nanotubes toxicity and exposure--appraisal of human health risk assessment based on open literature, Crit Rev Toxicol, 40 (2010) 759-790.

[35] A. Magrez, S. Kasas, V. Salicio, N. Pasquier, J.W. Seo, M. Celio, S. Catsicas, B. Schwaller, L. Forró, Cellular toxicity of carbon-based nanomaterials, Nano Lett., 6 (2006) 1121-1125.

[36] S. Jain, V.S. Thakare, M. Das, C. Godugu, A.K. Jain, R. Mathur, K. Chuttani, A.K. Mishra, Toxicity of multiwalled carbon nanotubes with end defects critically depends on their functionalization density, Chem. Res. Toxicol., 24 (2011) 2028-2039.

[37] NIOSH, General safe practices for working with engineered nanomaterials in research laboratories, dhhs (niosh) publication no. 2012-147, Department of Health and Human Services, Centers for Disease Control and Prevention, National Institute for Occupational Safety and Health, Cincinnati, OH: U.S., 2012.

[38] S.K. Doorn, R.E. Fields, H. Hu, M.A. Hamon, R.C. Haddon, J.P. Selegue, V. Majidi, High resolution capillary electrophoresis of carbon nanotubes, J. Am. Chem. Soc., 124 (2002) 3169-3174.

[39] C.Y. Khripin, S. Manohar, M. Zheng, A. Jagota, Measurement of electrostatic properties of DNA-carbon nanotube hybrids by capillary electrophoresis, J. Phys. Chem. C, 113 (2009) 13616-13621. 
[40] B. Smith, K. Wepasnick, K.E. Schrote, A.R. Bertele, W.P. Ball, C. O’Melia, D.H. Fairbrother, Colloidal properties of aqueous suspensions of acid-treated, multi-walled carbon nanotubes, Environ. Sci. Technol., 43 (2009) 819-825.

[41] B. Smith, K. Wepasnick, K.E. Schrote, H.-H. Cho, W.P. Ball, D.H. Fairbrother, Influence of surface oxides on the colloidal stability of multi-walled carbon nanotubes: A structure-property relationship, Langmuir, 25 (2009) 9767-9776.

[42] Y.S. Hwang, X. Qu, Q. Li, The role of photochemical transformations in the aggregation and deposition of carboxylated multiwall carbon nanotubes suspended in water, Carbon, 55 (2013) 81-89.

[43] N.B. Saleh, L.D. Pfefferle, M. Elimelech, Aggregation kinetics of multiwalled carbon nanotubes in aquatic systems: Measurements and environmental implications, Environ. Sci. Technol., 42 (2008) 7963-7969.

[44] L.Z. Avila, Y.H. Chu, E.C. Blossey, G.M. Whitesides, Use of affinity capillary electrophoresis to determine kinetic and equilibrium constants for binding of arylsulfonamides to bovine carbonic anhydrase, J. Med. Chem., 36 (1993) 126-133.

[45] J.N. Weiss, The hill equation revisited: Uses and misuses, FASEB J., 11 (1997) 835841.

[46] V. Hořejší, Some theoretical aspects of affinity electrophoresis, J. Chromatogr. A, 178 (1979) 1-13.

[47] M.U. Musheev, Y. Filiptsev, S.N. Krylov, Temperature difference between the cooled and the noncooled parts of an electrolyte in capillary electrophoresis, Anal. Chem., 82 (2010) 8692-8695.

[48] M.U. Musheev, Y. Filiptsev, S.N. Krylov, Noncooled capillary inlet: A source of systematic errors in capillary-electrophoresis-based affinity analyses, Anal. Chem., 82 (2010) 8637-8641.

[49] S. Gómez, N.M. Rendtorff, E.F. Aglietti, Y. Sakka, G. Suárez, Surface modification of multiwall carbon nanotubes by sulfonitric treatment, Appl. Surf. Sci., 379 (2016) 264-269.

[50] Z. Wu, S. Mitra, Length reduction of multi-walled carbon nanotubes via high energy ultrasonication and its effect on their dispersibility, J. Nanopart. Res., 16 (2014) 2563.

[51] V. Datsyuk, M. Kalyva, K. Papagelis, J. Parthenios, D. Tasis, A. Siokou, I. Kallitsis, C. Galiotis, Chemical oxidation of multiwalled carbon nanotubes, Carbon, 46 (2008) 833840.

[52] K.J. Siegrist, S.H. Reynolds, M.L. Kashon, D.T. Lowry, C. Dong, A.F. Hubbs, S.H. Young, J.L. Salisbury, D.W. Porter, S.A. Benkovic, M. McCawley, M.J. Keane, J.T. Mastovich, K.L. Bunker, L.G. Cena, M.C. Sparrow, J.L. Sturgeon, C.Z. Dinu, L.M. Sargent, Genotoxicity of multi-walled carbon nanotubes at occupationally relevant doses, Part. Fibre Toxicol., 11 (2014) 6. 
[53] A.K. Jain, V. Dubey, N.K. Mehra, N. Lodhi, M. Nahar, D.K. Mishra, N.K. Jain, Carbohydrate-conjugated multiwalled carbon nanotubes: Development and characterization, Nanomedicine, 5 (2009) 432-442.

[54] W. Zhou, S. Sasaki, A. Kawasaki, Effective control of nanodefects in multiwalled carbon nanotubes by acid treatment, Carbon, 78 (2014) 121-129. 


\section{Chapter 3:}

Peptide Probe for Multi-walled Carbon Nanotubes: Electrophoretic Assessment of the Binding Interface and Evaluation of Surface Functionalization

\section{Reproduced from [1]}

T.A. Davis, L.A. Holland, Peptide probe for multiwalled carbon nanotubes: electrophoretic assessment of the binding interface and evaluation of surface functionalization., ACS Appl Mater Interfaces. 10 (2018) 11311-11318. 


\subsection{INTRODUCTION}

Biosensors are valued in the billions of USD [2] and are dependent upon biomolecular recognition facilitated with protein receptors or enzymes [3-7]. Carbon nanomaterials serve as substrates for enzyme-based biosensors because the carbon functions as an electroactive surface for detection [8]. In order to realize the promise of carbon nanomaterial sensing on a routine basis, the protein-nanotube interface must be appropriate and universally applied to a wide range of proteins in a cost-effective manner which maintains protein functionality. Functionalization improves the dispersion of carbon nanotubes in aqueous solutions and provides a chemical moiety to attach proteins that are harnessed for molecular recognition. Proteins are typically covalently immobilized to carbon nanotubes with the goal of maintaining protein functionality $[9,10]$. While sophisticated chemistries have been demonstrated with different functional groups, carboxylation is the most prevalent form of carbon nanotube functionalization because it is easily achieved with mineral acid treatment [11-14].

Physical adsorption to pristine or oxidized carbon nanotubes is an appealing alternative to entrapment or covalent immobilization because it is simpler to implement and lower in cost. Unfortunately, many proteins change conformation when adsorbed onto the nanotube surface [15]. A decrease in activity of enzymes that were non-covalently adsorbed to single walled carbon nanotubes was attributed to changes to the protein structure [16]. It has been demonstrated that enzyme activity can be retained upon immobilization under certain conditions. For example, weak $\pi-\pi$ interactions supported the physical adsorption of laccase to multi-walled carboxylated carbon nanotubes [17]. Immobilized enzyme preparations were stable for 34 days, retaining $60 \%$ activity [17]. The activity was also maintained for noncovalently immobilized $\alpha$-chymotrypsin when an appropriate degree of carboxylation was used 
to facilitate protein-carbon nanotube interaction [18]. To facilitate noncovalent immobilization the chemistry, charge, and even curvature must be matched [19].

In order to realize the benefits of physical adsorption for biosensing, a more universal approach must be developed such that unique binding interactions for a protein can be quickly elucidated and the carbon nanotube surface tailored to support physical adsorption, but not loss of structure and subsequently function. The forces necessary to drive protein capture at the surface but not denaturation must be well characterized. Peptides with affinity for carbon nanotubes, which were discovered through phage display [20], mass spectrometry [21], or predicted based on adhesion [22], contain amino acids with hydrophobic side chains as well as positively charged side chains. Both electrostatic and hydrophobic forces contribute to the interaction between carboxylated carbon nanotubes and peptides.

Fundamental studies have focused on aromatic interactions and to a lesser extent electrostatic interactions of protein-carbon nanotube surface interactions. Among several candidate residues, tryptophan and arginine residues were identified as amino acids capable of participating in adsorption on the surface of carbon nanotubes [20, 22-27]. Computational modeling used to evaluate interactions indicated that arginine $[23,27]$ and tryptophan [28] gave rise to the strongest binding, with energies of -45 and $-49.6 \mathrm{~kJ} / \mathrm{mol}$, respectively [25]. Experimental characterization of arginine and tryptophan also demonstrated a strong binding affinity for carbon nanotubes [22,29,30]. Aromatic amino acids [24], especially tryptophan [20], were strongly bound to carbon nanotubes as a result of $\pi-\pi$ interaction. The indole ring of the tryptophan interacted with the carbon nanotube surface [28], as depicted in Figure 3-1A. Arginine also contributed significantly to peptide carbon nanotube binding [23], forming a hybrid hydrogen bond between the conjugated guanidinium system and the m-system on the carbon nanotube [25]. Carboxylation on the carbon nanotube surface changed the binding interface 
and increased the electrostatic interactions between arginine and functionalized nanotubes

(Figure 3-1B). This was significant because the degree of carbon nanotube carboxylation, which is a prevalent method of surface modification [14, 31-33], determined the number of binding sites for arginine and influenced the peptide-carbon nanotube binding affinity.

Figure 3-1: Conceptual Diagram of Tryptophan and Arginine Interaction with Carboxylated Carbon Nanotubes

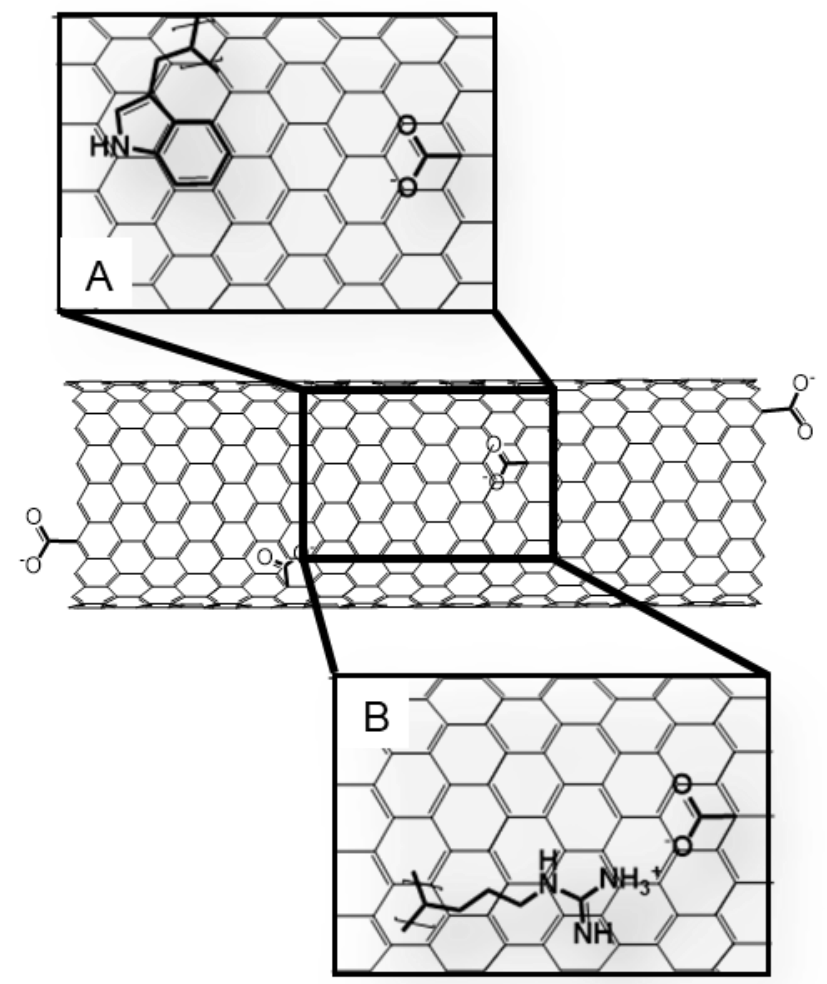

Figure 3-1: Conceptual diagrams of the binding interaction between the carboxylic acid functionalized carbon nanotube and (A) tryptophan and (B) arginine. Figure reproduced from [1]

It is reasonable to expect that a combination of electrostatic and hydrophobic interactions is needed to satisfy the physical adsorption of a wide range of proteins. The combination of 
electrostatic and hydrophobic interactions should be tailored to the protein target. Furthermore, the composition, sequence, and connectivity of amino acids must be evaluated using peptides that model protein-nanotube interactions. Surface curvature $[26,34,35]$ and the distribution of functional groups such as carboxylic acids that contribute to electrostatic interactions $[36,37]$ intrinsically contribute to protein nanotube system. Given these factors, a guided approach must be used to systematically evaluate peptide-carbon nanotube interactions in order to generate binding that is strong enough to immobilize the protein, but weak enough to avoid perturbing the 3-dimensional protein structure that supports protein function.

Analytical techniques used to shed light on the interactions that drive peptide-carbon nanotube adsorption include atomic force microscopy [18,22] and optical spectroscopy [21]. These methods are qualitative or low throughput. Recently, a capillary electrophoresis method was developed to quantify the degree of carboxylation of different multi-walled carbon nanotubes with a model amidated peptide [38]. The significance of the prior report [38] was that the method was a rapid and simple analytical strategy was developed to translate carboxylation of carbon nanotubes into dissociation based mobility shifts. The method utilized an amidated hexapeptide composed of a single arginine residue and 5 tryptophan residues [38]. This newly validated method was straightforward to implement and offers advantages over traditional affinity measurement techniques. The advantage of the capillary electrophoresis method is that it can be applied to a library of model peptides to tease out information about how the amino composition, proximity, and polymer length contributes to surface interactions. Information from a linear peptide sequence can provide insight into how short runs in the primary protein sequence may support surface interactions that sustain protein functionality. Such studies provide insight into specific orientations of amino acids in the 3-dimensional space of a folded protein that sustain favorable interactions with the carbon nanotube surface. Ultimately, the 
rapid screening technology achievable with capillary electrophoresis may be tailored to particular proteins as well as specific batches of carbon nanotube preparations.

The affinity capillary electrophoresis method adapted to carbon nanotubes does not require preequilibration of the receptor and ligand in order to obtain a complex unlike traditional affinity methods. Therefore, separation of the free receptor and complex states is not necessary for quantification of affinity, instead equilibrium is accomplished in capillary. Figure 3-2 shows a schematic of affinity capillary electrophoresis. Initially, the mobility of the free receptor $\left(\mu_{\mathrm{R}}\right)$ is determined by injecting and monitoring the receptor migration through the capillary. The ligand is then dispersed in the background electrolyte of the capillary and the mobility of the receptor is determined. As the receptor migrates through the capillary it interacts with ligand to form a complex that shifts the receptor mobility ( $\left.\mu_{\mathrm{R} L m i d}\right)$. Additional runs are performed at different ligand concentration. The mobility of the receptor changes with ligand concentration and is a function of the percentage of receptor that is in the bound versus free state. For the peptidecarbon nanotube complex a maximum shift is obtained at the lowest mobility $\left(\mu_{\mathrm{RL}}\right)$, which is achieved when all of the receptor is in the bound form. Each shift in mobility is used to quantify the dissociation constant with the Hill equation:

$\theta=\frac{\mu_{R L m i d}-\mu_{R}}{\mu_{\mathrm{R}}-\mu_{R L}}=\frac{[L]^{n}}{[L]^{n}+K_{D}{ }^{n}}$

Where $\Theta$ is the fraction of receptor bound at each concentration of ligand, L, in the capillary. The fraction bound is quantified with the mobilities of the receptor in the unbound, $\mu_{\mathrm{R}}$, bound, $\mu_{\mathrm{RL}}$, and at intermediate, $\mu_{\mathrm{RLmid}}$, states. The $\mathrm{n}$, cooperativity value, indicates whether binding of a ligand is influenced by the binding of other ligands; however, because several issues have been raised about the relevance of this value [39], in the current investigation, no conclusions are made based on these values of cooperativity. 
Figure 3-2: Schematic of Affinity Capillary Electrophoresis

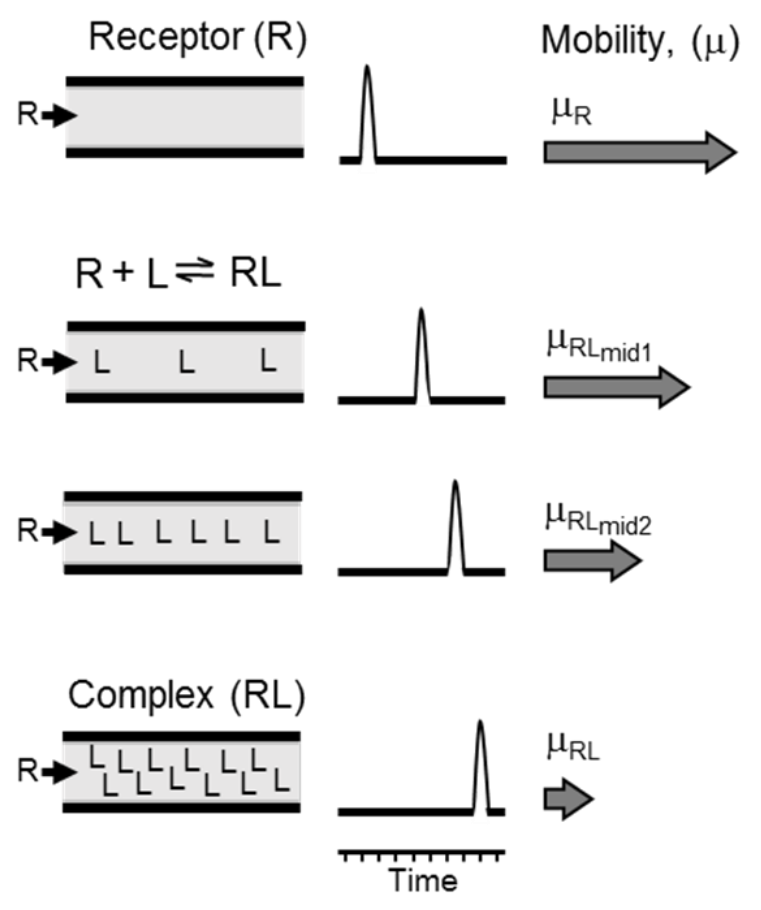

Figure 3-2: The injection and migration of receptor is depicted in increasing concentrations of ligand. The free and bound receptor have different mobility. The apparent mobility shifts when the receptor interacts with ligand to form a complex. Figure reproduced from [1]

Affinity capillary electrophoresis is employed to analyze the binding interface of peptides with functionalized multiwalled carbon nanotubes. The approach uses model peptides to evaluate how changes in amino acid composition and peptide length drive peptide-carbon nanotube interactions. The significance of arginine and tryptophan residues to binding is evaluated with different peptide sequences. Capillary electrophoresis is used to assess a peptide library of WR, WRW, WRWW, WRWWW, WWWWW, WWWW, WWW, WW, WRWWWW, WKWWWW, WRWWRW, and YRYYYY in order to delineate the contributions of electrostatic and hydrophobic interactions to the formation of the peptide-carbon nanotube complex. As expected the combination of both electrostatic and hydrophobic interactions are important; however, only a single cationic residue was necessary to drive the surface interaction. In order 
to demonstrate that the method can be used to screen peptide relevant peptide sequences in specific proteins short regions in the primary sequence of lysozyme that contained a single cationic amino acid and at least two aromatic residues were identified with Uniprot. A candidate peptide (WMCLAKW) was selected from this sequence search and used to demonstrate the potential of capillary electrophoresis and the potential to use it to rapidly screen peptide-carbon nanotube interactions so that the properties of the nanotube, including functionalization, can be tailored to support non-covalent protein adsorption.

\subsection{MATERIAL AND METHODS}

\subsubsection{Chemicals and Reagents.}

Precarboxylated carbon nanotubes (PD15L1-5-COOH) with outer diameter $15 \pm 5 \mathrm{~nm}$ and length 1- $5 \mu \mathrm{m}$ are from NanoLab Inc (Waltham, MA). The dipeptide WW and WR are from Anaspec (Fredmont, CA). All other peptides are synthesized by GenScript (Piscataway, NJ). Methanol, 3-N-morpholinopropane-1-sulfonic acid (MOPS), sodium hydroxide and mesityl oxide are from Sigma-Aldrich Corp. (St. Louis, MO). MOPS (25 mM) is prepared in deionized water obtained from an Elga Purelab ultra water system (Lowell, MA) and the $\mathrm{pH}$ is adjusted to 7 using sodium hydroxide.

\subsubsection{Capillary Electrophoresis}

Analyses are performed using a P/ACE MDQ (Sciex, Redwood City, CA) with a photodiode array as previously reported. ${ }^{37}$ Briefly, a bare fused silica capillary (Polymicro Technologies, Phoenix, AZ) with $25 \mu \mathrm{m}$ inner diameter and $360 \mu \mathrm{m}$ outer, with an effective length of $20.0 \mathrm{~cm}$ and a total length of $30.2 \mathrm{~cm}$ is used. The capillary is flushed daily with $1 \mathrm{M} \mathrm{NaOH}$ for 30 min at $138 \mathrm{kPa}(20 \mathrm{psi})$, deionized water for $15 \mathrm{~min}$ at $138 \mathrm{kPa}(20 \mathrm{psi})$, methanol for $15 \mathrm{~min}$ at 138 
$\mathrm{kPa}(20 \mathrm{psi})$, and deionized water for $15 \mathrm{~min}$ at $138 \mathrm{kPa}$ (20 psi) before analysis. Before each electrophoretic analysis the capillary is flushed with $1 \mathrm{M} \mathrm{NaOH}$ for 2 min at $138 \mathrm{kPa}(20 \mathrm{psi})$, and deionized water for $1 \mathrm{~min}$ at $138 \mathrm{kPa}(20 \mathrm{psi})$ to clean and prepare the capillary. The capillary is then filled with background electrolyte ( $25 \mathrm{mM}$ MOPS buffered to $\mathrm{pH}$ of 7 ) that also contained carbon nanotubes diluted in at different concentrations ranging from 0 to $50 \mathrm{mg} / \mathrm{L}$. During separation, the anodic and cathodic reservoirs contain the same background electrolyte that is loaded in the capillary. Serial injections of a $25 \mu \mathrm{M}$ peptide sample diluted in $25 \mathrm{mM}$ MOPS and $220 \mu \mathrm{M}$ of mesityl oxide diluted in $25 \mathrm{mM}$ MOPS are performed at $10 \mathrm{kV}$ for $5 \mathrm{sec}$ and $5 \mathrm{kV}$ for $5 \mathrm{sec}$, respectively. For the analysis of capacity factor the peptides and mesityl oxide are diluted in $25 \mathrm{mM}$ MOPS buffer to a final concentration of $25 \mu \mathrm{M}$ and $220 \mu \mathrm{M}$, respectively. The peptides and mesityl oxide sample is injected at $10 \mathrm{kV}$ for $5 \mathrm{sec}$. An applied voltage of $10 \mathrm{kV}(\mathrm{E}=333 \mathrm{~V} / \mathrm{cm}$ at normal polarity) was used for all separations. Data collection and analyses are performed on 32 Karat Software version 5.0 (Beckman Coulter). Nonlinear regression of the binding curves is obtained with Graphpad Prism Version 4.0 (Graphpad Software, San Diego, CA) curve-fitting software.

\subsection{RESULTS AND DISCUSSION}

\subsubsection{Role of Amino Acid Composition in Physical Adsorption to Carboxylated Carbon Nanotubes}

Insight into the binding interaction between peptides and carbon nanotubes can be garnered by evaluating the contributions of amino acid composition and sequence to binding affinity. In this report, affinity capillary electrophoresis method is adapted to the WRWWWW peptide composed

of a terminal carboxylic acid rather than one that is amidated as was reported previously [38]. With the application to standard peptide termini, the capillary electrophoresis method is used to 
elucidate the intermolecular forces governing the interactions of polytryptophan peptides with carboxylated carbon nanotubes. Figure 3-3 shows an affinity analysis of WRWWWW peptide receptor with increasing concentrations of carbon nanotube ligand. As the concentration of the carbon nanotube increases the peptide-carbon nanotube complex is formed and the peptide mobility shifts. This shift in mobility at each concentration is converted to the fraction of peptide bound to carbon nanotubes using the following equation.

$\theta=\frac{\text { Bound Peptide }}{\text { Total Peptide }}=\frac{[C N T]^{n}}{[C N T]^{n}+K_{D}{ }^{n}}$

A nonlinear binding curve (Figure 3-3) is formed by plotting the fraction of receptor that is bound versus the concentration of carbon nanotubes. The concentration $(\mathrm{mg} / \mathrm{L})$ of carbon nanotube at the point of half-saturation of this binding curve (i.e. $50 \%$ fractional binding) is defined as the dissociation constant. Strongly interacting peptide-carbon nanotube complexes have lower dissociation constants. As reported previously, ${ }^{37}$ the dissociation constant is quantified using the mass of the carbon nanotube ligand rather than molarity so that it is not necessary to determine the average molecular weight of the carbon nanotube sample. The dissociation constant of WRWWWW is $1.3 \pm 0.2 \mathrm{mg} / \mathrm{L}$ ( $n=3 \mathrm{~K}_{\mathrm{D}}$ ' experiments). Measuring the dissociation constant of other peptides and carboxylated carbon nanotubes serves as a means to quantitatively compare binding interactions. The WRWWWW peptide is the model peptide that is modified in order to determine how amino acid residues affect the interaction with carboxylated carbon nanotubes. 
Figure 3-3: Electropherograms and Resulting GraphPad Fitted for WRWWWW peptide and NanoLab Precarboxylated Carbon Nanotubes
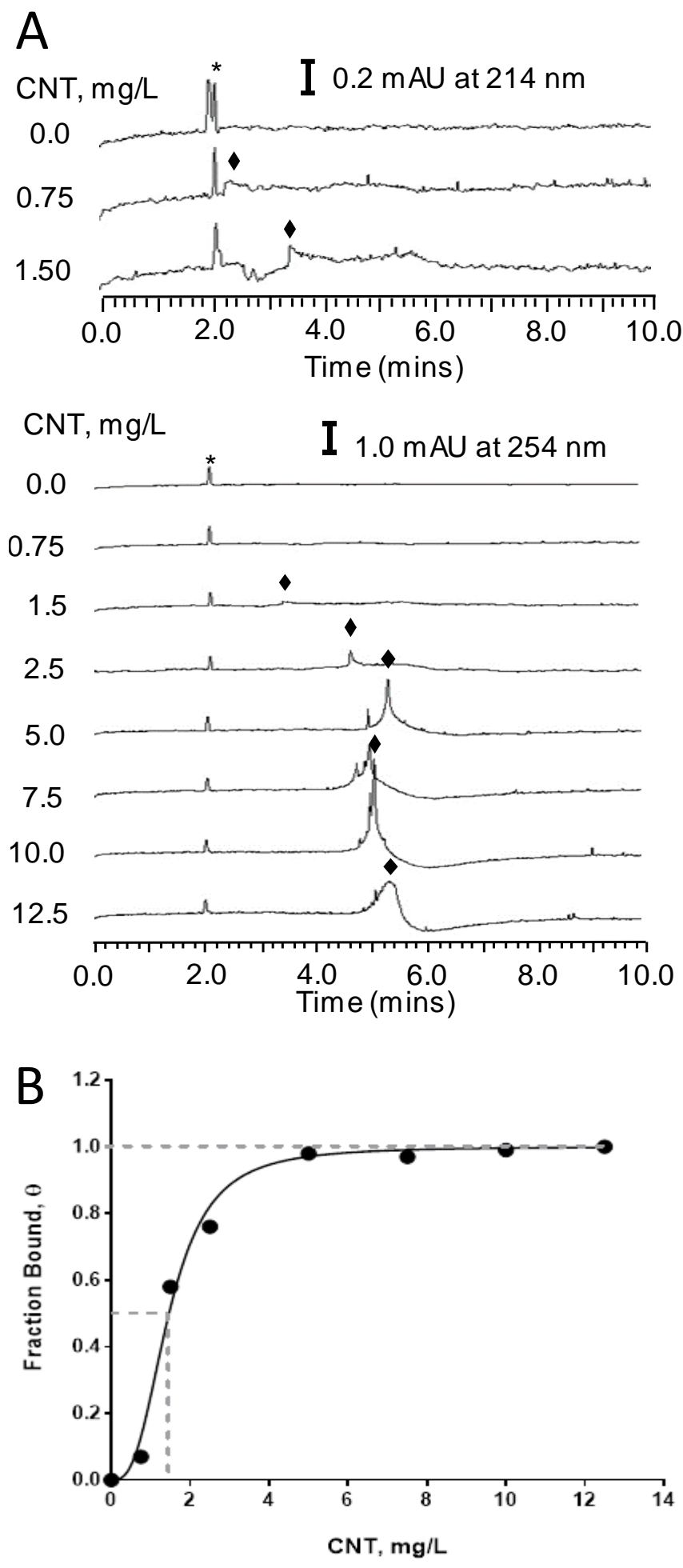
Figure 3-3: Depiction of the measurement of dissociation constant using the WRWWWW peptide and different amounts of carboxylated carbon nanotubes in the separation buffer. The electropherograms (part A) obtained with hexapeptide (25 $\mu \mathrm{M}$ WRWWWW) revealed the migration shift with carboxylated carbon nanotubes in separation buffer that ranged from $0-12.5$ $\mathrm{mg} / \mathrm{L}$. Data are simultaneously collected at $214 \mathrm{~nm}$ and $254 \mathrm{~nm}$. The traces labeled $0 \mathrm{mg} / \mathrm{L}-1.5$ $\mathrm{mg} / \mathrm{L}$ are detected at $214 \mathrm{~nm}$ to better display the peptide migration. All other traces displayed in the figure are obtained at $254 \mathrm{~nm}$, which is the optimum detection wavelength for the mesityl oxide neutral marker. Data are used to determine fractional binding, which is plotted and fit (part B) to obtain the apparent dissociation constant for peptide and carboxylated multi-walled carbon nanotubes. All separations are performed at $25^{\circ} \mathrm{C}$ in a $25 \mu \mathrm{M}$ inner diameter capillary with an effective length of $20 \mathrm{~cm}$ and $\mathrm{E}=333 \mathrm{~V} / \mathrm{cm}$ (normal polarity). Each sample contains $220 \mu \mathrm{M}$ of mesityl oxide, denoted by the asterisk, which identifies the electroosmotic flow. Peptide migration shifts are denoted with a diamond. Carbon nanotubes, purchased from NanoLab, are approximately $5 \%$ carboxylated. Figure reproduced from [1]

\subsubsection{Effect of Arginine on Binding Interaction}

To understand how electrostatic interaction contributes to peptide-carbon nanotube binding, the impact of an arginine versus lysine residue and the impact of two arginine residues on peptidecarbon nanotube binding is investigated. Both arginine and lysine will interact electrostatically with negatively charged carboxylic acid ligands on the carbon nanotube surface. The specificity of arginine over lysine to support electrostatic interactions with carbon nanotubes is evaluated with capillary electrophoresis to compare the binding affinity of WKWWWW to WRWWWW. Arginine, with a higher pKa than lysine, should have a stronger interaction. As summarized in Table 3-1, the dissociation constant of the lysine containing peptide is 2 -fold higher than the arginine containing peptide. The effect of increasing the arginine composition is quantified by replacing a tryptophan with a second arginine residue (WRWWRW). The WRWWRW peptide yields a dissociation constant similar to model peptide WRWWW, $3.3 \pm 0.2 \mathrm{mg} / \mathrm{L}$ and $4.0 \pm 0.7$ $\mathrm{mg} / \mathrm{L}$, respectively. The second arginine amino acid does not contribute to additional electrostatic interaction. This may be due to the low concentration of carboxylic acid functionalization on the carbon nanotube surface, which is reported to be 2 to $7 \%$ by the 
manufacturer and measured as $4.8 \%$ by XPS [38]. If carboxylic acids on the carbon nanotube are distributed across the surface, then the additional arginine would interact with an uncharged region of the carbon nanotube. Molecular simulations of arginine reported by others indicated that the guanidinium group in arginine had the potential to interact with the carbon nanotube backbone via a monopole - induced dipole interaction and with a similar binding energy as tryptophan [25]. These findings reveal that cationic residues drive peptide adsorption on carboxylated carbon nanotubes; however, the decreased interaction when two arginine residues are present points to the importance of $\pi-\pi$ interactions as well.

\section{Table 3-1: $K_{D}$ Values of Peptides}

Peptide $\quad \mathrm{K}^{\prime}{ }^{\prime}(\mathrm{mg} / \mathrm{L})^{\mathrm{a}}$

Single Amino Acid Substitution

$\begin{array}{ll}\text { WKWWWW } & 2.2 \pm 0.3 \\ \text { WRWWRW } & 3.3 \pm 0.2\end{array}$

Tryptophan Substitution

YRYYYY $\quad 9.2 \pm 0.7$

$\underline{W R}(W)_{n}$ Peptide Library

WRWWWW $\quad 1.3 \pm 0.2$

WRWWW $\quad 4.0 \pm 0.7$

WRWW $\quad 5.1 \pm 0.4$

WRW $6.4 \pm 0.1$

${ }^{a}$ data are the average of independent dissociation constant measurements $(n=$ 3) of peptides with carboxylated multiwalled carbon nanotubes

Table reproduced from [1]

\subsubsection{Effect of Aromaticity on Peptide-Carboxylated Carbon Nanotube Binding}


The dissociation constant measurements are utilized to compare the affinity of aromatic amino acids tryptophan and tyrosine. The indole ring of the tryptophan was previously estimated to have a stronger interaction with the pristine carbon nanotube backbone than the aromatic ring of tyrosine [28]. To determine the difference in affinity of tryptophan versus tyrosine, the capillary electrophoresis method is used to quantify the affinity of carbon nanotubes for WRWWWW and YRYYYY. The dissociation constant of YRYYYY is 7-fold higher than the WRWWWW peptide. The lower affinity of the tyrosine peptide binding is attributed to the absence of the nitrogencontaining pyrrole group on the tyrosine amino acid. This is in agreement with a previous report that estimated an increase in binding strength between the tryptophan and tyrosine amino acids $[26,40]$. While binding with tyrosine polypeptide still occurs, tryptophan is significantly greater. This indicates the importance of tryptophan amino acids for the interaction of carbon nanotubes with proteins and peptides.

\subsubsection{Tryptophan Composition Contributes to WRWWWW Binding}

The $\pi-\pi$ interaction aromatic amino acids with the carbon nanotube backbone plays a key role in solubility and surface functionalization for biosensors [21, 41, 42]. The number of hydrophobic residues within the peptide chain should drive the binding interaction of peptides with carboxylated carbon nanotubes. Capillary electrophoresis is used to study a library of $\mathrm{WR}(\mathrm{W})_{\mathrm{n}}$ peptides to evaluate the change in dissociation constant with the number of aromatic residues in the peptide. Table 3-1 summarizes the dissociation constant measurements for a $\mathrm{WR}(\mathrm{W})_{\mathrm{n}}$ peptide series. A 5 -fold increase in the dissociation constant from $1.3 \pm 0.2 \mathrm{mg} / \mathrm{L}$ for WRWWWW to $6.4 \pm 0.1 \mathrm{mg} / \mathrm{L}$ for WRW is obtained. The binding strength of the complex increases successively with length (see Table 3-1). This is attributed to $\pi-\pi$ intermolecular force governing peptide carbon nanotubes interaction, which increases with number of hydrophobic residues and subsequently improves the binding stability. When the peptide is 
reduced to two amino acid residues, the dipeptides WR or WW produce only marginal mobility shifts (Figure 3-4) indicative of weaker binding. The capillary electrophoresis method can not be used to derive $K_{D}$ values for these dipeptides. As the number of tryptophan residues increases, the solubility decreases (see Table 3-2). Binding studies of peptides in the $W R(W)_{n}$ series with more than 5 tryptophan residues cannot be achieved with capillary electrophoresis because of the poor aqueous solubility of the longer peptides. Analyses of polytryptophan-containing peptides is necessary to distinguish the electrostatic contributions to binding of arginine from the

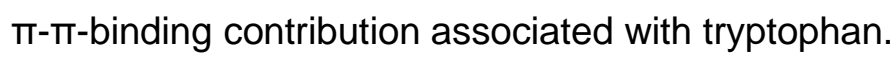

Figure 3-4: Electrophoregrams of WW and WR peptide interaction with NanoLab Precarboxylated Carbon Nanotubes
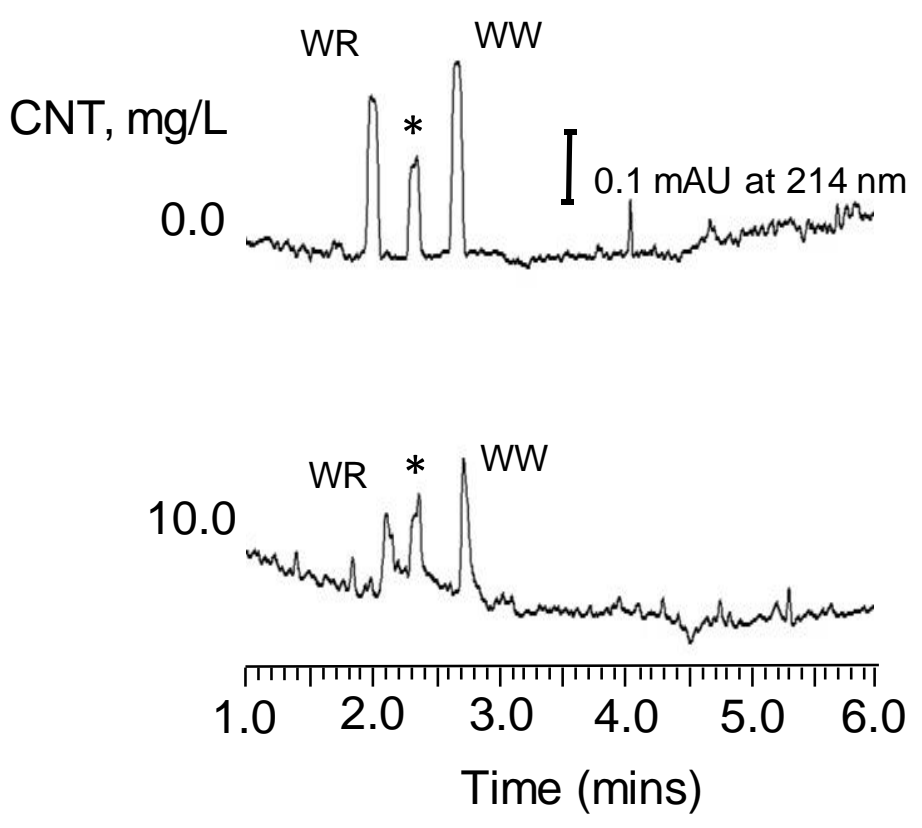

Figure 3-4: The electropherograms obtained with a mixture composed of $25 \mu \mathrm{M}$ WR and $25 \mu \mathrm{M}$ WW revealed reduction in peptide area and no migration shift with $0 \mathrm{mg} / \mathrm{L}$ and $10 \mathrm{mg} / \mathrm{L}$ carboxylated carbon nanotubes in the separation buffer. Experimental conditions were as described in Figure 3-3. Figure reproduced from [1] 


\section{Table 3-2: Solubility Measurement of WR(W)n peptide series}

\begin{tabular}{lc}
\hline & $\begin{array}{c}\text { Solubility in } \\
\text { Water, } \mathrm{mg} / \mathrm{mL}^{\mathrm{a}}\end{array}$ \\
\hline WRWWWW & 0.1 \\
WRWWW & 5 \\
WRWW & 15 \\
WRW & 10 \\
\hline aMeasurements provided by peptide \\
manufacture Genscript, Piscataway, \\
NJ
\end{tabular}

Table reproduced from [1]

\subsubsection{Evaluation of Weak $\pi-\pi$ Binding with Capillary Electrophoresis}

The increase in binding affinity may be attributed to length or additive effects of multiple tryptophan residues interacting with the carbon nanotube backbone via weak $\pi-\pi$ interactions. A series of polytryptophan peptides is investigated to determine the binding affinity without the presence of electrostatic interactions. However, the polytryptophan peptides display very weak interactions with carboxylated carbon nanotubes and do not produce quantifiable mobility shifts when carbon nanotubes are present in the background electrolyte. Although affinity capillary electrophoresis cannot be used to determine binding strength with polytryptophan peptides, the distribution of peptide bound to carbon nanotube or free in the background electrolyte solution is measured as capacity factor as an alternative strategy to assess changes in binding interactions. The higher the capacity factor the stronger the interaction of the carbon nanotube with the peptide. Capacity factor, reported as the mole ratio of peptide bound to the carbon nanotube or in free solution, is measured with three electrophoretic analyses. To quantify the capacity factor, the mobility of the carbon nanotube and the mobility of peptide in the presence 
and absence of the carbon nanotube in background are used in equation A-13 in Appendix A $[43,44]$.

Capacity factor data reveals that there is little interaction of the polytryptophan peptides with carbon nanotubes (Table 3-3). The WWWWW peptide has double the mole ratio of bound peptide compared to WW, WWW, and WWWW, which may be attributed to the lower solubility of the pentapeptide. Higher binding ratios are anticipated for a polytryptophan hexapeptide; however, the low aqueous solubility prevents the analysis of this peptide within the concentration range achievable with UV-visible absorbance detection used with capillary electrophoresis. It is notable that the number of tryptophans within the peptides effects the peak area. Lower peak areas are observed with longer tryptophan polypeptides (see Table 3-4), which also reflects the change in solubility with polytryptophan peptide length. To demonstrate the utility of capacity factor measurements, they are also applied to a series of $\mathrm{WR}(\mathrm{W})_{\mathrm{n}}$ peptides. As shown in Table 3-3, the mole ratio of peptide bound to carbon nanotube increases with tryptophan content. These results demonstrate that polytryptophan binding affinity is insignificant in the absence of arginine. These studies of tryptophan and arginine reveal the importance of a combination of aromatic and electrostatic interactions for binding peptides to functionalized carbon nanotubes. The $W R(W)_{n}$ motif is an atypical sequence in proteins. The capillary electrophoresis method must also be applied to amino acid sequences relevant to proteins found in nature and used in combination with carbon nanotubes. 


\begin{tabular}{ll}
\hline \multicolumn{2}{l}{ Table 3-3: Capacity Factor Values } \\
\hline Peptide & Capacity Factor, ${ }^{a}$ \\
\hline WWWWW & $0.09 \pm 0.02$ \\
WWWW & $0.04 \pm 0.01$ \\
WWW & $0.04 \pm 0.01$ \\
WW & $0.04 \pm 0.02$ \\
& \\
WRWWWW & $4.5 \pm 0.1$ \\
WRWWW & $4.2 \pm 0.2$ \\
WRWW & $3.1 \pm 0.2$ \\
WRW & $0.26 \pm 0.05$ \\
WR & $0.03 \pm 0.01$ \\
\hline
\end{tabular}

${ }^{\mathrm{a}}$ data are the average of independent capacity factor measurements $(n=3)$ of peptides with carboxylated multi-walled carbon nanotubes

Table reproduced from [1]

Table 3-4: Reduction of Polytryptophan Peak Area from Carbon Nanotube Interaction ${ }^{a}$

\begin{tabular}{lccc}
\hline & Buffer & \multicolumn{2}{c}{ Carbon Nanotube } \\
\hline Peptide & Area & Area & \% Decrease \\
WWWWW & $2000 \pm 100$ & $500 \pm 100$ & 77 \\
WWWW & $1900 \pm 30$ & $1100 \pm 60$ & 42 \\
WWW & $1900 \pm 100$ & $1500 \pm 60$ & 21 \\
WW & $1800 \pm 100$ & $1560 \pm 20$ & 13 \\
\hline a data averaged from triple capacity factor measurements $(\mathrm{n}=$ \\
3) of peptides with carboxylated multiwalled carbon nanotubes
\end{tabular}

Table reproduced from [1]

\subsubsection{Evaluation of Peptide Fragments from Protein}

The assessment of model peptides is expanded to protein fragments to understand how proteins interact with carboxylated carbon nanotubes. Proteins that denature on the carbon 
nanotubes have lost secondary and tertiary structure upon interacting with the carbon nanotube and therefore must contain regions within the primary sequence that promote surface

interaction. Lysozyme, a glycoside hydrolase enzyme, has reportedly shown strong interaction with both carboxylated and pristine carbon nanotubes [45-48]. Lysozyme denatures on the carbon nanotubes surface [49] and both tryptophan and cationic side chains play a role [48]. A search of the amino acid sequence of lysozyme using Uniprot [50] can identify short stretches of amino acids that possess a residue with a hydrophobic side chain as well as a residue with a cationic side chain. Upon conducting this search of the lysozyme sequence, six regions are isolated (see Table 3-5) that contain a combination of hydrophobic (tryptophan or tyrosine) and cationic (arginine or lysine) residues within a region composed of 10 amino acids.

\section{Table 3-5: Peptide Regions Selected from} Lysozyme Protein Primary Structure ${ }^{a}$

\begin{tabular}{|c|}
\hline Peptide Sequences $^{b}$ \\
\hline$\underline{\text { YRGISLANW }}$ \\
\hline$\underline{W M C L A K W}$ \\
\hline$\underline{\text { YNTRATNY }}$ \\
\hline 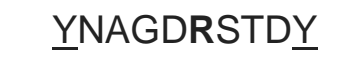 \\
\hline$\underline{\text { YGIFQINSRYW }}$ \\
\hline
\end{tabular}

\footnotetext{
a Sequences contained a positive amino acid with aromatic amino acids to the left and right ${ }^{b}$ Positive amino acids are bold, Aromatic amino acids are underline
}

Table reproduced from [1]

One peptide residue, WMCLAKW, of those identified is noteworthy as it contains two tryptophan residues and a lysine residue. This sequence was synthesized and evaluated with capillary electrophoresis. Electropherograms (see Figure 3-5) obtained with this peptide produce 
sharper peak shapes than those obtained with WRWWWW. Dynamic light scattering experiments were previously performed with the amidated hexapeptide WRWWWW [38] and confirmed that upon introduction of the peptide a size change is observed. The formation of agglomerates in the presence of a binding agent is dependent upon the binding interaction as well as affinity and can contribute to differences in peak shape of the complex. Two other reports describe capillary electrophoresis separations of carbon nanotubes that generated sharp peaks when the nanomaterials were injected in the capillary rather than incorporated in the separation buffer [51,52]. A dissociation constant of $6.9 \pm 0.5 \mathrm{mg} / \mathrm{L}$ is obtained for the WMCLAKW lysozyme fragment in this study. This dissociation constant is comparable to the model peptide WRW $(6.4 \pm 0.1 \mathrm{mg} / \mathrm{L})$, which also contains two tryptophan residues and one positive amino acid. As a lower dissociation constant is obtained for $\mathrm{WK}(\mathrm{W})_{4}$ as compared to $\mathrm{WR}(\mathrm{W})_{4}$, it may be that the presence of the lysine residue is responsible for lower binding interactions. Alternatively, the results that are obtained with WMCLAKW may demonstrate that position rather than composition is more important to binding. A lower binding affinity would support physical adsorption without denaturation better than strong binding affinity. In addition, the position of the amino acids that interact with the carbon nanotube surface may also be a key factor to maintaining protein structure and function during physical adsorption to the carbon nanotube surface. 
Figure 3-5: Electropherograms WMCLAKW peptide and NanoLab Precarboxylated Carbon Nanotubes
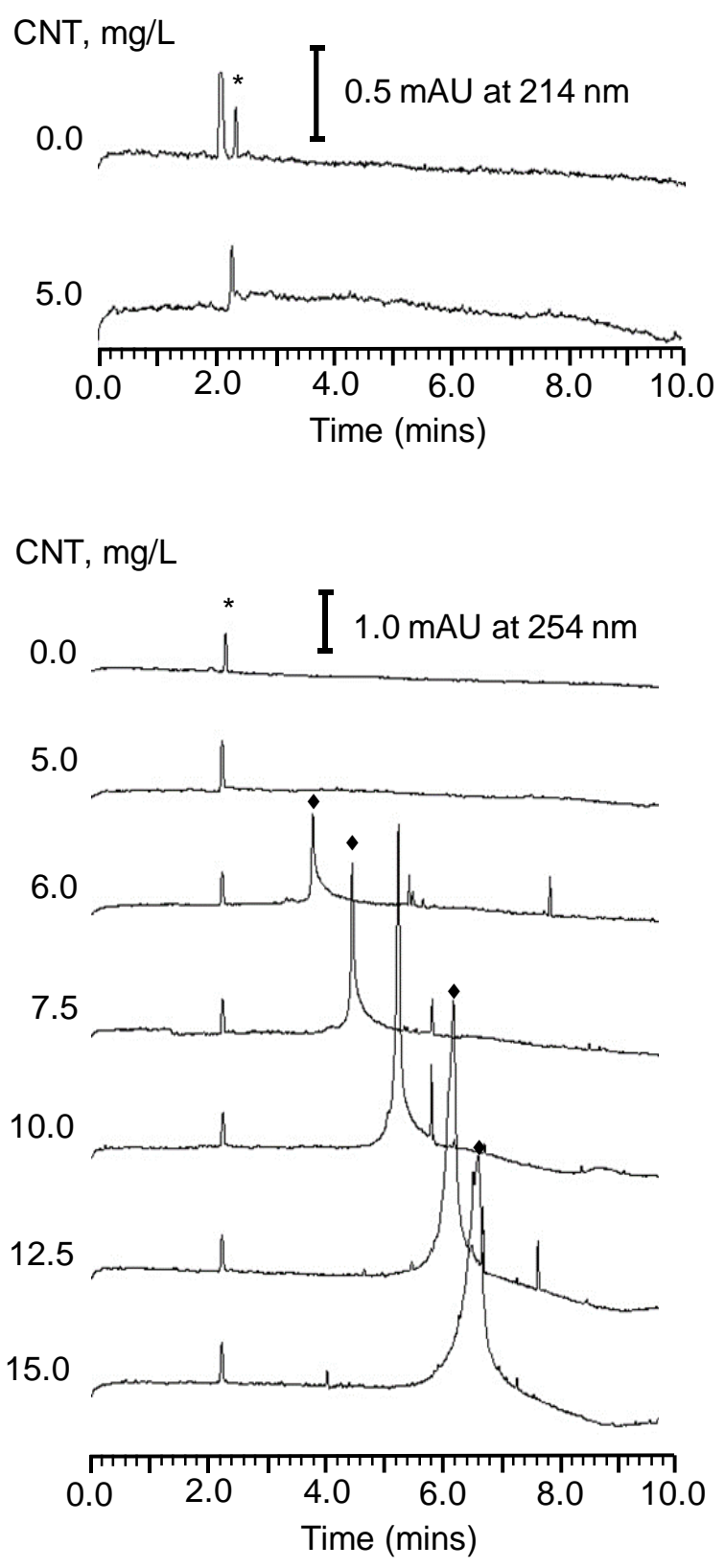

Figure 3-5: Electropherograms for affinity capillary electrophoresis analysis of lysozyme peptide fragment WMACLKW $(25 \mu \mathrm{M})$ with carboxylated carbon nanotubes in separation buffer that ranged from $0-15 \mathrm{mg} / \mathrm{L}$. The traces at $214 \mathrm{~nm}$ depict analysis at $0 \mathrm{mg} / \mathrm{L}$ and $0.5 \mathrm{mg} / \mathrm{L}$ carbon nanotubes. All other traces are obtained at $254 \mathrm{~nm}$. Each sample contains $220 \mu \mathrm{M}$ of mesityl oxide, denoted by the asterisk, which identifies the electroosmotic flow. Peptide migration shifts are denoted with a diamond. Carbon nanotubes, purchased from NanoLab, are approximately $5 \%$ carboxylated. Experimental conditions are as described in Figure 3-3. Figure reproduced from [1] 


\subsection{CONCLUSIONS AND FUTURE DIRECTIONS}

The effect of amino acid composition is clarified using a unique capillary electrophoresis method. Measurements of dissociation constant demonstrate that carboxylated carbon nanotubes interacted strongly with the $\mathrm{WR}(\mathrm{W})_{\mathrm{n}}$ peptide series. Both the presence of an arginine residue and the number of tryptophan residues in the peptide are important factors for the formation of a peptide-carbon nanotube complex. Substitution of amino acids in WRWWWW reveals improvement in binding of tryptophan in comparison to tyrosine. Lysine supports electrostatic interaction, although arginine is more effective than lysine. Measurements also demonstrate that when the peptide contains two arginine residues the binding does not improve, indicating arginine does not interact strongly with the carbon nanotube backbone. In contrast, the number of the aromatic tryptophan residues does contribute to binding stability and affinity, but only if an arginine residue is present. A comparison of peptides containing either two or four tryptophan residues confirms that the chain length does not affect binding affinity. However, capacity factor analyses of polytryptophan peptides reveal weak $\pi-\pi$ interaction. The results of these experiments serve as an important step to understanding the interaction of individual amino acids.

Affinity capillary electrophoresis is a simple method to analyze the interactions of peptide fragments from proteins. The dissociation constant measurement of the lysozyme peptide fragment demonstrates the capability of this method to identify regions that interact with oxidized carbon nanotubes. Maintaining protein structure and function following physical adsorption to the carbon nanotube surface is crucial to advance biosensor applications. Affinity capillary electrophoresis can rapidly probe multiple sequences to determine local regions that contribute strongly to adsorption. Capillary electrophoresis is an enabling tool to determine the 
appropriate level of carbon nanotube functionalization to support physical adsorption, but not protein denaturation. While this paper focuses solely on the primary sequence of lysozyme, future directions include analyses of whole proteins so that amino acids co-located at the protein surface as a result of secondary and tertiary structure can also be assessed. 


\subsection{BIBLIOGRAPHY}

[1] T.A. Davis, L.A. Holland, Peptide Probe for Multi-walled Carbon Nanotubes: Electrophoretic Assessment of the Binding Interface and Evaluation of Surface Functionalization, ACS Appl Mater Interfaces. 10 (2018) 11311-11318.

[2] J. Kirsch, C. Siltanen, Q. Zhou, A. Revzin, A. Simonian, Biosensor technology: Recent advances in threat agent detection and medicine, Chem. Soc. Rev., 42 (2013) 87338768.

[3] G. Rocchitta, A. Spanu, S. Babudieri, G. Latte, G. Madeddu, G. Galleri, S. Nuvoli, P. Bagella, M.I. Demartis, V. Fiore, R. Manetti, P.A. Serra, Enzyme biosensors for biomedical applications: Strategies for safeguarding analytical performances in biological fluids, Sensors, 16 (2016) 1-21.

[4] C.N. Kotanen, F.G. Moussy, S. Carrara, A. Guiseppi-Elie, Implantable enzyme amperometric biosensors, Biosens. Bioelectron., 35 (2012) 14-26.

[5] P. Das, M. Das, S.R. Chinnadayyala, I.M. Singha, P. Goswami, Recent advances on developing 3rd generation enzyme electrode for biosensor applications, Biosens. Bioelectron., 79 (2016) 386-397.

[6] A. Weltin, J. Kieninger, G. Urban, Microfabricated, amperometric, enzyme-based biosensors for in vivo applications, Anal. Bioanal. Chem., 408 (2016) 4503-4521.

[7] A. Amine, F. Arduini, D. Moscone, G. Palleschi, Recent advances in biosensors based on enzyme inhibition, Biosens. Bioelectron., 76 (2016) 180-194.

[8] C.B. Jacobs, M.J. Peairs, B.J. Venton, Review: Carbon nanotube based electrochemical sensors for biomolecules, Anal. Chim. Acta, 662 (2010) 105-127.

[9] S. Marchesan, M. Prato, Under the Lens: Carbon Nanotube and Protein Interaction at the Nanoscale. Chemical Communications, 51 (2015) 4347-4359.

[10] S. Ding, A.A. Cargill, I.L. Medintz, and J.C. Claussen, Increasing the Activity of Immobilized Enzymes with Nanoparticle Conjugation. Curr. Opin. Biotechnol., 34 (2015) 242-250.

[11] J. Liu, A.G. Rinzler, H. Dai, J.H. Hafner, R.K. Bradley, P.J. Boul, A. Lu, T. Iverson, K. Shelimov, C.B. Huffman, F. Rodriguez-Macias, Y.-S. Shon, T.R. Lee, D.T. Colbert, R.E. Smalley, Fullerene pipes, Science, 280 (1998) 1253-1256.

[12] S. Gómez, N.M. Rendtorff, E.F. Aglietti, Y. Sakka, G. Suárez, Surface modification of multiwall carbon nanotubes by sulfonitric treatment, Appl. Surf. Sci., 379 (2016) 264-269.

[13] Z. Wu, S. Mitra, Length reduction of multi-walled carbon nanotubes via high energy ultrasonication and its effect on their dispersibility, J. Nanopart. Res., 16 (2014) 2563.

[14] V. Datsyuk, M. Kalyva, K. Papagelis, J. Parthenios, D. Tasis, A. Siokou, I. Kallitsis, C. Galiotis, Chemical oxidation of multiwalled carbon nanotubes, Carbon, 46 (2008) 833840. 
[15] A. Antonucci, Kupis-Rozmysłowicz, J. \& Boghossian, A. A. Noncovalent Protein and Peptide Functionalization of Single-Walled Carbon Nanotubes for Biodelivery and Optical Sensing Applications. ACS Appl Mater Interfaces, 2017, 9, 11321-11331

[16] S.S. Karajanagi, A.A. Vertegel, R.S. Kane, J.S. Dordick, Structure and Function of Enzymes Adsorbed onto Single-Walled Carbon Nanotubes. Langmuir, 2004, 20, 1159411599.

[17] A. P. M. Tavares, C.G. Silva, G. Dražić, A.M.T. Silva, J.M. Loureiro, J.L. Faria, Laccase Immobilization over Multi-Walled Carbon Nanotubes: Kinetic, Thermodynamic and Stability Studies. J. Colloid Interface Sci., 2015, 454, 52-60.

[18] X. Zhao, F. Hao, D. Lu, W. Liu, Q. Zhou, G. Jiang, Influence of the surface functional group density on the carbon-nanotube-induced $\alpha$-chymotrypsin structure and activity alterations, ACS Appl. Mater. Interfaces, 7 (2015) 18880-18890.

[19] Q. Mu, W. Liu, Y. Xing, H. Zhou, Z. Li, Y. Zhang, L. Ji, F. Wang, Z. Si, B. Zhang, B. Yan, Protein Binding by Functionalized Multiwalled Carbon Nanotubes Is Governed by the Surface Chemistry of Both Parties and the Nanotube Diameter. J. Phys. Chem. C, 2008, $112,3300-3307$.

[20] S. Wang, E.S. Humphreys, S.-Y. Chung, D.F. Delduco, S.R. Lustig, H. Wang, K.N. Parker, N.W. Rizzo, S. Subramoney, Y.-M. Chiang, A. Jagota, Peptides with selective affinity for carbon nanotubes, Nat. Mater., 2 (2003) 196-200.

[21] M.S. Deshpande, S. Mazumdar, Sequence specific association of tryptic peptides with multiwalled carbon nanotubes: Effect of localization of hydrophobic residues, Biomacromolecules, 13 (2012) 1410-1419.

[22] X. Li, W. Chen, Q. Zhan, L. Dai, L. Sowards, M. Pender, R.R. Naik, Direct measurements of interactions between polypeptides and carbon nanotubes, J. Phys. Chem. B, 110 (2006) 12621-12625.

[23] E. Wu, M.-O. Coppens, S. Garde, Role of arginine in mediating protein-carbon nanotube interactions, Langmuir, 31 (2015) 1683-1692.

[24] H. Xie, E.J. Becraft, R.H. Baughman, A.B. Dalton, G.R. Dieckmann, G. R. Ranking the affinity of aromatic residues for carbon nanotubes by using designed surfactant peptides. J Pept Sci. 14 (2008) 139-151.

[25] Z. He, J. Zhou, Probing carbon nanotube-amino acid interactions in aqueous solution with molecular dynamics simulations, Carbon, 78 (2014) 500-509.

[26] C. Rajesh, C. Majumder, H. Mizuseki, Y. Kawazoe, A theoretical study on the interaction of aromatic amino acids with graphene and single walled carbon nanotube, J. Chem. Phys., 130 (2009) 124911(124911-124916).

[27] A. de Leon, A.F. Jalbout, V.A. Basiuk, Swnt-amino acid interactions: A theoretical study, Chem. Phys. Lett., 457 (2008) 185-190. 
[28] S.M. Tomásio, T.R. Walsh, Modeling the binding affinity of peptides for graphitic surfaces. Influences of aromatic content and interfacial shape, J. Phys. Chem. C, 113 (2009) 8778-8785.

[29] Z. Su, K. Mui, E. Daub, T. Leung, J. Honek, Single-walled carbon nanotube binding peptides: Probing tryptophan's importance by unnatural amino acid substitution, J. Phys. Chem. B, 111 (2007) 14411-14417.

[30] A. Hirano, T. Tanaka, H. Kataura, T. Kameda, Arginine side chains as a dispersant for individual single-wall carbon nanotubes, Chem.-Eur. J., 20 (2014) 4922-4930.

[31] S. Jain, V.S. Thakare, M. Das, C. Godugu, A.K. Jain, R. Mathur, K. Chuttani, A.K. Mishra, Toxicity of multiwalled carbon nanotubes with end defects critically depends on their functionalization density, Chem. Res. Toxicol., 24 (2011) 2028-2039.

[32] M. Prato, K. Kostarelos, A. Bianco, Functionalized carbon nanotubes in drug design and discovery, Acc. Chem. Res., 41 (2008) 60-68.

[33] K.A. Wepasnick, B.A. Smith, K.E. Schrote, H.K. Wilson, S.R. Diegelmann, D.H. Fairbrother, Surface and structural characterization of multi-walled carbon nanotubes following different oxidative treatments, Carbon, 49 (2011) 24-36.

[34] C. Wang, S. Li, R. Zhang, and Z. Lin, Adsorption and Properties of Aromatic Amino Acids on Single-Walled Carbon Nanotubes. Nanoscale, 4 (2012) 1146-1153.

[35] A.K. Jana, M.K. Tiwari, K. Vanka, N. Sengupta, Unraveling Origins of the Heterogeneous Curvature Dependence of Polypeptide Interactions with Carbon Nanostructures. Phys. Chem. Chem. Phys., 18 (2016) 5910-5924.

[36] J. Du, C. Ge, Y. Liu, R. Bai, D. Li, Y. Yang, L. Liao, and C. Chen, The Interaction of Serum Proteins with Carbon Nanotubes Depend on the Physicochemical Properties of Nanotubes. J. Nanosci. Nanotechnol., 11 (2011) 10102-10110.

[37] T.R. Walsh, S.M. Tomasio, Investigation of the Influence of Surface Defects on Peptide Adsorption onto Carbon Nanotubes. Molecular BioSystems, 6 (2010) 1707-1718.

[38] T. Takada, Kurosaki, R.; Konno, Y.; Abe, S. Interaction of Multi-Walled Carbon Nanotubes with Water-Soluble Proteins: Effect of Sidewall Carboxylation. J. Nanosci. Nanotechnol., 14 (2014) 3216-3220.

[39] T.A. Davis, S.M. Patberg, D.T. Lowry, L. Sargent, A. Stefaniak, L.A. Holland, Affinity capillary electrophoresis to assess carboxylation of multi-walled carbon nanotubes, Anal. Chim. Acta, (accepted).

[40] J.N. Weiss, The hill equation revisited: Uses and misuses, FASEB J., 11 (1997) 835841.

[41] C.G. Salzmann, M.A.H. Ward, R.M.J. Jacobs, G. Tobias, M.L.H. Green, Interaction of tyrosine-, tryptophan-, and lysine-containing polypeptides with single-wall carbon nanotubes and its relevance for the rational design of dispersing agents, J. Phys. Chem. C, 111 (2007) 18520-18524. 
[42] M. Son, D. Kim, K.S. Park, S. Hong, T.H. Park, Detection of aquaporin-4 antibody using aquaporin-4 extracellular loop-based carbon nanotube biosensor for the diagnosis of neuromyelitis optica, Biosens. Bioelectron., 78 (2016) 87-91.

[43] V. Zorbas, Smith, A. L.; Xie, H.; Ortiz-Acevedo, A.; Dalton, A. B.; Dieckmann, G. R.; Draper, R. K.; Baughman, R. H.; Musselman, I. H. Importance of Aromatic Content for Peptide/Single-Walled Carbon Nanotube Interactions. J. Am. Chem. Soc., 127 (2005) 12323-12328

[44] K.R. Nielson, J.P. Foley, Micellar electrokinetic capillary chromatography, in: P. Camilleri (Ed.) Capillary electrophoresis: Theory and practice, CRC Press, Boca Raton, 1998, pp. 135-182.

[45] J.O. Mills, L.A. Holland, Membrane-mediated capillary electrophoresis: Interaction of cationic peptides with bicelles, Electrophoresis, 25 (2004) 1237-1242.

[46] P. Du, J. Zhao, H. Mashayekhi, B. Xing, Adsorption of bovine serum albumin and lysozyme on functionalized carbon nanotubes, J. Phys. Chem. C, 118 (2014) 2224922257.

[47] D. Nepal, K.E. Geckeler, Ph-sensitive dispersion and debundling of single-walled carbon nanotubes: Lysozyme as a tool, Small, 2 (2006) 406-412.

[48] D.W. Horn, K. Tracy, C.J. Easley, V.A. Davis, Lysozyme dispersed single-walled carbon nanotubes: Interaction and activity, J. Phys. Chem. C, 116 (2012) 10341-10348.

[49] F. Bomboi, A. Bonincontro, C. La Mesa, F. Tardani, Interactions between single-walled carbon nanotubes and lysozyme, J. Colloid Interface Sci., 355 (2011) 342-347.

[50] K. Matsuura, T. Saito, T. Okazaki, S. Ohshima, M. Yumura, S. lijima, Selectivity of water-soluble proteins in single-walled carbon nanotube dispersions, Chem. Phys. Lett., 429 (2006) 497-502.

[51] Uniprot. accessed December 29, 2017; Available from: http://www.uniprot.org/.

[52] S.K. Doorn, R.E. Fields, H. Hu, M.A. Hamon, R.C. Haddon, J.P. Selegue, V. Majidi, High resolution capillary electrophoresis of carbon nanotubes, J. Am. Chem. Soc., 124 (2002) 3169-3174.

[53] C.Y. Khripin, S. Manohar, M. Zheng, A. Jagota, Measurement of electrostatic properties of DNA-carbon nanotube hybrids by capillary electrophoresis, J. Phys. Chem. C, 113 (2009) 13616-13621. 
Chapter 4:

Future Direction 


\subsection{INTRODUCTION}

Affinity capillary electrophoresis has demonstrated the ability to characterize both surface carboxylation and surface interaction of multiwalled carbon nanotubes. This unique method utilizes the affinity of a peptide probe to differentiate degree of carboxylation for characterization prior to applications development. The method was then applied to systematically studying the affinity of multiple peptides was used to elucidate the forces that governing functionalized carbon nanotube and protein binding. This simple, rapid methodology uses minimal sample volumes to determine minute differences in carbon nanotube carboxylation and interactions that are not easily determine by other methods. This work, however, is in the beginning stages and has the potential to be expanded in multiples ways. The following chapter discusses the future directions of capillary electrophoresis based characterization surface modification and surface interactions of nanomaterials.

\subsection{CHARACTERIZATION OF SINGLE STRANDED DNA-CARBON NANOTUBE INTERACTIONS}

Chapter 3 discussed a systematic study of carboxylated carbon nanotube interaction with multiple peptides to elucidate the contribution of amino acids arginine and tryptophan. The study also looked at a lysozyme protein fragment to determine binding interaction of lysozyme with carbon nanotubes. This study should be expanded to determine the binding interaction of not only other specific amino acids and protein fragments with carbon nanotubes but other biomolecules as well. Of particular interest is the study of single stranded DNA to generate information about binding mechanisms that support carbon nanotube sorting [1-9]. A recent study shows that recognition single-stranded DNA has the potential to be a superior dispersant, capable of recognizing and differentiating single carbon nanotubes species and enantiomers 
$[2,10]$. Unlike other DNA sequences, which bind indiscriminately, recognition DNA can be used to specifically target carbon nanotubes species for sorting from bulk samples [1,3,4]. However, little is known about the secondary structures that form these unique DNA-carbon nanotube hybrids and enable selective separation of different species of single walled carbon nanotube from a heterogenous mixture. Thoughtful characterization of recognition ssDNA interaction will shed light on fundamental differences required for developing future DNA-based separations of single walled carbon nanotubes. For analysis with affinity capillary electrophoresis, the peptide analyte is replaced with the single stranded DNA of interest and migration shift is monitored. Changes in affinity based on DNA or carbon nanotube chirality can quickly and easily be assessed. The outcomes of this research will thus advance our knowledge of DNA-SWCNT selective hybridization, improve our measurement capabilities for such nanoparticle-biomolecule hybrids, and inform knowledge-based development of sorting and separating nanostructures.

\subsection{OTHER AREAS OF INTEREST}

\subsubsection{Characterization of Other Surface Modifications and Nanomaterials}

Carbon nanotubes can be functionalized in a multibed of difference ways [11-14]. As discussed in Chapter 1 and 2, oxidation is the most common functionalization method and is often used as an initial step in other surface modifications; however, characterization of other covalent bonded functional groups is necessary for future application development as well. The affinity method can be adopted to look at other functional groups by modifying the amino acids within the peptide chain or replacing amino acids with molecules that form rapid interactions with the functional group of interest. For example, amine functionalization has been used to control carbon nanotube dispersion in nanocomposites [15]. In affinity capillary electrophoresis, characterization of these carbon nanotubes the arginine amino acid in the peptide should be 
replace with a peptide containing negative charged aspartic acid and glutamic acid. Again, the rapid electrostatic interaction of the functional group on the carbon nanotube with the probe can be used to differentiate degree of functionalization. Additionally, the characterization potential of affinity capillary electrophoresis should be expanded to other carbon nanomaterials like carbon fibers, graphene and graphene oxide as well as functionalized metal nanoparticles. For each new material, affinity capillary electrophoresis will need to be adjusted. Potential adjustments include the use of fluorescence detection to improve detection of analytes that do not cause light scattering or suffer significant band broadening with interactions.

\subsubsection{Other Affinity Based Capillary Electrophoresis Methods}

While ACE is a powerful tool for characterization of carbon nanotubes, other affinity based capillary electrophoresis methods should be explored. Nonequilibrium capillary electrophoresis of equilibrium mixture (NECEEM) can potentially measure the affinity of the carbon nanotubes for biomolecules in a single run, further cutting down on material usage and time. NECEEM generates the dissociation constant $\left(\mathrm{K}_{\mathrm{d}}\right)$ as well as rate constants ( $\mathrm{k}_{\text {on }}$ and $\left.\mathrm{k}_{\text {off }}\right)$ in a single run [16-18]. Analyte and carbon nanotube are preincubated before injection into the capillary. The complex is not allowed to reach equilibrium prior to injection and produces an exponential decay from complex to free analyte. The area of the complex, analyte, and exponential decay are then used to quantify the dissociation constant. This unique method can be applied to analyze multiple carbon nanotube and analyte combines rapidly and efficiently. A potential pitfall of NECEEM measurements is that it requires fluorescence detection to monitor the free and bound analyte only. Fluorescence quenching caused by the carbon nanotubes [19-21] may require the addition of fluorescence linkers onto the analyte to prevent quenching. 


\subsection{BIBLIOGRAPHY}

[1] D. Roxbury, X. Tu, M. Zheng, A. Jagota, Recognition ability of DNA for carbon nanotubes correlates with their binding affinity., Langmuir. 27 (2011) 8282-8293.

[2] G. Ao, C.Y. Khripin, M. Zheng, DNA-controlled partition of carbon nanotubes in polymer aqueous two-phase systems., J Am Chem Soc. 136 (2014) 10383-10392.

[3] A. Shankar, J. Mittal, A. Jagota, Binding between DNA and carbon nanotubes strongly depends upon sequence and chirality., Langmuir. 30 (2014) 3176-3183.

[4] X. Tu, S. Manohar, A. Jagota, M. Zheng, DNA sequence motifs for structure-specific recognition and separation of carbon nanotubes., Nature. 460 (2009) 250-253.

[5] J.A. Asenjo, B.A. Andrews, Aqueous two-phase systems for protein separation: a perspective., J Chromatogr A. 1218 (2011) 8826-8835.

[6] A. Antonucci, J. Kupis-Rozmysłowicz, A.A. Boghossian, Noncovalent Protein and Peptide Functionalization of Single-Walled Carbon Nanotubes for Biodelivery and Optical Sensing Applications., ACS Appl Mater Interfaces. 9 (2017) 11321-11331.

[7] S.S. Karajanagi, H. Yang, P. Asuri, E. Sellitto, J.S. Dordick, R.S. Kane, Protein-assisted solubilization of single-walled carbon nanotubes., Langmuir. 22 (2006) 1392-1395.

[8] X. Zhao, D. Lu, F. Hao, R. Liu, Exploring the diameter and surface dependent conformational changes in carbon nanotube-protein corona and the related cytotoxicity., $\mathrm{J}$ Hazard Mater. 292 (2015) 98-107.

[9] S.F. Oliveira, G. Bisker, N.A. Bakh, S.L. Gibbs, M.P. Landry, M.S. Strano, Protein functionalized carbon nanomaterials for biomedical applications, Carbon N Y. 95 (2015) 767-779.

[10] G. Ao, J.K. Streit, J.A. Fagan, M. Zheng, Differentiating Left- and Right-Handed Carbon Nanotubes by DNA., J Am Chem Soc. 138 (2016) 16677-16685.

[11] Y.-L. Zhao, J.F. Stoddart, Noncovalent functionalization of single-walled carbon nanotubes., Acc Chem Res. 42 (2009) 1161-1171.

[12] Y.-P. Sun, K. Fu, Y. Lin, W. Huang, Functionalized carbon nanotubes: properties and applications., Acc Chem Res. 35 (2002) 1096-1104.

[13] Y. Zhang, Y. Bai, B. Yan, Functionalized carbon nanotubes for potential medicinal applications., Drug Discov Today. 15 (2010) 428-435.

[14] D.J. Nelson, H. Rhoads, C. Brammer, Characterizing Covalently Sidewall-Functionalized SWNTs' ${ }^{\dagger}$, J. Phys. Chem. C. 111 (2007) 17872-17878.

[15] S.-M. Xue, Z.-L. Xu, Y.-J. Tang, C.-H. Ji, Polypiperazine-amide Nanofiltration Membrane Modified by Different Functionalized Multiwalled Carbon Nanotubes (MWCNTs)., ACS Appl Mater Interfaces. 8 (2016) 19135-19144. 
[16] M. Kanoatov, V.A. Galievsky, S.M. Krylova, L.T. Cherney, H.K. Jankowski, S.N. Krylov, Using nonequilibrium capillary electrophoresis of equilibrium mixtures (NECEEM) for simultaneous determination of concentration and equilibrium constant., Anal Chem. 87 (2015) 3099-3106.

[17] L.T. Cherney, M. Kanoatov, S.N. Krylov, Method for determination of peak areas in nonequilibrium capillary electrophoresis of equilibrium mixtures., Anal Chem. 83 (2011) 8617-8622.

[18] M. Berezovski, S.N. Krylov, Nonequilibrium capillary electrophoresis of equilibrium mixtures--a single experiment reveals equilibrium and kinetic parameters of protein-DNA interactions., J Am Chem Soc. 124 (2002) 13674-13675.

[19] S. Palencia, S. Vera, A.M. Díez-Pascual, M.P. San Andrés, Quenching of fluorene fluorescence by single-walled carbon nanotube dispersions with surfactants: application for fluorene quantification in wastewater., Anal Bioanal Chem. 407 (2015) 4671-4682.

[20] J.J. Brege, C. Gallaway, A.R. Barron, Fluorescence Quenching of Single-Walled Carbon Nanotubes with Transition-Metal lons, J. Phys. Chem. C. 113 (2009) 4270-4276.

[21] J.J. Brege, C. Gallaway, A.R. Barron, Fluorescence Quenching of Single-Walled Carbon Nanotubes in SDBS Surfactant Suspension by Metal lons: Quenching Efficiency as a Function of Metal and Nanotube Identity ${ }^{\dagger}$, J. Phys. Chem. C. 111 (2007) 17812-17820. 


\section{APPENDIX A: Equations}

\section{Reproduced from [1]}

T.A. Davis, S. Patberg, A. Stefaniak, L. Sargent, L.A. Holland, Capillary Electrophoresis Analysis of Affinity to Assess Carboxylation of Multi-Walled, Anal. Chimica Acta (2018) accepted

\section{Reproduced from [2]}

T.A. Davis, L.A. Holland, Peptide probe for multiwalled carbon nanotubes: electrophoretic assessment of the binding interface and evaluation of surface functionalization., ACS Appl Mater Interfaces. (2018). 10 (2018) 11311-11318. 


\section{A.1.0: EQUATIONS}

\section{A.1.1: Derivation for the Hill Equation from Chemical Equation}

The chemical equation for interaction of WRWWWW peptide with carboxylated multiwalled carbon nanotube assumes a single peptide binds via $\pi-\pi$ stacking to the carbon nanotube backbone or via electrostatic interaction with the carboxyl acid functional group on the carbon nanotube:

$P+n C \rightarrow P C$

equation $A-1$

Where $P$ is the peptide, $C$ is the carbon nanotube and $P C$ is the complex

The dissociation constant for the peptide-carbon nanotube interaction is equal to the product of the concentration of reactants at equilibrium over the concentration of peptide-carbon nanotube complex at equilibrium:

$K_{d}=\frac{[C]^{n}[P]}{[P C]}$

equation $A-2$

During peptide and carbon nanotube interaction the concentration of peptide that is bound is monitored. Therefore, the fraction of peptide bound to carbon nanotube is summarized as:

$\theta=\frac{\text { Bound } P}{\text { Total } P}=\frac{[P C]}{[P C]+[P]}$ equation $A-3$

Where $\Theta$ is the fraction of bound peptide over the total concentration of peptide. 
The dissociation constant equation can be rearranged to equal complex:

$$
[P C]=\frac{[C]^{n}[P]}{K_{d}}
$$

equation $A-4$

and equation A4 can be substituted into the equation for fraction of peptide bound, equation A3:

$$
\theta=\frac{\frac{[C]^{n}[P]}{K_{d}}}{\frac{[C]^{n}[P]}{K_{d}}+[P]}
$$

Simplified:

$$
\theta=\frac{[C]^{n}}{[C]^{n}+K_{d}}
$$

$\mathrm{K}_{d}$ is the apparent dissociation for all binding sites. To determine the binding of a single site, micro dissociation, $\mathrm{K}_{\mathrm{D}}$ or $\mathrm{K}_{0.5}=[\mathrm{L}]$ at which half of the receptors are bound, and is equivalent to the $\mathrm{n}^{\text {th }}$ root of the dissociation constant $\mathrm{K}_{\mathrm{d}}[3,4]$.

Substitute $\mathrm{K}_{d}$ with micro dissociation $\mathrm{K}_{\mathrm{D}}^{\mathrm{n}}$ :

$$
\theta=\frac{[C]^{n}}{[C]^{n}+K_{D}{ }^{n}}
$$

\section{A.1.2: Derive Binding Fraction for Affinity Capillary Electrophoresis}


Affinity capillary electrophoresis utilizes shift in mobility of the peptide to quantify the fraction bound, $\Theta$. The peptide mobility will shift from a free or unbound state (peptide mobility in the absence of carbon nanotube in the background electrolyte, $\mu_{\text {free }}$ ) to complexed or fully bound state (peptide mobility with maximum concentration of MWCNT in background electrolyte, $\mu_{\operatorname{Max}}$ ). Peptide mobility that is partially bound to carbon nanotubes is observed as shifts in between the free and bound states, $\mu_{\text {mid. }}$. This peptide mobility is a fraction of the peptides mobility in the unbound and bound states.

$\mu_{\text {mid }}=f_{1} * \mu_{\max }+f_{2} * \mu_{\text {free }}$ equation $A-8$

Where $f_{1}$ is the bound and $f_{2}$ is the fraction of peptide that is unbound. The sum of $f_{1}$ and $f_{2}$ is 1 and can be rearranged to equal:

$f_{2}=1-f_{1}$ equation $A-9$

Equation A-9 A when substituted into equation 8 results in:

$\mu_{\text {mid }}=f_{1} * \mu_{\text {Max }}+\left(1-f_{1}\right) * \mu_{\text {free }}$ equation $\mathrm{A}-10$

Equation A-10 can be rearranged several times to get the fraction of peptide bound $[5,6]$ :

$f_{1}=$ Fraction Bound Peptide, $\theta=\frac{\left[\mu_{\text {Bound }}-\mu_{\text {free }}\right]}{\left[\mu_{\max }-\mu_{\text {free }}\right]}$ equation $A-11$

Equation $A-11$ is substituted into equation $A-7$, Hill equation: 


$$
\frac{\left[\mu_{\text {Bound }}-\mu_{\text {free }}\right]}{\left[\mu_{\text {max }}-\mu_{\text {free }}\right]}=\frac{[\mathrm{CNT}]^{\mathrm{n}}}{\mathrm{K}_{\mathrm{D}} \mathrm{n}+[\mathrm{CNT}]^{\mathrm{n}}}
$$

equation $\mathrm{A}-12$

\section{A.1.3: Calculating $K_{D}$ from the Increase in Migration Time (i.e. Shift)}

The determination of the dissociation constant $\left(\mathrm{K}_{\mathrm{D}}\right)$ is accomplished in three steps. First, at each concentration of carbon nanotubes in the background electrolyte (i.e. 0 to $20 \mathrm{mg} / \mathrm{L}$ ), the migration time for the peptide and the mesityl oxide neutral marker are collected at $214 \mathrm{~nm}$ and $254 \mathrm{~nm}$, respectively. The migration time of the peptide reflects the apparent mobility $\left(\mu_{\mathrm{app}}\right)$, while the migration time of the marker is used to calculate the electroosmotic flow $\left(\mu_{\mathrm{EOF}}\right)$. Second, the electrophoretic mobility of the peptide in the free, partially bound, or bound state is calculated by subtracting the electroosmotic flow mobility from the apparent mobility. The electrophoretic mobility of the peptide in the absence of carbon nanotube $\left(\mu_{\mathrm{free}}\right)$ is the starting position of the migration shift. The electrophoretic mobility of the peptide when fully bound to carbon nanotubes $\left(\mu_{\max }\right)$ is the maximum migration shift of the peptide. The electrophoretic mobility of the peptide when partially bound to carbon nanotubes $\left(\mu_{\text {mid }}\right)$ is observed for migration shifts between the free and bound states of the peptide. Third, the fraction bound is then calculated by dividing the difference of the $\mu_{\text {mid }}$ and $\mu_{\text {free }}$ by the difference of $\mu_{\text {Max }}$ and $\mu_{\text {free. }}$ This represents the fraction of the peptide bound in between the free and complete complexed state. Therefore, at each carbon nanotube concentration used a fraction is determine using the $\mu_{\text {free }}$ and $\mu_{\max }$. The following example shows how the fraction of peptide bound to carbon nanotube was determine at $1.5 \mathrm{mg} / \mathrm{L}$ carbon nanotube in the background electrolyte.

1. Calculation of apparent mobility and electroosmotic flow for $0,1.5$ and $20 \mathrm{mg} / \mathrm{L}$ is shown in the following example: 
At $0 \mathrm{mg} / \mathrm{L}$ the migration time of the peptide is 127.50 secs and neutral marker 156.00 secs

$$
\begin{aligned}
\mu_{\text {app } \_}\left(\frac{\mathrm{cm}^{2}}{V \text { Secs }}\right) & =\frac{\text { Length Capillary }(\mathrm{cm}) * \text { Length to Detector }(\mathrm{cm})}{\text { Voltage }(V) * \text { migration time }(\mathrm{s})} \\
& =\frac{30.00 \pm 0.03 \mathrm{~cm} * 20.00 \pm 0.03 \mathrm{~cm}}{10000 \pm 100 \mathrm{~V} * 127.50 \pm 0.25 \mathrm{~s}}=\mathbf{0 . 0 0 0 4 7 1} \pm \mathbf{0 . 0 0 0 0 0 5} \\
\mu_{\text {EOF }}\left(\frac{\mathrm{cm}^{2}}{V \text { secs }}\right)= & \frac{\text { Length Capillary }(\mathrm{cm}) * \text { Length to Detector }(\mathrm{cm})}{\text { Voltage }(\mathrm{V}) * \text { migration time }(\mathrm{s})} \\
& =\frac{30.00 \pm 0.03 \mathrm{~cm} * 20.00 \pm 0.03 \mathrm{~cm}}{10000 \pm 100 \mathrm{~V} * 156.00 \pm 0.25 \mathrm{~s}}=\mathbf{0 . 0 0 0 3 8 5} \pm \mathbf{0 . 0 0 0 0 0 4}
\end{aligned}
$$

At $1.5 \mathrm{mg} / \mathrm{L}$ the migration time of the peptide is 321.48 secs and neutral marker 160.02 secs

$$
\begin{gathered}
\mu_{\text {app_ } 1.5}\left(\frac{\mathrm{cm}^{2}}{V \text { secs }}\right)=\frac{30.00 \pm 0.03 \mathrm{~cm} * 20.00 \pm 0.03 \mathrm{~cm}}{10000 \pm 100 \mathrm{~V} * 321.48 \pm 0.25 \mathrm{~s}}=\mathbf{0 . 0 0 0 1 8 7} \pm \mathbf{0 . 0 0 0 0 0 2} \\
\mu_{E O F}\left(\frac{\mathrm{cm}^{2}}{V \operatorname{secs}}\right)=\frac{30.00 \pm 0.03 \mathrm{~cm} * 20.00 \pm 0.03 \mathrm{~cm}}{10000 \pm 100 \mathrm{~V} * 160.02 \pm 0.25 \mathrm{~s}}=\mathbf{0 . 0 0 0 3 7 5} \pm \mathbf{0 . 0 0 0 0 0 4}
\end{gathered}
$$

At $20 \mathrm{mg} / \mathrm{L}$ the migration time of the peptide is 565.74 secs and neutral marker 152.76 secs

$$
\begin{gathered}
\mu_{\text {app_20 }}\left(\frac{\mathrm{cm}^{2}}{V \text { secs }}\right)=\frac{30.00 \pm 0.03 \mathrm{~cm} * 20.00 \pm 0.03 \mathrm{~cm}}{10000 \pm 100 \mathrm{~V} * 565.74 \pm 0.25 \mathrm{~s}}=\mathbf{0 . 0 0 0 1 0 6} \pm \mathbf{0 . 0 0 0 0 0 1} \\
\mu_{E O F}\left(\frac{\mathrm{cm}^{2}}{V \operatorname{secs}}\right)=\frac{30.00 \pm 0.03 \mathrm{~cm} * 20.00 \pm 0.03 \mathrm{~cm}}{10000 \pm 100 \mathrm{~V} * 152.76 \pm 0.25 \mathrm{~s}}=\mathbf{0 . 0 0 0 3 9 3} \pm \mathbf{0 . 0 0 0 0 0 4}
\end{gathered}
$$

^Initial error is instrumental and propagated within the calculation. 
2. Calculation of electrophoretic mobility peptide in $0\left(\mu_{\text {free }}\right), 1.5 \mathrm{mg} / \mathrm{L}\left(\mu_{\operatorname{mid}}\right), 20 \mathrm{mg} / \mathrm{L}\left(\mu_{\max }\right)$ carbon nanotubes background electrolyte. The electrophoretic mobility is the difference of the apparent mobility of the peptide and the $\mu_{\mathrm{EOF}}$ determined at each concentration and detailed above.

$$
\begin{aligned}
& \mu_{\text {free }}=\mu_{\text {app_o }}-\mu_{E O F}=0.000471 \pm 0.000005-0.000385 \pm 0.000004 \\
& =0.000086 \pm 0.00006 \\
& \mu_{\text {mid }}=\mu_{\text {app_1.5 }}-\mu_{E O F}=0.000187 \pm 0.000002-0.000375 \pm 0.000004 \\
& =-0.000188 \pm 0.00004 \\
& \mu_{\text {max }}=\mu_{\text {app } \_20}-\mu_{E O F}=0.000106 \pm 0.000002-0.000393 \pm 0.000004 \\
& =-0.000287 \pm 0.00004
\end{aligned}
$$

${ }^{\wedge}$ Error is propagated for this calculation.

3. Calculation of fraction bound in $1.5 \mathrm{mg} / \mathrm{L}$ carbon nanotubes in background electrolyte, where $\mu_{\text {free }}$ is the electrophoretic mobility of the peptide with no carbon nanotube in the background electrolyte and $\mu_{\max }$ (maximum bound) is the electrophoretic mobility of peptide when the peptide is fully bound to carbon nanotubes. The bound fraction for 0 $\mathrm{mg} / \mathrm{L}$ is equal to 0 as no binding has occurred and is 1 when at maximum binding at 20 $\mathrm{mg} / \mathrm{L}$.

$$
\frac{\mu_{\text {mid }}-\mu_{\text {free }}}{\mu_{\text {max }}-\mu_{\text {free }}}=\frac{-0.000188 \pm 0.000004-0.000086 \pm 0.000006}{-0.000287 \pm 0.000004-0.000086 \pm 0.000006}=\mathbf{0 . 7 4} \pm \mathbf{0 . 0 3}(\mathbf{3 . 5} \%)
$$

${ }^{\wedge}$ Error is propagated for this calculation. Reproduced from [1] 
Table A-1: Sample Calculation of Fractional Binding of each point in a single curve

\begin{tabular}{lllllllll}
\hline $\begin{array}{l}{[\mathrm{CNT}]} \\
\mathrm{mg} / \mathrm{L}\end{array}$ & $\begin{array}{l}\text { Peptide } \\
\mathrm{t}_{\mathrm{m}}(\mathrm{s})\end{array}$ & $\begin{array}{l}\boldsymbol{\mu}_{\mathrm{app}} \pm \mathrm{SD} \\
\left(\mathrm{cm}^{2} / \mathrm{Vs}\right) \\
\mathrm{x10^{6 }}\end{array}$ & $\begin{array}{l}\text { Mesityl } \\
\mathbf{0 x i d e} \\
\mathrm{tm}(\mathrm{s})\end{array}$ & $\begin{array}{l}\boldsymbol{\mu}_{\mathrm{EOF}} \pm \mathrm{SD} \\
\left(\mathrm{cm}^{2} / \mathrm{Vs}\right) \\
\mathrm{x} 10^{6}\end{array}$ & $\begin{array}{l}\boldsymbol{\mu}_{\mathrm{EPH}} \pm \mathrm{SD} \\
\left(\mathrm{cm}^{2} / \mathrm{Vs}\right) \\
\mathrm{x} 10^{6}\end{array}$ & $\begin{array}{l}\text { Numerator } \\
\pm \mathrm{SD} \\
\left(\mathrm{cm}^{2} / \mathrm{Vs}\right) \times 10^{6}\end{array}$ & $\begin{array}{l}\text { Denominator } \\
\pm \mathrm{SD} \\
\left(\mathrm{cm}^{2} / \mathrm{Vs}\right) \times 10^{6}\end{array}$ & $\begin{array}{l}\text { Fraction } \\
\pm \mathrm{SD}(\% \mathrm{RSD})\end{array}$ \\
\hline $\mathbf{0}$ & 127.50 & $471 \pm 5$ & 156.00 & $385 \pm 4$ & $86 \pm 6$ & $0 \pm 9$ & $-373 \pm 8$ & $0 \pm 0(\mathrm{~N} / \mathrm{A})$ \\
$\mathbf{0 . 5}$ & 138.78 & $432 \pm 4$ & 158.28 & $379 \pm 4$ & $53 \pm 6$ & $-54 \pm 6$ & $-373 \pm 8$ & $0.09 \pm 0.02(22 \%)$ \\
$\mathbf{1}$ & 202.98 & $296 \pm 3$ & 158.76 & $378 \pm 4$ & $82 \pm 5$ & $-82 \pm 5$ & $-373 \pm 8$ & $0.45 \pm 0.02(4 \%)$ \\
$\mathbf{1 . 5}$ & 321.48 & $187 \pm 2$ & 160.02 & $375 \pm 4$ & $188 \pm 4$ & $-274 \pm 8$ & $-373 \pm 8$ & $0.74 \pm 0.03(4 \%)$ \\
$\mathbf{2 . 5}$ & 358.50 & $167 \pm 2$ & 155.76 & $385 \pm 4$ & $218 \pm 4$ & $-304 \pm 4$ & $-373 \pm 8$ & $0.82 \pm 0.03(4 \%)$ \\
$\mathbf{5}$ & 433.98 & $138 \pm 1$ & 156.00 & $385 \pm 4$ & $246 \pm 4$ & $-332 \pm 4$ & $-373 \pm 8$ & $0.89 \pm 0.03(3 \%)$ \\
$\mathbf{1 0}$ & 452.76 & $133 \pm 1$ & 157.74 & $380 \pm 4$ & $248 \pm 4$ & $-334 \pm 4$ & $-373 \pm 8$ & $0.90 \pm 0.03(3 \%)$ \\
$\mathbf{2 0}$ & 565.74 & $106 \pm 1$ & 152.76 & $393 \pm 4$ & $287 \pm 4$ & $-373 \pm 4$ & $-373 \pm 8$ & $1.0 \pm 0.03(3 \%)$ \\
\hline
\end{tabular}

Table reproduced from [1].

\section{A.1.4: Capacity Factor}

The equation for capacity factor, $\mathrm{k}^{\prime}$, is as follows:

$k^{\prime}=\frac{\text { mole peptide bound to } C N T}{\text { mole peptide in buffer }}=\frac{t_{\text {pep }}\left(1+u_{r}\right)+t_{E O F}}{t_{\text {eof }}\left(1+\frac{t_{p e p}}{t_{C N T}}\right)}$

equation $A-13$

where $t_{\mathrm{CNT}}$ is the migration time of the carbon nanotubes in the separation buffer (For analysis of carbon nanotube mobility, the carbon nanotubes are diluted in $25 \mathrm{mM}$ MOPS buffer to final concentration of either 100 or $200 \mathrm{mg} / \mathrm{L}$. The carbon nanotube sample is injected at $6.9 \mathrm{kPa}$ (1 psi) for $5 \mathrm{sec}$ following an injection of $30 \mu \mathrm{M}$ mesityl oxide at $10 \mathrm{kV}$ for $5 \mathrm{sec}$ ), tpep and teOF are the migration times of the peptide and electroosmotic flow migration marker (mesityl oxide) in the presence of carbon nanotube in the separation buffer, and $u_{\mathrm{r}}$ is the relative mobility of the peptide in the absence of carbon nanotubes $[7,8]$. 
$u_{r}=\frac{\mu_{E P H}}{\mu_{E O F}}$

equation $\mathrm{A}-14$

For this equation, the $\mu_{\mathrm{EPH}}$ is the electrophoretic mobility of the peptide calculated by subtracting the mobility of the electroosmotic flow migration marker, $\mu_{\mathrm{EOF}}$, from the apparent mobility of the peptide, $\mu_{\text {app }}$. These equations are listed below:

$\mu_{E O F}=\frac{\text { Length Capillary }(\mathrm{cm}) * \text { Length to Dectector }(\mathrm{cm})}{\text { Voltage }(\mathrm{V}) * \text { migration neutral marker }(\mathrm{s})}=\frac{\mathrm{cm}^{2}}{V-\mathrm{s}}$

equation $\mathrm{A}-15$

$\mu_{a p p}=\frac{\text { Length Capillary }(\mathrm{cm}) * \text { Length to Dectector }(\mathrm{cm})}{\text { Voltage }(V) * \text { migration time of peptide }(\mathrm{s})}=\frac{\mathrm{cm}^{2}}{V-s}$

equation $\mathrm{A}-16$

$\mu_{E P H}=\mu_{a p p}-\mu_{E O F}$

equation $\mathrm{A}-17$ 


\section{A.1.5. BIBLIOGRAPHY}

[1] T.A. Davis, S. Patberg, A. Stefaniak, L. Sargent, L.A. Holland, Capillary Electrophoresis Analysis of Affinity to Assess Carboxylation of Multi-Walled, Anal. Chim. Acta (2018) accepted

[2] T.A. Davis, L.A. Holland, Peptide Probe for Multi-walled Carbon Nanotubes: Electrophoretic Assessment of the Binding Interface and Evaluation of Surface Functionalization., ACS Appl Mater Interfaces, 10 (2018) 11311-11318.

[3] N. Li, S. Zeng, L. He, W. Zhong, Probing nanoparticle--protein interaction by capillary electrophoresis., Anal Chem. 82 (2010) 7460-7466

[4] J.N. Weiss, The Hill equation revisited: uses and misuses., FASEB J. 11 (1997) 835841.

[5] N.H.H. Heegaard, M.H. Nissen, D.D.Y. Chen, Applications of on-line weak affinity interactions in free solution capillary electrophoresis., Electrophoresis. 23 (2002) 815822.

[6] L.Z. Avila, Y.H. Chu, E.C. Blossey, G.M. Whitesides, Uses of affinity capillary electrophoresis to determine kinetic and equilibrium constants for binding of arylsulfonamides to bovine carbonic anhydrase., J Med Chem. 36 (1993) 126-133.

[7] J.O. Mills, L.A. Holland, Membrane-mediated capillary electrophoresis: interaction of cationic peptides with bicelles., Electrophoresis. 25 (2004) 1237-1242.

[8] K.R. Nielson, J.P. Foley, Micellar Electrokinetic Capillary Chromatography, in Capillary Electrophoresis: Theory and Practice, P. Camilleri, Editor. (1998) CRC Press: Boca Raton. 135-182 


\section{APPENDIX B: Supporting Figures and Tables}

\section{Reproduced from [1]}

Davis, T.A., Patberg, S.M., Sargent, L., Stefaniak, A., Holland, L.A., Affinity Capillary Electrophoresis to Assess Carboxylation of Multi-Walled Carbon Nanotubes. Anal. Chim. Acta, accepted 


\section{B.1.0: Supporting Figures and Tables:}

Figure B-1: Plot of Increase in Peptide-Carbon Nanotube Complex Size with Time

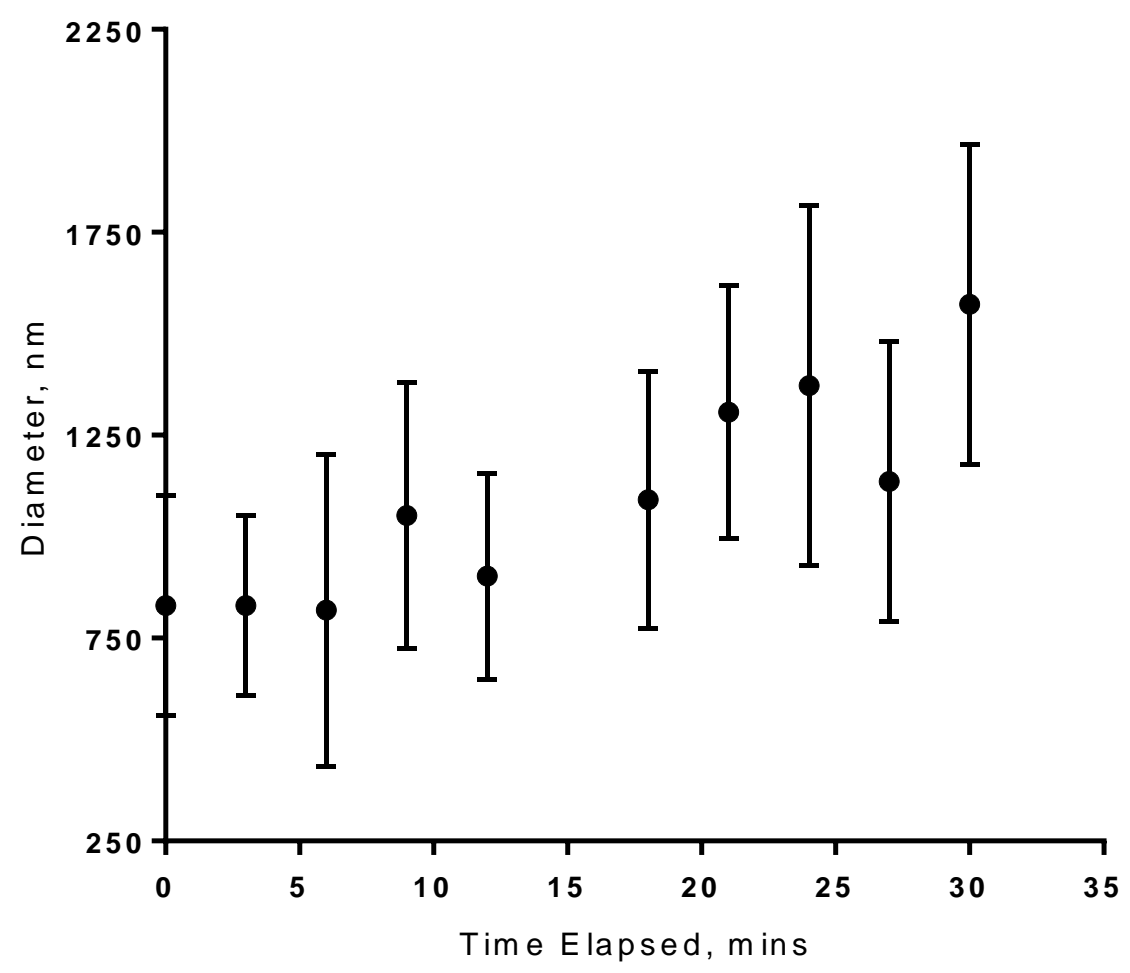

Figure B-1: A plot of the size of peptide-carbon nanotubes complex measured with dynamic light scattering at a ratio of peptide:carbon nanotube of $28.5: 20 \mathrm{mg} / \mathrm{L}$. Error bars are associated with standard deviation from the peak distribution. Measurements were done with NanoLab precarboxyled carbon nanotubes ( $15 \pm 5 \mathrm{~nm}$ OD, 1 - $5 \mu \mathrm{m}$ length) and $25 \mu \mathrm{M}$ WRWWWW.

Figure reproduced from [1] 


\section{Figure B-2: Sedimentation of Peptide-Carbon Nanotube Complex}

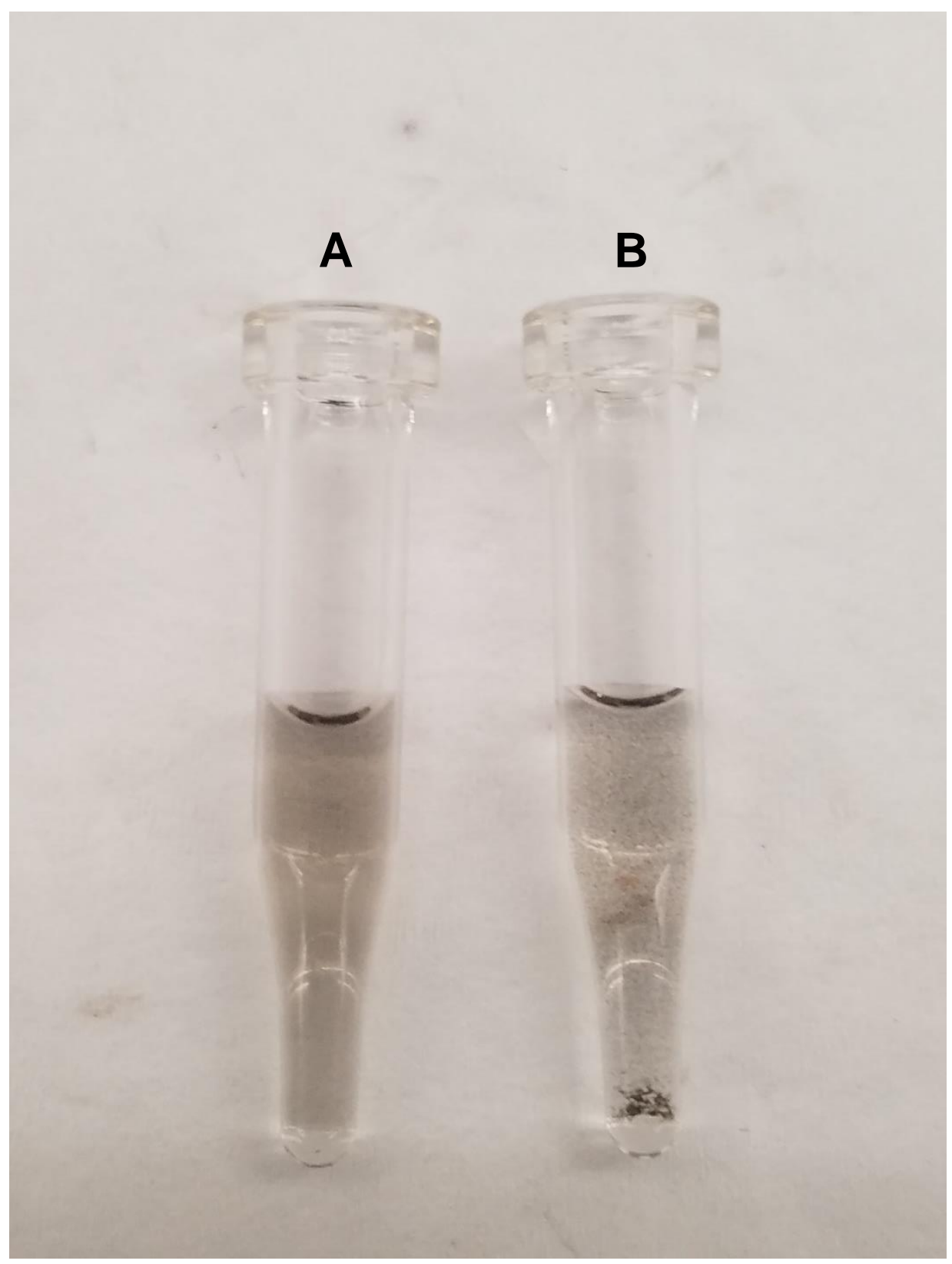

Figure B-2: A picture of peptide-carbon nanotubes complex sedimentation after 30 minutes. The vial A contains $20 \mathrm{mg} / \mathrm{L}$ of carbon nanotubes and vial B contains both $25 \mu \mathrm{M}$ WRWWWW and $20 \mathrm{mg} / \mathrm{L}$ of carbon nanotubes (i.e. at a peptide:carbon nanotube ratio of 28.5:20 mg/L).

Measurements were done with NanoLab precarboxylated carbon nanotubes (15 \pm nm OD, 1 - 5 $\mu \mathrm{m}$ length). Figure reproduced from [1] 
Figure B-3: Control Runs Demonstrating Complex Formation Due to Interaction

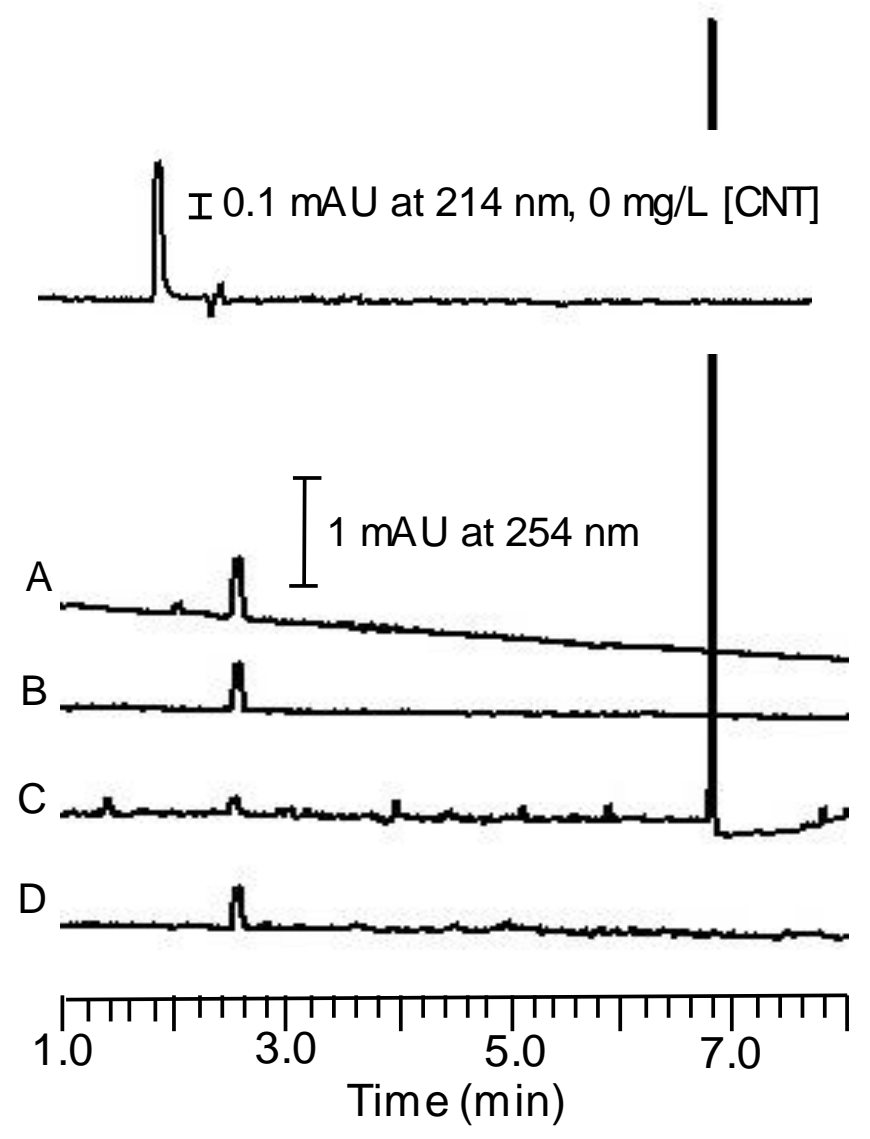

Figure B-3: Depicts the control electropherograms for capillary electrophoresis analyses demonstrating that the complex formation is only observed in the presence of WRWWWW peptide. Trace A is of $25 \mu \mathrm{M}$ WRWWWW and $220 \mu \mathrm{M}$ mesityl oxide in $0 \mathrm{mg} / \mathrm{L}$ carbon nanotubes in background electrolyte. Trace $B$ is $220 \mu \mathrm{M}$ mesityl oxide in $0 \mathrm{mg} / \mathrm{L}$ carbon nanotubes in background electrolyte. Trace $C$ is of $25 \mu \mathrm{M} \mathrm{WRWWWW}$ and $220 \mu \mathrm{M}$ mesityl oxide in $2.5 \mathrm{mg} / \mathrm{L}$ carbon nanotubes in background electrolyte. Trace $D$ is of $220 \mu \mathrm{M}$ mesityl oxide in $2.5 \mathrm{mg} / \mathrm{L}$ carbon nanotubes in background electrolyte. Figure reproduced from [1]. 


\begin{tabular}{|c|c|c|}
\hline \multicolumn{3}{|c|}{$\begin{array}{l}\text { Table B-1: Effects of Acid Treatment } \\
\text { Temperature on Dissociation Constant }\end{array}$} \\
\hline \multirow[b]{2}{*}{$\begin{array}{l}\text { Acid } \\
\text { Treatment } \\
\text { (hours) }\end{array}$} & \multicolumn{2}{|c|}{$\begin{array}{l}\text { Dissociation Constant } \\
\text { (mg/L) }\end{array}$} \\
\hline & $20-25^{\circ} \mathrm{C}$ & $0^{\circ} \mathrm{C}$ \\
\hline $\begin{array}{l}1 \\
3\end{array}$ & $\begin{array}{l}3.8 \pm 0.1 \\
1.3 \pm 0.1\end{array}$ & $\begin{array}{l}11 \pm 3 \\
3.7 \pm 0.6\end{array}$ \\
\hline
\end{tabular}

Table reproduced from [1] 
Table B-2: Dissociation Constant Obtained within a Single Preparation of Carbon Nanotubes $(n=3$ curves)

\begin{tabular}{llllll}
\hline & \multicolumn{3}{c}{ Hill Equation } & \multicolumn{2}{c}{ One Site Binding } \\
\hline Curve & $\mathrm{K}_{\mathrm{D}}$ & $\mathrm{n}$ value & $\mathrm{R}^{2}$ & $\mathrm{~K}_{\mathrm{D}}$ & $\mathrm{R}^{2}$ \\
& $(\mathrm{mg} / \mathrm{L})$ & & & $(\mathrm{mg} / \mathrm{L})$ & \\
\hline Curve 1 & $1.4 \pm 0.3$ & $1.6 \pm 0.6$ & 0.9834 & $1.3 \pm 0.6$ & 0.9477 \\
Curve 2 & $1.2 \pm 0.2$ & $3.0 \pm 2.0$ & 0.9807 & $1.1 \pm 0.9$ & 0.8838 \\
Curve 3 & $1.1 \pm 0.2$ & $2.0 \pm 1.0$ & 0.9762 & $1.0 \pm 0.7$ & 0.9061 \\
Average & $1.2 \pm 0.2(22 \%)$ & $2.0 \pm 1.0$ & & $1.1 \pm 0.7$ & \\
\hline
\end{tabular}

The cooperativity values $(n)$ for the curves were all greater than two, demonstrating a positive cooperatively between the first and second ligand. A positive cooperativity means that the binding of first ligand improves the likelihood of the second ligand binding. When the data is refit maintaining an $n$ value of 1 (i.e. one site binding) the dissociation constant, $K_{D}$ remains the same. However, the R-squared of curve is reduced indicating the importance of $n$ cooperativity to the curve fitting. 


\begin{tabular}{lll}
\hline \multicolumn{2}{l}{ Table B-3: Dissociation Constant and $\mathrm{n}$ values } \\
\hline$\underline{\text { Manufacturer }}$ & $\underline{\mathrm{K}_{\mathrm{D}}}$ & $\underline{\mathrm{n} \text { value }}$ \\
NL15-1 & $1.2 \pm 0.2$ & $2.0 \pm 1.0$ \\
NL15-2 & $0.9 \pm 0.2$ & $1.9 \pm 0.8$ \\
NL15-3 & $1.1 \pm 0.2$ & $1.6 \pm 0.8$ \\
US15 & $3.9 \pm 0.9$ & $2.1 \pm 0.8$ \\
& & \\
Acid Treatment (hrs) & $\underline{\mathrm{K}_{\mathrm{D}}}$ & $\underline{\mathrm{n} \text { value }}$ \\
3.0 & $1.3 \pm 0.4$ & $2.0 \pm 1.0$ \\
2.0 & $2.6 \pm 0.5$ & $1.9 \pm 0.5$ \\
1.0 & $3.8 \pm 0.4$ & $2.4 \pm 0.5$ \\
0.75 & $4.6 \pm 0.5$ & $3.0 \pm 0.8$ \\
0.5 & $8.3 \pm 0.8$ & $4.0 \pm 1.0$ \\
\hline
\end{tabular}


Figure B-4: Deconvoluted Peak Fitting for Carbon Region for Acid Treated Carbon Nanotubes in X-ray Photoelectron Spectroscopy

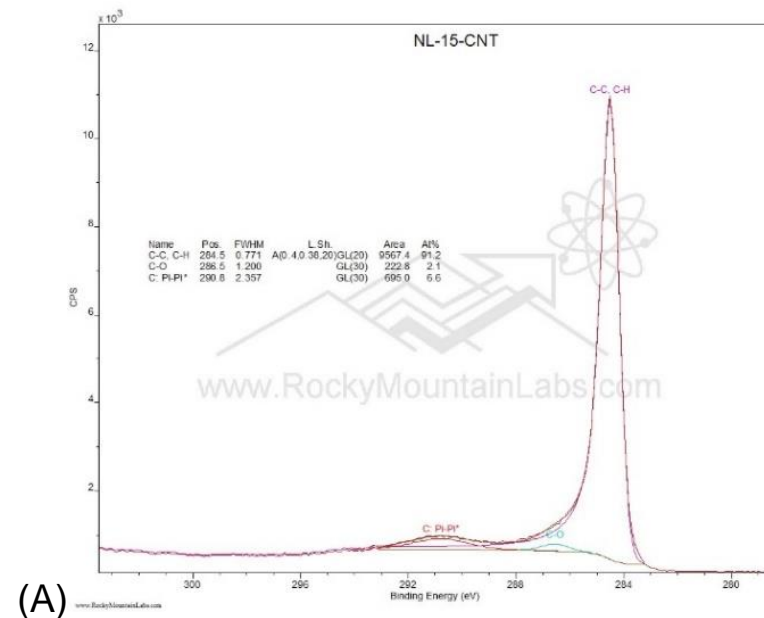

(A)

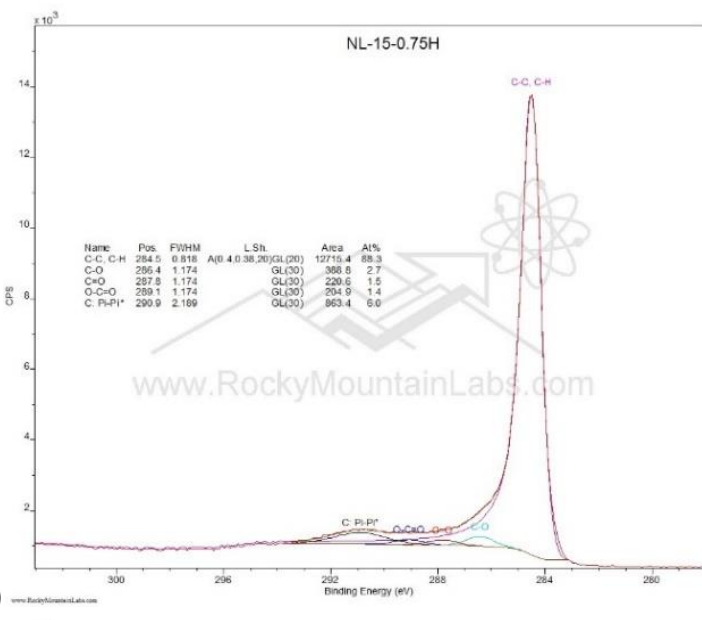

(C)

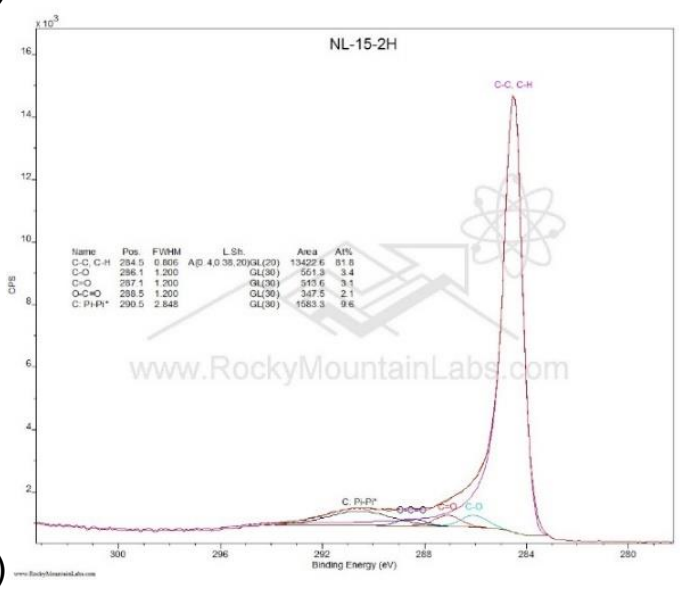

(B)

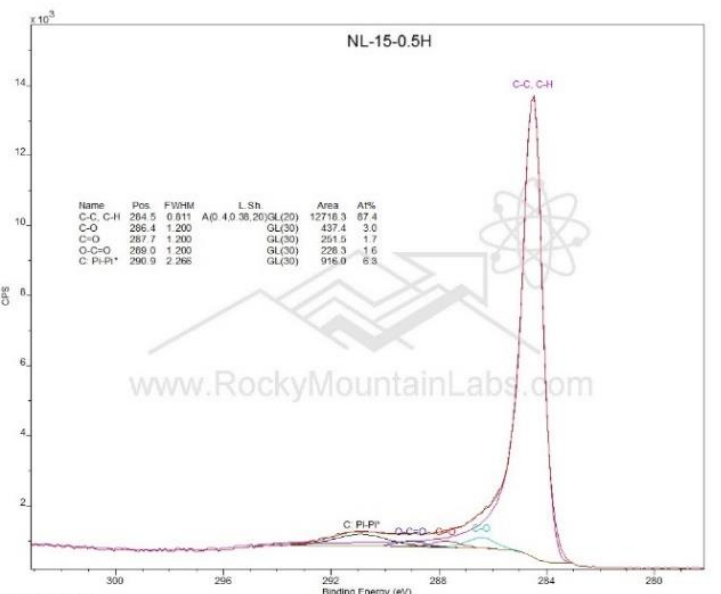

(D)
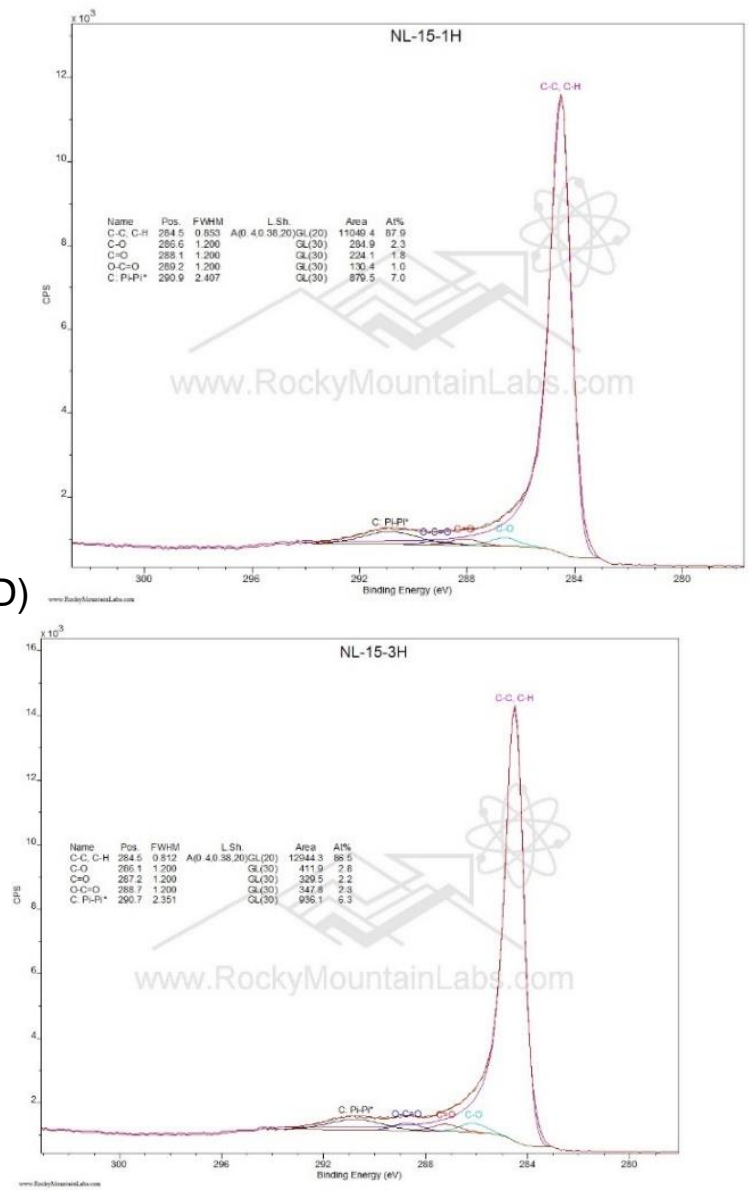

Figure B-4: Deconvolution and peak fitting for X-ray Photoelectron Spectroscopy analysis of carbon $1 \mathrm{~s}$ region for acid treated NanoLab pristine multi-walled carbon nanotubes $(A)$ no treatment, (B) 0.5 hour, (C) 0.75 hour, (D) 1 hour, (E) 2 hours and (F) 3 hours. Figure reproduced from [1]. 


\section{B.1.2: BIBLIOGRAPHY}

[1] T.A. Davis, S. Patberg, A. Stefaniak, L. Sargent, L.A. Holland, Capillary Electrophoresis Analysis of Affinity to Assess Carboxylation of Multi-Walled, Anal. Chim. Acta (2018) accepted 


\title{
Tyler Davis \\ Morgantown WV, 26505 \\ tdavis6@mix.wvu.edu \\ datyler87@gmail.com
}

Education:

\section{Curriculum Vitae}

\author{
2011 - 2018 Ph.D. Candidate in Chemistry \\ West Virginia University \\ Morgantown, West Virginia \\ $2006-2010$ B.A. in Chemistry, \\ University of North Carolina at Chapel Hill \\ Chapel Hill, NC
}

\section{Fellowships Awarded:}

2012-2014:Recipient of the National Science Foundation's NanoSafe Graduate Fellowship

2014 - 2017: Recipient of the National Science Foundation's Interdisciplinary Graduate Education and Research Traineeship Fellowship (IGERT)

\section{Publication:}

Davis T. A., L. Holland, L., Evaluation of MWCNT Binding Interface and Surface Carboxylation using Electrophoretic Assessment with Peptides, ACS Applied Material and Interface, under revision

Davis T. A., Patberg, S., Stefaniak, A., Sargent, L., Holland, L., Binding Affinity of Peptides to Multiwalled Carbon Nanotubes using Capillary Electrophoresis, Anal.

Chima. Act. accepted

Davis T. A, Athey, S. L., Vandevender, M. L., Crihfield, C. L., Kolanko, C. C. E., Shao, S., Ellington, M. C. G., Dicks, J. K., Carver, J. S., . Holland, L. A., Electrolysis of Water in the Secondary School Science Laboratory with Inexpensive Microfluidics, Journal of Chemical Education., 2015, 92, 1, 116-119

Boulos S., Davis T. A., Holland L. A., Murphy C. J.; Nanoparticle-protein interaction: a thermodynamic, kinetic, and structural study of the adsorption of bovine serum albumin to gold nanoparticles surface, Langmuir, 2013, 29, 48, 14984-14996 
Ramakrishnan, B., Moncrief, A. J., Davis, T. A., Holland, L. A., Qasba, P. K., Investigations on $\beta 1,4$-galactosyltransferase I using 6-sulfo-GlcNAc as an acceptor sugar substrate, Glycoconjugate Journal, 2013, 30, 9, 835-842

Li Y., Nese A., Lebedeva N. V., Davis T. A., Matyjaszewski K., Sheiko, S. S., Molecular Tensile Machines: Intrinsic Acceleration of Disulfide Reduction by Dithiothreitol, Journal of the American Chemical Society, 2011, 133, 43, 17479-17484.

\section{Provisional Patents Applications:}

Davis, T., Holland, L., (2016) US Patent Application No. 62430636, United States Patent and Trademark Office (USPTO)

Bostick, C., Davis, T., Despeaux, E., Han, A., Mandler, K., Pisane, K, (2016) US Patent Application No. 15380041, United States Patent and Trademark Office (USPTO)

\section{Professional Presentations (5 of 12 total):}

- Nanogel Microfluidics for the Identification of Biomolecules, December 2, 2012, Latin American Capillary Electrophoresis Conference, Buenos Aires, Argentina, Poster presentation

- Towards Efficient Separations of Biomolecules in Microfluidics with Nanogels, April 7, 2013, Bioelectronics and Biosensing Symposium, Morgantown, WV, Poster presentation

- West Virginia University -- NanoSAFE - Excellence in Interdisciplinary Science Video, February 4, 2014, WebEdge Production: Interviewee

- Identification of Deadly Species of Aspergillus in a Microfluidic Device with Phospholipid Nanogel, March 9, 2015, Pittsburgh Conference on Analytical Chemistry and Applied Spectroscopy, New Orleans, LS, Oral presentation

- Surface Characterization of Carbon Nanotubes with Capillary Electrophoresis, August 23, 2017, American Chemical Society, Washington DC, Oral presentation 